\title{
Arylidene Derivatives as Synthons in Heterocyclic Synthesis
}

\author{
N. S. El-Gohary \\ Department of Medicinal Chemistry, Faculty of Pharmacy, Mansoura University, Mansoura, Egypt \\ Email: dr.nadiaelgohary@yahoo.com
}

Received 18 March 2014; revised 25 April 2014; accepted 7 May 2014

Copyright (C) 2014 by author and OALib.

This work is licensed under the Creative Commons Attribution International License (CC BY). http://creativecommons.org/licenses/by/4.0/

(c) (i) Open Access

\begin{abstract}
This review describes the synthetic procedures for the preparation of arylideneacetophenones, arylidenecycloalkanones, 2-arylidene-1-indanones, 2-arylidene-1-tetralones, 2-arylidene-1-benzosuberones, aurones, 1-thioaurones, 3-arylidene-4-chromanones, 3-arylidene-1-thio-4-chromanones, 3-arylideneflavanones, 3-arylidene-1-thioflavanones, arylideneanilines, arylidenemalononitriles, diethyl arylidenemalonates, ethyl arylidenecyanoacetates, arylidenecyanoacetamides, 5arylidene derivatives of barbituric and thiobarbituric acids, arylidene derivatives of Meldrum's acid and arylidene derivatives of dimedone. Also, it demonstrates the reactivity of these arylidene derivatives in heterocyclic synthesis with emphasis on the most recent findings. Some of these are the $\alpha, \beta$-enones, víz. aurones and 3 -arylidene-4-chromanones belong to the natural products. The others are synthetic substances which are convenient and important intermediates for the synthesis of a variety of useful and novel heterocyclic systems.
\end{abstract}

\section{Keywords}

Arylidenes, Synthesis, Reactions, Heterocycles

\section{Introduction}

The chemistry of different arylidene compounds has generated intensive scientific studies throughout the world. Especial interest has been focused on the synthesis and pharmacological activities of different arylidene compounds. They are versatile synthons so that a variety of novel heterocycles with good pharmaceutical profiles can be designed. Those arylidenes are usually prepared through Knoevenagel condensations of aldehydes with active methylene compounds, they are usually base [1], Lewis acid [2], or surfactant-catalyzed [3]; thus, create much wastes. Recently, there was an interest in so-called solvent-free [4] [5] Knoevenagel condensations on solid supports that were promoted by infrared [6] or microwave irradiation [7] [8]. Unfortunately, the latter techniques 
require solvents for the extraction from the solid supports as well as for the preparation of the initial adsorbates, and do not yield pure products. Thus, further solvents are required for purifying the workup. Even catalyst-free Knoevenagel reactions in water could not reach quantitative yields [9]-[11]. This research deals with the various methods of preparation of arylideneacetophenones, arylidenecycloalkanones, 2-arylidene-1-indanones, 2-arylidene-1-tetralones, 2-arylidene-1-benzosuberones, aurones, 1-thioaurones, 3-arylidene-4-chromanones, 3-arylidene-1-thio-4-chromanones, 3-arylideneflavanones, 3-arylidene-1-thioflavanones, arylideneanilines, arylidenemalononitriles, diethyl arylidenemalonates, ethyl arylidenecyanoacetates, arylidenecyanoacetamides, 5-arylidene derivatives of barbituric and thiobarbituric acids, arylidene derivatives of Meldrum's acid and arylidene derivatives of dimedone as well as their utilization in heterocyclic synthesis.

\section{Synthesis}

\subsection{Synthesis of Arylideneacetophenone Derivatives (Chalcones)}

Different methods are available for the preparation of chalcones [12]-[14]. The most convenient method is the Claisen-Schimdt condensation of equimolar quantities of arylmethylketones with aryl aldehydes in the presence of aqueous alcoholic alkali [15]-[25]. Chalcones are used to synthesize several derivatives like cyanopyridines, pyrazolines, isoxazoles, and pyrimidines having different heterocyclic ring systems [26]-[29].

\subsubsection{Various Condensing Agents Have Been Used in the Synthesis of Chalcones}

1) Alkali

Alkalis are the most widely used condensing agents for the synthesis of chalcones. They are used as an aqueous alcoholic solution of suitable concentration viz. 30\%, 40\%, 50\% and 70\% [15]-[25].

\section{2) Acids}

Methanolic solution of dry hydrochloric acid gas at $0^{\circ} \mathrm{C}$ was used for the synthesis of chalcones from aromatic ketones and aldehydes [26] [27]. In addition, concentrated sulfuric acid in acetic acid was used as a condensing agent in the synthesis of chalcones [28].

3) Other Condensing Agents

Raval and Shah [29] used phosphorous oxychloride as a condensing agent to synthesize chalcones. In addition, Szell and Sipos [30] condensed 2-hydroxy-5-nitroacetophenone with benzaldehyde using anhydrous $\mathrm{AlCl}_{3}$.

Besides the above, other condensing agents have been used in the synthesis of chalcones; namely, amino acids [31], an aqueous solution of borax [32], perchloric acid [33], piperidine [34], boron trifloride [35], alkali metal alkoxides [36], magnesium tert-butoxide [37], and thionyl chloride [38].

In recent years, microwave assisted solid support solvent-free organic synthesis have attracted the attention as they offer several advantages such as simple procedure, fast reaction rate, mild reaction conditions, eco-friendly and improved yields as compared to conventional methods [39] [40].

\subsubsection{Mechanism}

The following mechanisms have been suggested for the synthesis of chalcones:

1) Base catalyzed reaction (Scheme 1) [21] [41].

2) Acid catalyzed reaction (Scheme 2) [42].

\subsubsection{Reactivity of Chalcone Derivatives}

The chalcones $\mathbf{1}$ are useful intermediates for the synthesis of a variety of heterocyclic compounds. Isoxazoles $\mathbf{2}$ are prepared by the reaction of chalcones $\mathbf{1}$ with hydroxylamine hydrochloride and sodium acetate [43] (Scheme 3). Treatment of chalcones $\mathbf{1}$ with guanidine hydrochloride in the presence of alkali afforded 2-aminopyrimidines 3 [44] (Scheme 3). Thiazines $\mathbf{4}$ and oxazines $\mathbf{5}$ can be synthesized by reaction of chalcones $\mathbf{1}$ with thiourea and urea, respectively [45] (Scheme 3). Pyrazoles 6, 7 are obtained through the reaction of chalcones $\mathbf{1}$ with hydrazine hydrate and phenyl hydrazine derivatives, respectively [46]-[49] (Scheme 3). Furthermore, reaction of hydrazine hydrate with $\mathbf{1}$ in the presence of different aliphatic acids resulted in the formation of pyrazole derivatives containing $N$-acyl moiety 8a-c [49] [50] (Scheme 3). Condensation of chalcones $\mathbf{1}$ with malononitrile and ammonium acetate yields 2-amino-3-cyanopyridines 9 [49] [51] (Scheme 3). On the other hand, reaction of $\mathbf{1}$ with malononitrile in refluxing methanol or ethanol and in the presence of freshly prepared sodium alkoxide solution yielded 3-cyanopyridines 10 [52] (Scheme 3). Reaction of cyanopyridines 10 with hydrazine hydrate 
(i)

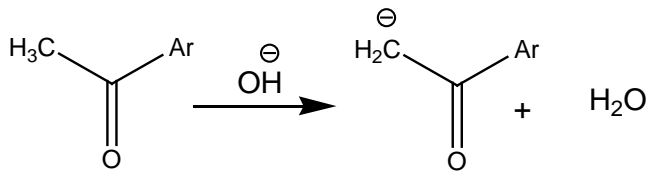

(ii)

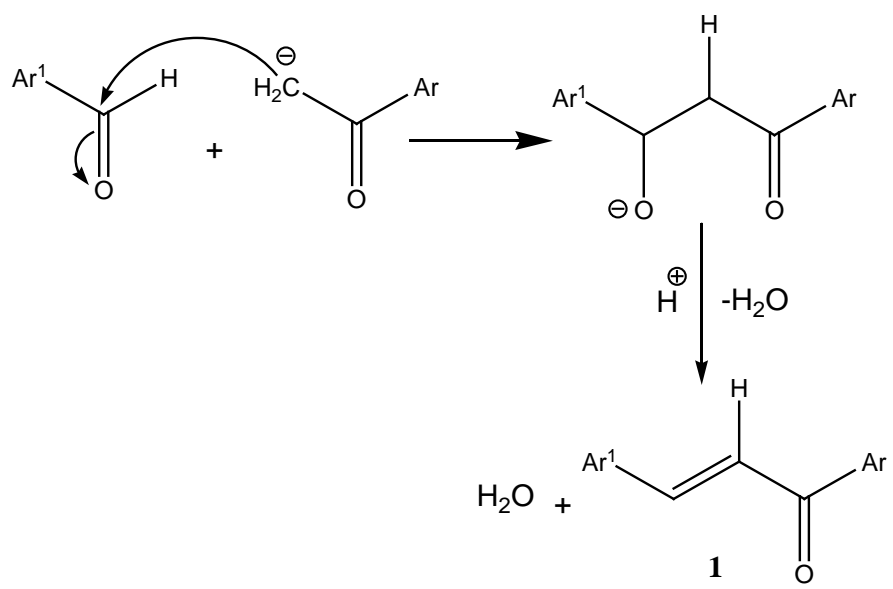

Scheme 1. Mechanism of base catalyzed condensation of aromatic ketones with aldehydes.

(i)
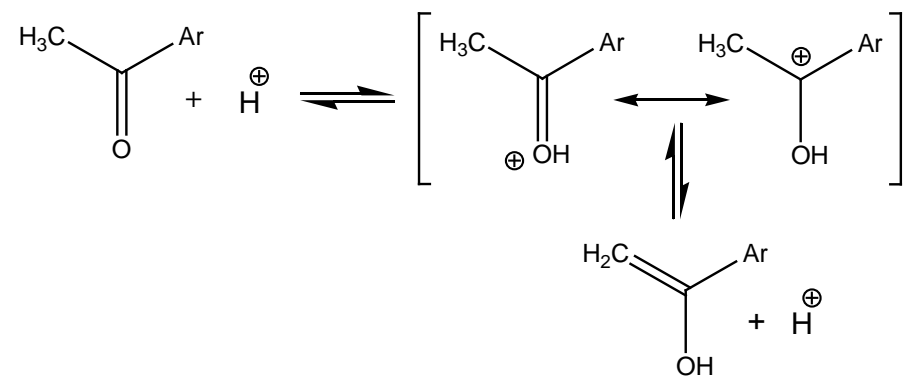

(ii)
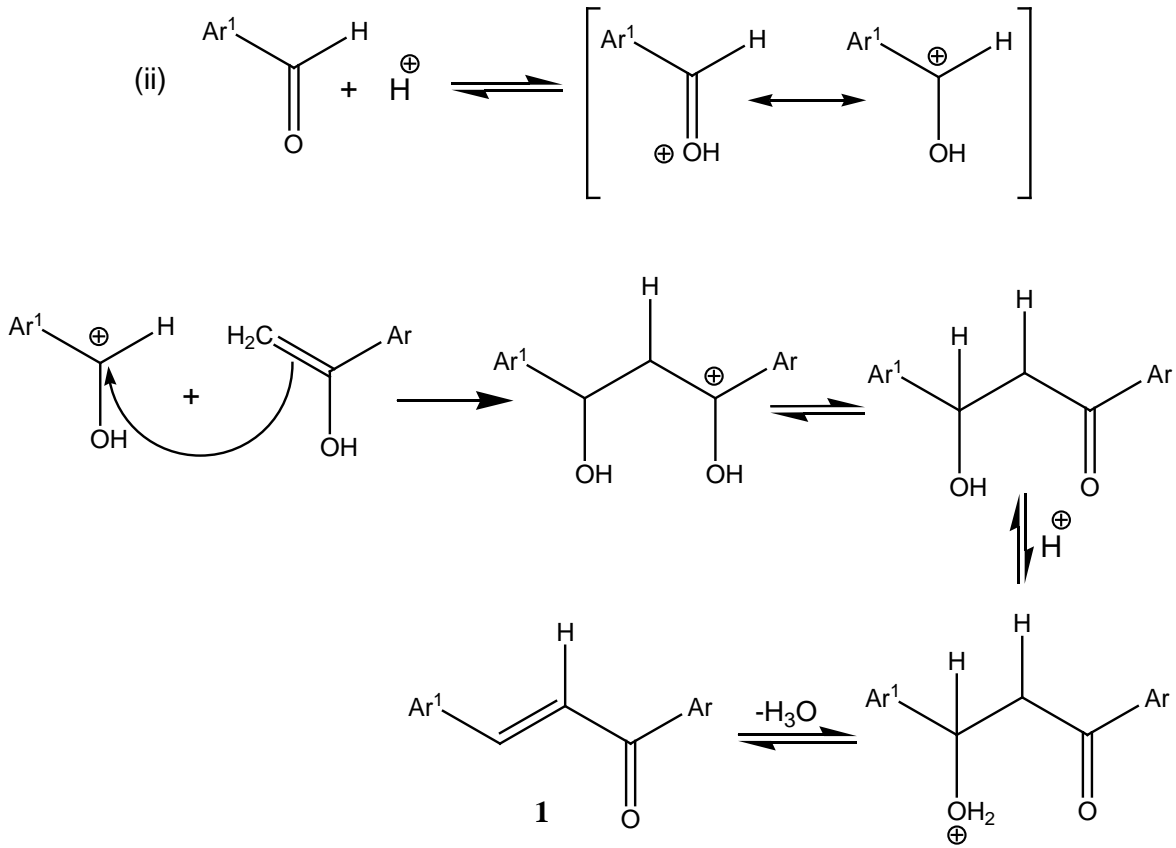

Scheme 2. Mechanism of acid catalyzed condensation of aromatic ketones with aldehydes. 


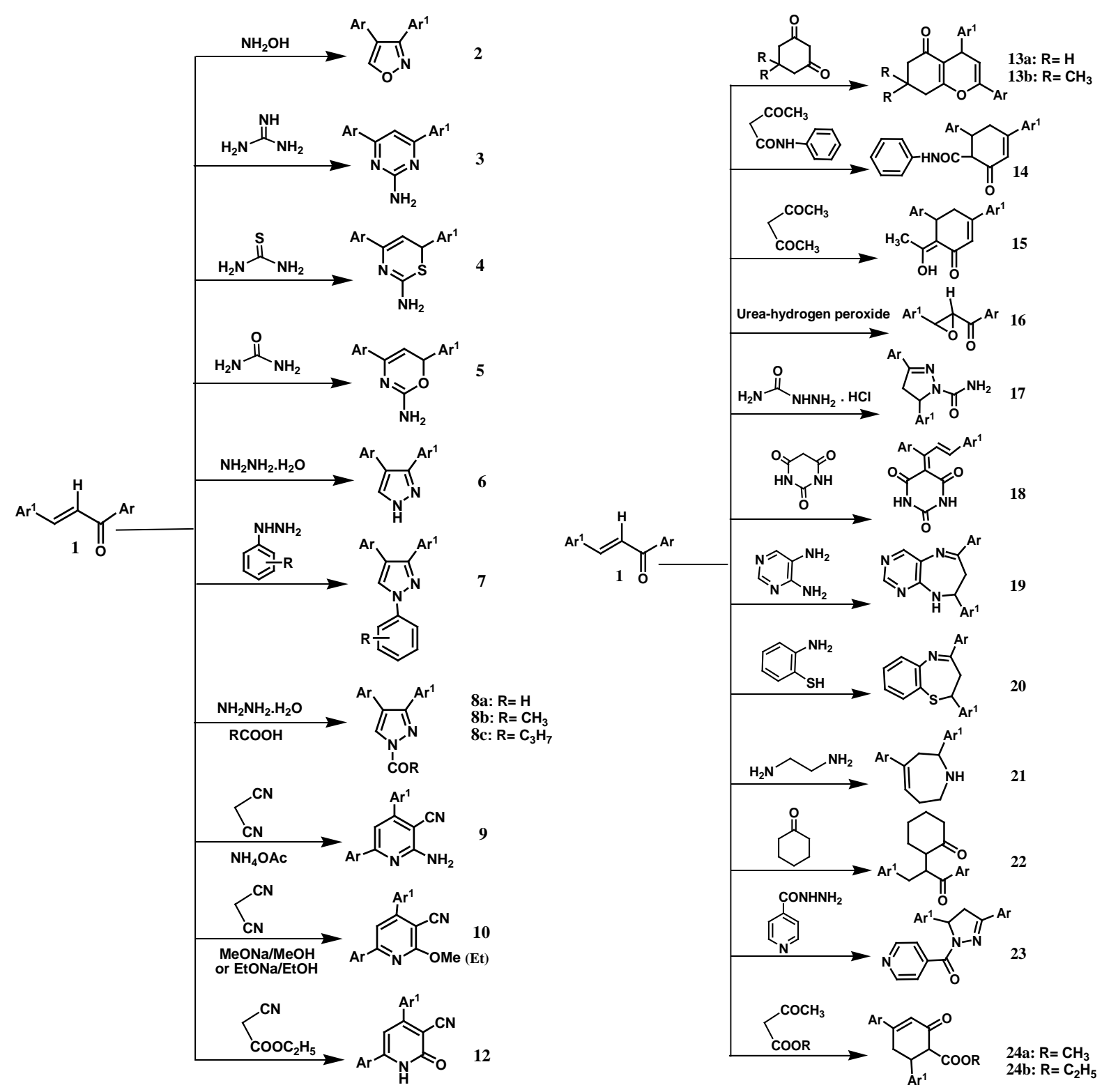

Scheme 3. Preparation of compounds 2-10 and 12-24.

using Lewis acid (1.0 equivalent of $\mathrm{BF}_{3} \cdot \mathrm{Et}_{2} \mathrm{O}$ ) in refluxing ethanol under anhydrous conditions afforded $1 \mathrm{H}$-pyrazolo[3,4-b]pyridines 11 in very good yields and short reaction time [52] (Scheme 4). Similarly, treatment of 1 with ethyl cyanoacetate in absolute ethanol and in the presence of ammonium acetate afforded cyanopyridine derivatives 12 [49] (Scheme 3). Reaction of 1 with cyclohexane-1,3-diones produced 2,4-diaryl-5-oxo-5,6,7,8tetrahydro-2-chromenes 13a, b. [53] Similarly, acetoacetanilide and acetylacetone reacted with chalcones 1 to afford cyclohexenone derivatives 14 and 15, respectively [49] (Scheme 3). Epoxidation of chalcones 1 with urea-hydrogen peroxide (UHP) under ultrasound irradiation gave oxirane derivatives 16 [54] (Scheme 3). Reaction of 1 with semicarbazide hydrochloride in glacial acetic acid/dioxane afforded pyrazoline-1-carboxamides 17 [55] (Scheme 3). The barbitones 18 are obtained upon condensation of chalcones $\mathbf{1}$ with barbituric acid [49] [56] [57] (Scheme 3). Treating $\mathbf{1}$ with 4,5-diaminopyrimidine gave [1,4]diazepine derivatives 19 [58] (Scheme 3). Condensation of chalcones 1 with 2-aminothiophenol afforded [1,4]benzothiazepines 20 [59] (Scheme 3). Tetrahydro- $1 H$-azepines $\mathbf{2 1}$ were synthesized via reaction of $\mathbf{1}$ with ethylenediamine [60] (Scheme 3). Reaction of chalcones $\mathbf{1}$ with cyclohexanone in benzene in the presence of sodium hydroxide and a catalytic amount of 
tributyl benzyl ammonium chloride (TBBAC) at room temperatue afforded 2-(1-oxo-1,3-diarylpropan-2-yl) cyclohexanones 22 [61] [62] (Scheme 3). Furthermore, reaction of 1 with isonicotinoyl hydrazide in refluxing ethanol gave $N$-isonicotinoyl-3,5-diarylpyrazolines 23 (Scheme 3) [49]. Reaction of $\mathbf{1}$ with methyl acetoacetate or ethyl acetoacetate in refluxing ethanol and in the presence of catalytic amounts of piperidine and basic alumina afforded 4,6-diaryl-2-oxocyclohex-3-enecarboxylates 24a, b [49] [63] (Scheme 3). Condensation of cyclohexenecarboxylates 24a, b with hydrazine hydrate produced 4,6-diaryl-3-oxo-2,3,4,5-tetrahydroindazoles 25 [49] (Scheme 5).

\subsection{Synthesis of Arylidenecycloalkanone Derivatives}

Arylidenecycloalkanones are frequently used $\alpha, \beta$-unsaturated ketones. Their synthesis is based on the reaction of the appropriate cyclic ketone with aldehydes, through aldol condensation reaction. Several reports exist for their synthesis [64]-[69], involving the use of organic and inorganic bases, metal catalysts, different types of FriedelCrafts catalysts and trichloro-1,3,5-triazine (TCT). A more convenient method used solid potassium hydroxide [70] [71] or sodium hydroxide [72] as a catalyst for the condensation of different aldehydes with cycloalkanones in ethanol and resulted in $\alpha, \alpha^{\prime}$-bis(substituted benzylidene)cycloalkanones $\mathbf{2 6}$ and $\mathbf{2 7}$ in good yields. This method is economical and eco-friendly as neither any byproduct was formed nor any toxic material was used during the synthesis, and the reactions were carried out at ambient temperature. In addition, the same condensation was carried out in refluxing ethanol and in the presence of a catalytic amount of ammonium chloride to afford $\alpha, \alpha^{\prime}$-bis(arylidene)cycloalkanones [73]. Moreover, a simple and efficient procedure for the synthesis of $\alpha, \alpha^{\prime}$-bis (arylidene)cycloalkanones has been developed using $N$-bromosuccinimide (NBS) as a catalyst under mild reaction conditions [74]. Recently, a simple, improved and solvent-free synthesis of $\mathbf{2 6}$ and $\mathbf{2 7}$ was performed using activated barium hydroxide and grinding three to five minutes at room temperature [75].

Reaction of cyclopentanone with substituted benzaldehydes (1:2 molar ratio) in alcoholic alkali solution produced $\alpha, \alpha$-bis(substituted benzylidene)cyclopentanones 26 (Scheme 6) [76] [77].

Cyclohexanone was reacted with substituted benzaldehydes under alkaline reaction conditions (1:2 molar ratio) to afford $\alpha, \alpha^{\prime}$-bis(substituted benzylidene)cyclohexanones $\mathbf{2 7}$ which could be easily separated (Scheme 7) [76]-[82]. The same condensation was carried out using amino-functionalized ionic liquid, 1-aminoethyl-3-methyl tetrafluoroborate ([2-aemim] $\left.\left[\mathrm{BF}_{4}\right]\right)$ as solvent and catalyst [83]. In addition, Brønsted acid-surfactant catalyst was utilized for synthesis of $\alpha, \dot{\alpha}$-bis(substituted benzylidene)cyclohexanones in aqueous media [84].

In addition, $\alpha, \alpha^{\prime}$-bis(substituted benzylidene)cycloalkanones $\mathbf{2 6}$ and 27 could be obtained by refluxing 1,1diacetates and cycloalkanones in tetrahydrofuran (THF) and in the presence of Samarium (III) Triiodide ( $\left.\mathrm{SmI}_{3}\right)$ as a catalyst (Scheme 8) [85].

Cyclohexylphenyl methanols $\mathbf{2 8}$ were prepared by $D$-glucosamine catalyzed aldol reaction of cyclohexanone with substituted benzaldehydes (Scheme 9) [86].

3,5-Dibenzylidene-4H-pyran-4-ones (30, $\mathrm{X}=\mathrm{O})$ and 3,5-dibenzylidene-4H-1-thiopyran-4-ones (30, $\mathrm{X}=\mathrm{S})$ were synthesized via reaction of tetrahydro-4H-pyran-4-one $(\mathbf{2 9}, \mathrm{X}=\mathrm{O})$ or tetrahydro-4H-1-thiopyran-4-one (29, $\mathrm{X}=\mathrm{S}$ ) with substituted benzaldehydes either under alkaline [87]-[90] or acidic [91] [92] reaction conditions (Scheme 10).

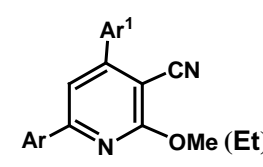

10

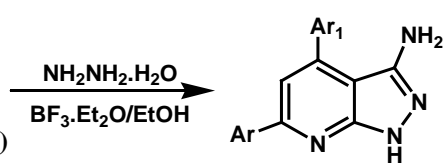

11

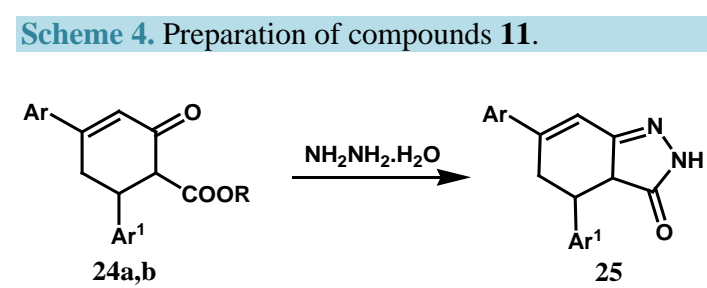

Scheme 5. Preparation of compounds 25. 


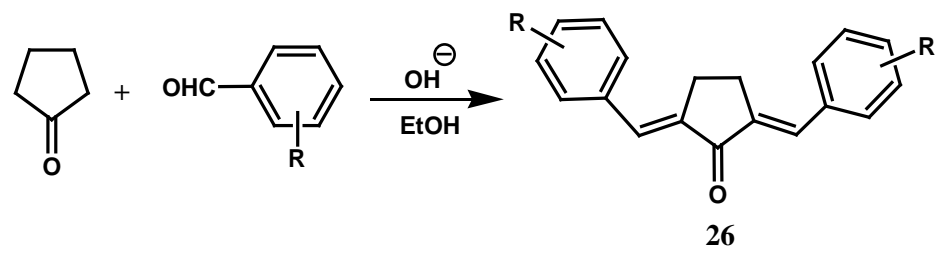

Scheme 6. Preparation of compounds $\mathbf{2 6}$ through reaction of cyclopentanone with substituted benzaldehydes under alkaline conditions.

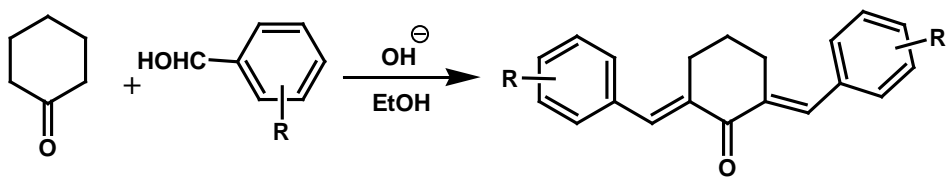

27

Scheme 7. Preparation of compounds 27 through reaction of cyclohexanone with substituted benzaldehydes under alkaline conditions.

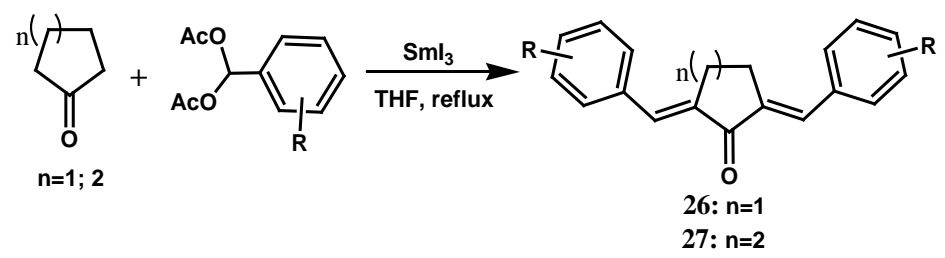

Scheme 8. Preparation of compounds $\mathbf{2 6}$ and 27 through reaction of 1,1diacetates and cycloalkanones.

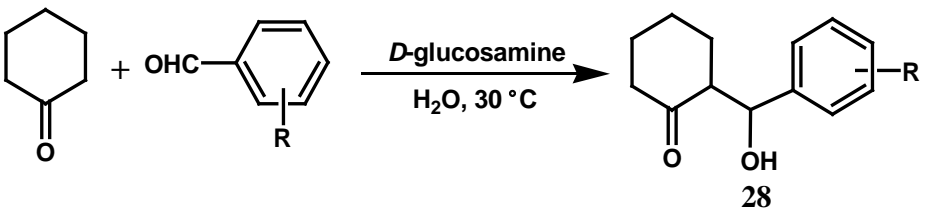

Scheme 9. Preparation of compounds 28.

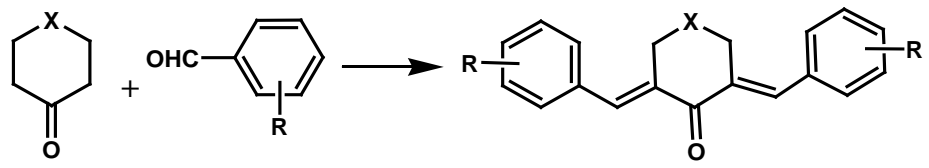

29: $x=0$; $s$

30: $\mathrm{X}=0 ; \mathrm{S}$

\section{Scheme 10. Preparation of compounds 30.}

\subsection{Synthesis of 2-Arylidene-1-Indanone Derivatives}

2-Arylidene-1-indanones 32 are important intermediates for the synthesis of a wide variety of heterocyclic ring systems. For this reason, it is useful to have simple and convenient procedures for their preparation. Most of the utilized syntheses are based on the condensation of 1-indanones $\mathbf{3 1}$ with aldehydes in the presence of a catalyst to afford 2-arylidene-1-indanones 32 (Scheme 11).

In most cases sodium or potassium hydroxide is used as a catalyst [93]-[99] and 2-arylidene-1-indanones 32 are obtained in good yields. In addition, various inorganic acids, viz. sulfuric, phosphoric or hydrochloric acids were used as catalysts to prepare 32 [100]-[105]. It is worth mentioning that acetic anhydride was used to facilitate the condensation of indanones with substituted benzaldehydes [106]. Basavaiah and Reddy [107] have introduced a simple one-pot procedure for the preparation of 2-arylidene-1-indanones $\mathbf{3 2}$ starting from tert-butyl 3-aryl-3-hydroxy-2-methylenepropanoate 33, which was allowed to react with a catalytic amount of concen- 
trated sulfuric acid in benzene followed by reaction of the intermediates formed with trifluoroacetic anhydride (TFAA) in methylene chloride to afford 32 (Scheme 12).

\section{Reactivity of 2-Arylidene-1-Indanone Derivatives}

The synthesis of indeno[1,2-c]pyrazoles $\mathbf{3 4}$ was accomplished via reaction of 2-arylidene-1-indanones $\mathbf{3 2}$ with phenylsulfonylhydrazide in an inert solvent such as aromatic hydrocarbon and in the presence of a catalytic amount of acid [108] (Scheme 13). The [3 + 2] cycloaddition reactions of 2-arylideneindanones 32 with the arylnitrile oxides generated in situ from arylhydroxyaminoyl chlorides 35 and triethylamine led to the formation of the spiro derivatives 36 [109] (Scheme 14).

\subsection{Synthesis of 2-Arylidene-1-Tetralone Derivatives}

2-Arylidene-1-tetralones $\mathbf{3 8}$ are useful intermediates for the synthesis of polycyclic ring systems. Several synthetic methods have been developed for their preparation. The majority of compounds $\mathbf{3 8}$ have been synthesized by the condensation of 1-tetralones $\mathbf{3 7}$ with aromatic aldehydes in aqueous alcoholic solution of sodium or potassium hydroxide [94] [110]-[122]. Piperidine is another alkaline catalyst which has also been used to obtain 2-arylidene-1-tetralones 38 [108] [123]-[126]. In addition, acidic catalysts such as sulfuric, phosphoric and hydrochloric acids were utilized for this condensation [127]-[129] (Scheme 15).

\section{Reactivity of 2-Arylidene-1-Tetralone Derivatives}

The naphtho[1,2-c]pyrazole derivatives 39 were prepared via reaction of 2-arylidene-1-tetralones $\mathbf{3 8}$ with phenylsulfonylhydrazide in an inert solvent such as aromatic hydrocarbon and in the presence of a catalytic amount of acid [108] (Scheme 16).

The reaction of $\mathbf{3 8}$ with the bicyclic carbonyl ylide $\mathbf{4 1}$ generated from the $\alpha$-diazo ketone $\mathbf{4 0}$ in the presence of $\mathrm{Rh}_{2}(\mathrm{OAc})_{4}$, afforded the spirodioxa ring systems 42 [130] (Scheme 17).<smiles>[R]c1ccc2c(c1)CC[C+]2C(=O)C=Cc1cc2c(cc1[R])C(=C[18F])C2=O</smiles>

Scheme 11. Preparation of compounds 32 through condensation of 1-indanones $\mathbf{3 1}$ with aldehydes.

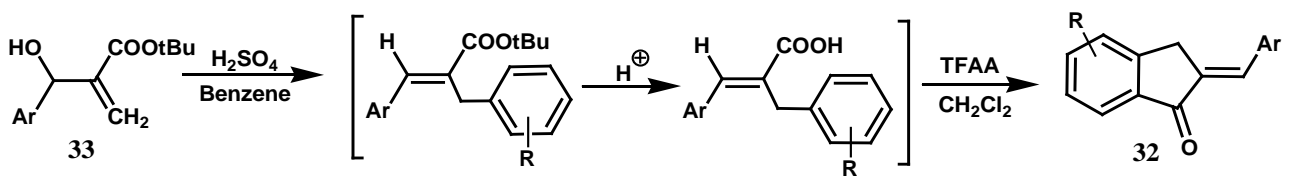

Scheme 12. Preparation of compounds 32 starting from tert-butyl 3-aryl-3-hydroxy-2-methylenepropanoate 33.

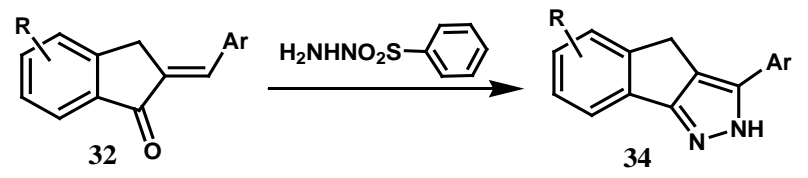

Scheme 13. Preparation of compounds 34.

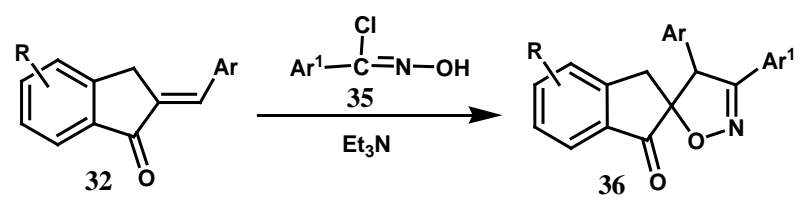

Scheme 14. Preparation of compounds 36. 


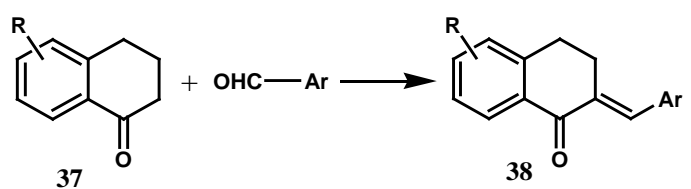

Scheme 15. Preparation of compounds $\mathbf{3 8}$.

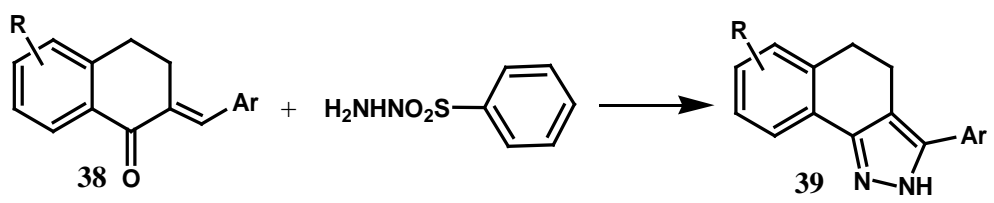

Scheme 16. Preparation of compounds 39.<smiles>CC1(C(=O)C=[W])CCCCC1=O</smiles>

40

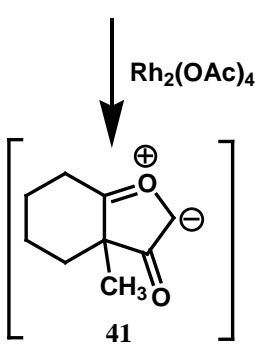

$+$<smiles>[R]c1cccc2c1CC/C(=C\[Bi]C=C)C2=O</smiles><smiles>[R]c1cccc2c1CCC(=C[Hg])C21OC23CCCCC2(C)C(=O)C1O3</smiles>

42

Scheme 17. Preparation of compounds 42.

Moreover, the preparation of benzo[g]pyrazolo[3,4- $b$ ]quinolines $\mathbf{4 3}$ was accomplished via cyclocondensation reaction of $\mathbf{3 8}$ with aminopyrazoles under solvent-free conditions [131] (Scheme 18).

Treatment of 38 with potassium isothiocyanate gave 2-[aryl(isothiocyanato)methyl]-3,4-dihydronaphthalen$1(2 \mathrm{H})$-ones $\mathbf{4 4}$. Reaction of $\mathbf{4 4}$ with primary aromatic amines gave 4-aryl-1-(substituted phenyl)-1,4,5,6-terahydrobenzo[h]quinazoline-2-thiols 45 [129] (Scheme 19).

Dispiropyrrolidinyl derivatives, 1',2',3',4'-tetrahydronaphthalen-1'-one-spiro[3'.3]-4-aryl- $N$-methylpyrrolidine2-spiro-2"-acenaphthen-1"-ones 48 were obtained through reaction of 2-arylidene-1-tetralones 38, acenaphthylenequinone $\mathbf{4 6}$ and sarcosine $\mathbf{4 7}$ in aqueous methanol [132] (Scheme 20).

Furthermore, 1',2',3',4'-tetrahydronaphthalen-1'-one-spiro[2'.3]-(4-aryl)pyrrolidine-spiro-[2.2"]oxindoles 50 were synthesized via reaction of 2-arylidene-1-tetralones 38, isatin (49) and benzylamine in dry acetonitrile [132] (Scheme 21).

A new method to prepare benzo[c]xanthones $\mathbf{5 1}$ was reported by the ultraviolet radiation-mediated tandem reaction through irradiating a solution of 2-benzylidene-1-tetralones $\mathbf{3 8}$ in acetonitrile with ultraviolet light (500 W middle-pressure Hg) [133] (Scheme 22).

\subsection{Synthesis of 2-Arylidene-1-Benzosuberone Derivatives}

2-Arylidene-1-benzosuberones 53 were synthesized by the condensation of 1-benzosuberone 52 with aromatic aldehydes using alkaline [96] [121] [134] [135] or acidic [136] catalysts (Scheme 23).

\subsection{Synthesis of Aurone Derivatives}

Aurones 55 are the oxa analogues of the 2-arylidene-1-indanones 32, different procedures were adopted for their 


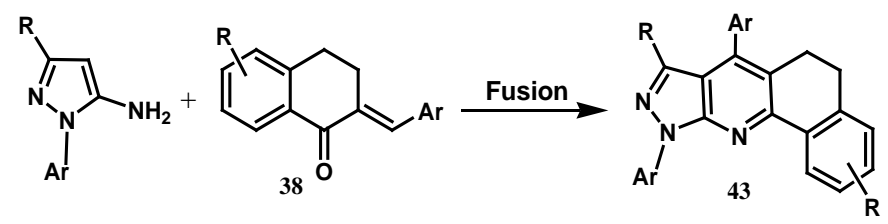

Scheme 18. Preparation of compounds 43.

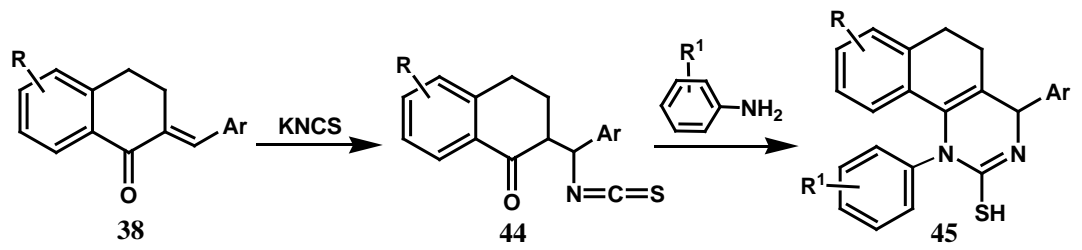

Scheme 19. Preparation of compounds 45.<smiles>O=C1C(=O)c2cccc3cccc1c23</smiles>

46<smiles>C=CCC(=O)O</smiles>

47

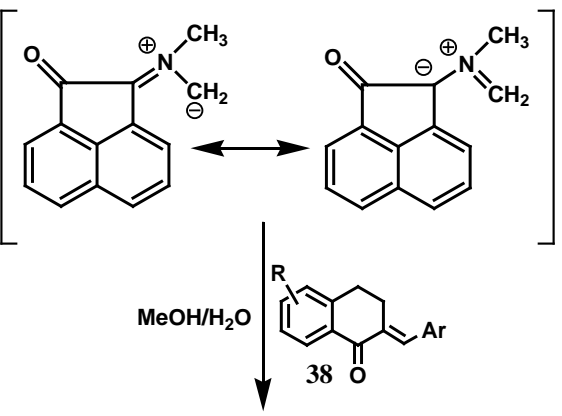

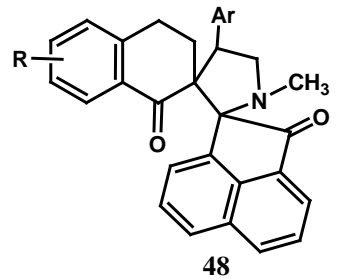

Scheme 20. Preparation of compounds 48.

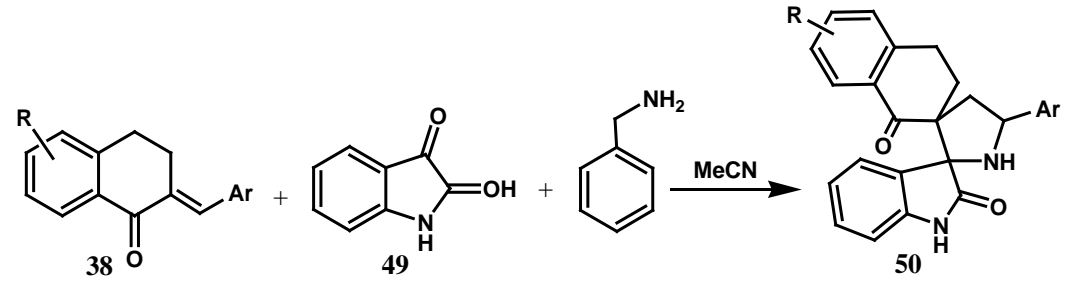

Scheme 21. Preparation of compounds $\mathbf{5 0 .}$

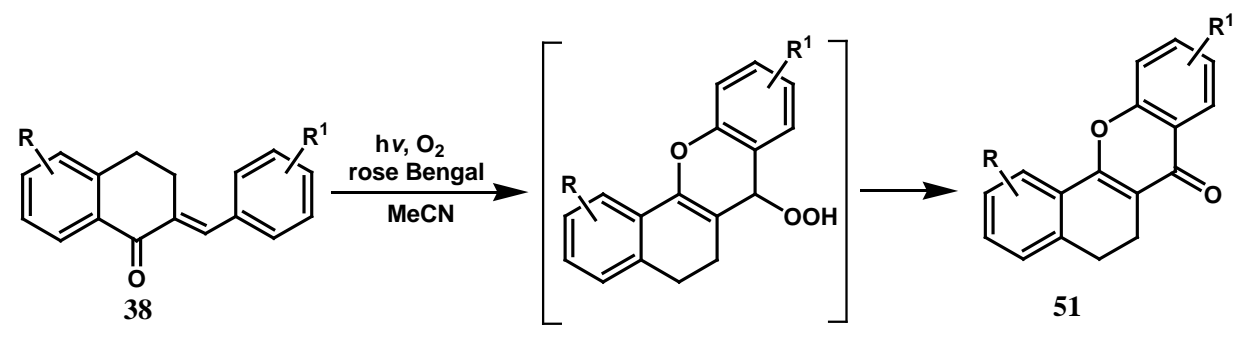

Scheme 22. Preparation of compounds 51. 
preparation. First, the Algar-Flynn-Oyamada reaction based on the oxidative cyclization of 2'-hydroxychalcones, where aurone is one of the products formed during preparation of 2'-hydroxychalcone [137]-[139]. Another procedure described by Donnelly and co-workers [140] [141] is based on bromomethylation of chalcones and 2'-acetoxychalcones followed by ring closure of the bromodihydro analogues providing aurones $\mathbf{5 5}$. However, none of these procedures can be considered as a rational method for the synthesis of aurones.

The most common synthetic procedures for aurones $\mathbf{5 5}$ are based on the condensation of coumaran-3-ones $\mathbf{5 4}$ with substituted benzaldehydes in the presence of a catalyst. As catalyst, sodium hydroxide [142] [143], potassium hydroxide [144], anhydrous sodium acetate [145], sulfuric [145], hydrochloric [146], and phosphoric acids [147] were used for this condensation (Scheme 24). Farkas et al. [148]-[150] performed the condensation of the appropriate coumaran-3-one $\mathbf{5 4}$ with substituted benzaldehydes in refluxing acetic anhydride to obtain aurones $\mathbf{5 5}$.

Another synthetic procedure was developed for the preparation of aurones 55 through cyclization of 1-(2-hydroxyphenyl)-3-(substituted phenyl)prop-2-en-1-ones $\mathbf{5 6}$ in methanol and in the presence of a catalytic amount of silver nitrate [151] (Scheme 25).

In addition, other synthetic procedures were adopted for the preparation of aurones $\mathbf{5 5}$ through cyclization of 56 using mercuric acetate in pyridine [152] [153], mercuric acetate in polyethylene glycol (PEG-400) [154], mercuric acetate in dimethyl sulfoxide (DMSO) [155], and cupric bromide in DMSO [152] (Scheme 25).

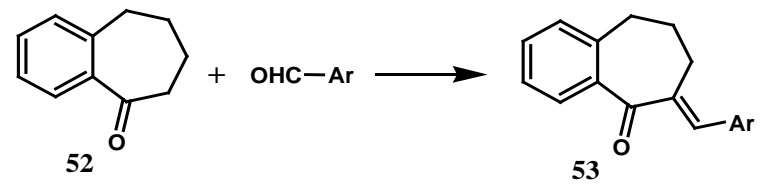

Scheme 23. Preparation of compounds 53.

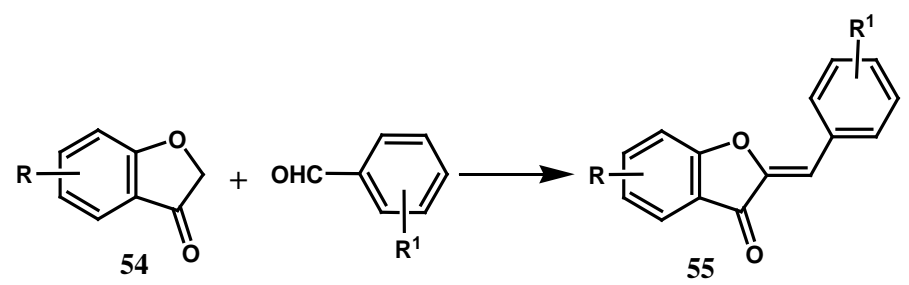

Scheme 24. Preparation of compounds 55 through condensation of coumaran-3ones 54 with substituted benzaldehydes.

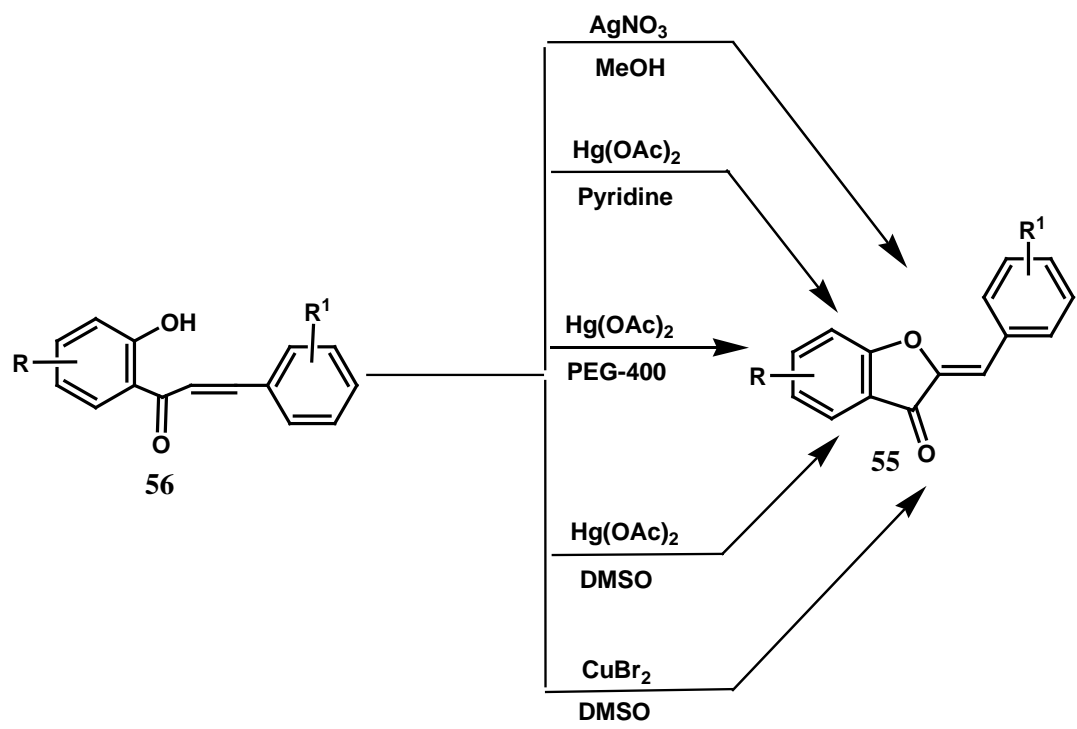

Scheme 25. Preparation of compounds 55 through cyclization of 1-(2-hydroxyphenyl)-3-(substituted phenyl)prop-2-en-1-ones $\mathbf{5 6 .}$ 
Mechanism of Cyclization Using Mercuric Acetate in Pyridine [152]

The mechanism of cyclization of $\mathbf{5 6}$ into aurone derivatives $\mathbf{5 5}$ is illustrated in Scheme $\mathbf{2 6}$.

Furthermore, gold-catalyzed cyclization of alkynol derivatives $\mathbf{5 7}$ has become an efficient tool in the synthesis of aurones $\mathbf{5 5}$ and provided the best results under mild reaction conditions and excellent selectivities, avoiding the formation of flavones as byproducts [156] [157] (Scheme 27).

\subsection{Synthesis of 1-Thioaurone Derivatives}

1-Thioaurones 59 are synthetic thio analogues of the naturally-occurring aurones, their synthesis has already been published [158]-[162]. Condensation of 1-thiocoumaran-3-ones $\mathbf{5 8}$ with aromatic aldehydes in the presence of phosphoric acid [147] or piperidine [159] afforded 59. In addition, the same reaction was carried out in THF and in the presence of 1.5 equivalents of lithium diisopropylamide (LDA) at $-10^{\circ} \mathrm{C}$ [163] (Scheme 28).

Moreover, a convenient one-step synthesis has been published [161], whereas, equimolar amounts of (2-methylthio)benzoic acid derivatives $\mathbf{6 0}$ and aromatic aldehydes were allowed to react with 2.0 equivalents of LDA in THF at $0^{\circ} \mathrm{C}$ to yield 1-thioaurones 59 (Scheme 29).

In 2010, Boughaleb et al. [162] described new synthetic pathway for the preparation of 1-thioaurones 59 (Scheme 30).

\section{Reactivity of Aurone and 1-Thioaurone Derivatives}

Reaction of $\mathbf{5 5}$ or $\mathbf{5 9}$ with 2-aminothiophenol in ethanol and in the presence of sodium ethoxide gave the spiro compounds 61a, b. By the way of contrast, the 6,12-dihydrobenzofuro[2,3-c][1,5]benzothiazepines 62a and the

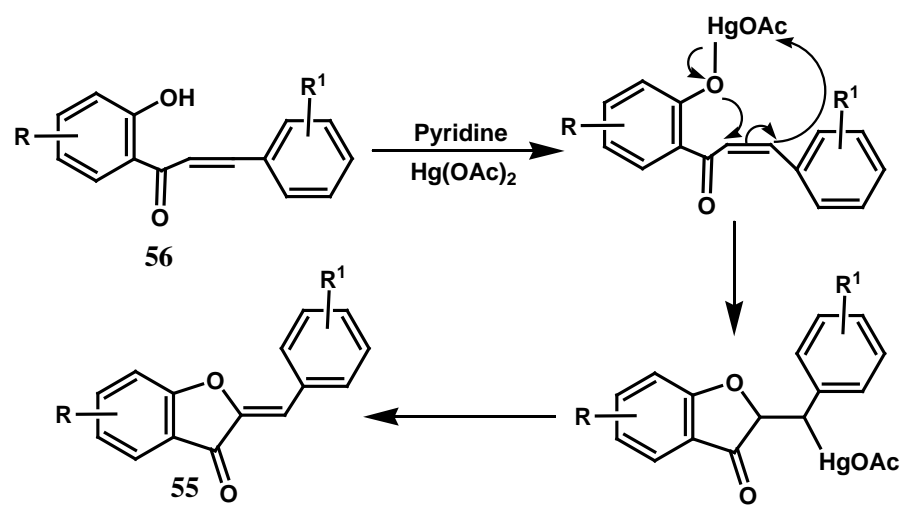

Scheme 26. Mechanism of cyclization of compounds 56 into aurone derivatives 55 using mercuric acetate in pyridine.

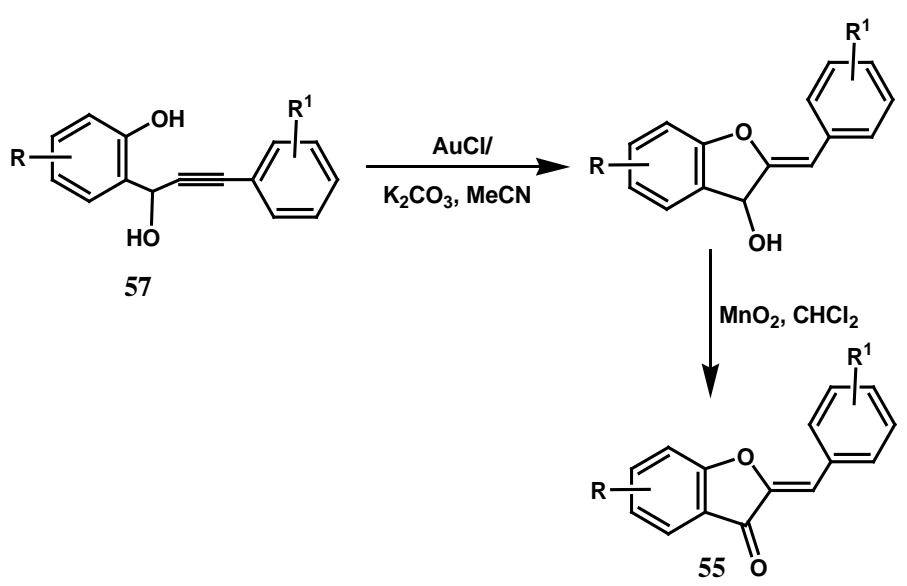

Scheme 27. Preparation of compounds 55 through cyclization of alkynol derivatives 57. 


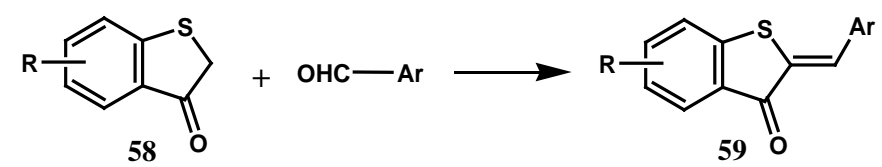

Scheme 28. Preparation of compounds 59 through condensation of 1-thiocoumaran-3-ones 58 with aromatic aldehydes.

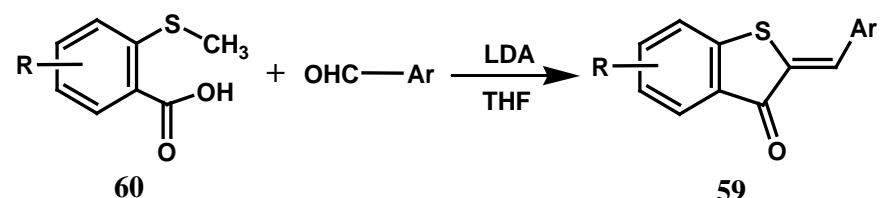

Scheme 29. Preparation of compounds 59 through reaction of (2-methylthio)benzoic acid derivatives 60 with aromatic aldehydes.

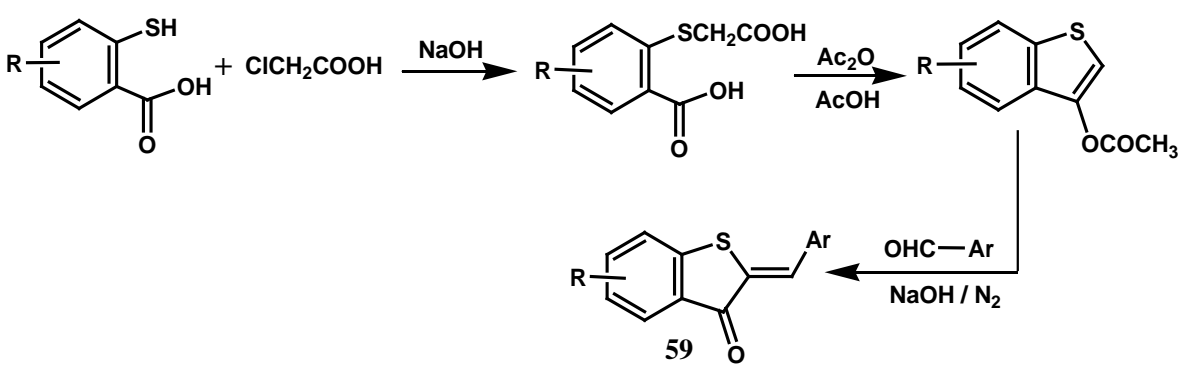

Scheme 30. Preparation of compounds 59 starting from 2-mercaptobenzoic acid derivatives.

6,12-dihydrobenzothieno[2,3-c][1,5]benzothiazepines $\mathbf{6 2 b}$ were obtained in good yields via heating $\mathbf{5 5}$ or $\mathbf{5 9}$, respectively with 2-aminothiophenol in polyphosphoric acid (PPA) under nitrogen. Treatment of $\mathbf{6 2 a}$, $\mathbf{b}$ with 2-chloroethyl- $N, N$-dimethylammonium chloride and potassium carbonate in ethyl acetate produced the annulated benzofuran and benzothiophene derivatives 63a, b. The tetracyclic derivatives 62a, b were deprotonated with sodium hydride in DMF to afford compounds 64a, b [164] (Scheme 31).

Reaction of aurones $\mathbf{5 5}$ with hydrazine hydrate in ethanol gave the benzofuro[3,2-c]pyrazole derivatives $\mathbf{6 5}$. Refluxing aurones 55 with phenyl hydrazine in glacial acetic acid gave the benzofuro[3,2-c]pyrazole derivatives 66. In addition, benzofuro[3,2-c] isoxazole derivatives $\mathbf{6 7}$ were synthesized by the reaction of aurones $\mathbf{5 5}$ with hydroxylamine hydrochloride in alcoholic solution of potassium hydroxide. Furthermore, benzofuro[2,3-c]pyridine derivatives $\mathbf{6 8}$ were obtained through reaction of aurones $\mathbf{5 5}$ with acetamide in alcoholic solution of potassium hydroxide. Finally, benzofuro[3,2-d]pyrimidine derivatives 69 were synthesized via reaction of aurones 55 with urea or thiourea in alcoholic solution of potassium hydroxide [165] (Scheme 32).

\subsection{Synthesis of 3-Arylidene-4-Chromanone Derivatives}

The synthesis and chemical transformation of 3-arylidene-4-chromanones and related compounds received much attention due to the abundance of this moiety in many natural products and biologically active substances [166]-[169]. Thiochromones are synthetic compounds and some of their derivatives are reported to have medicinal uses [170] [171]. Current literature showed that there has been an increasing trend towards the synthesis of heterocycles containing these two ring systems [172].

The synthesis of 3-arylidene-4-chromanones $\mathbf{7 1}$ is based on the condensation of 4-chromanones $\mathbf{7 0}$ with aromatic aldehydes in the presence of a catalyst (Scheme 33). Acid-catalyzed condensation $\left(\mathrm{H}_{2} \mathrm{SO}_{4}, \mathrm{H}_{3} \mathrm{PO}_{4}\right.$ or $\mathrm{HCl}$ ) of the two components was accomplished [173]-[180]. In addition, Farkas et al. [181]-[183] performed the same reaction in hot acetic anhydride, which is a very simple and convenient method, but sometimes it requires a prolonged time. Another procedure used for the synthesis of $\mathbf{7 1}$ is the base catalyzed condensation of 4-chromanones 70 with aromatic aldehydes using sodium hydroxide [184], sodium methoxide [185], anhydrous potassium acetate [186], piperidine [187]-[189], or pyrrolidine [190]. A new synthetic method for $\mathbf{7 1}$ was through 

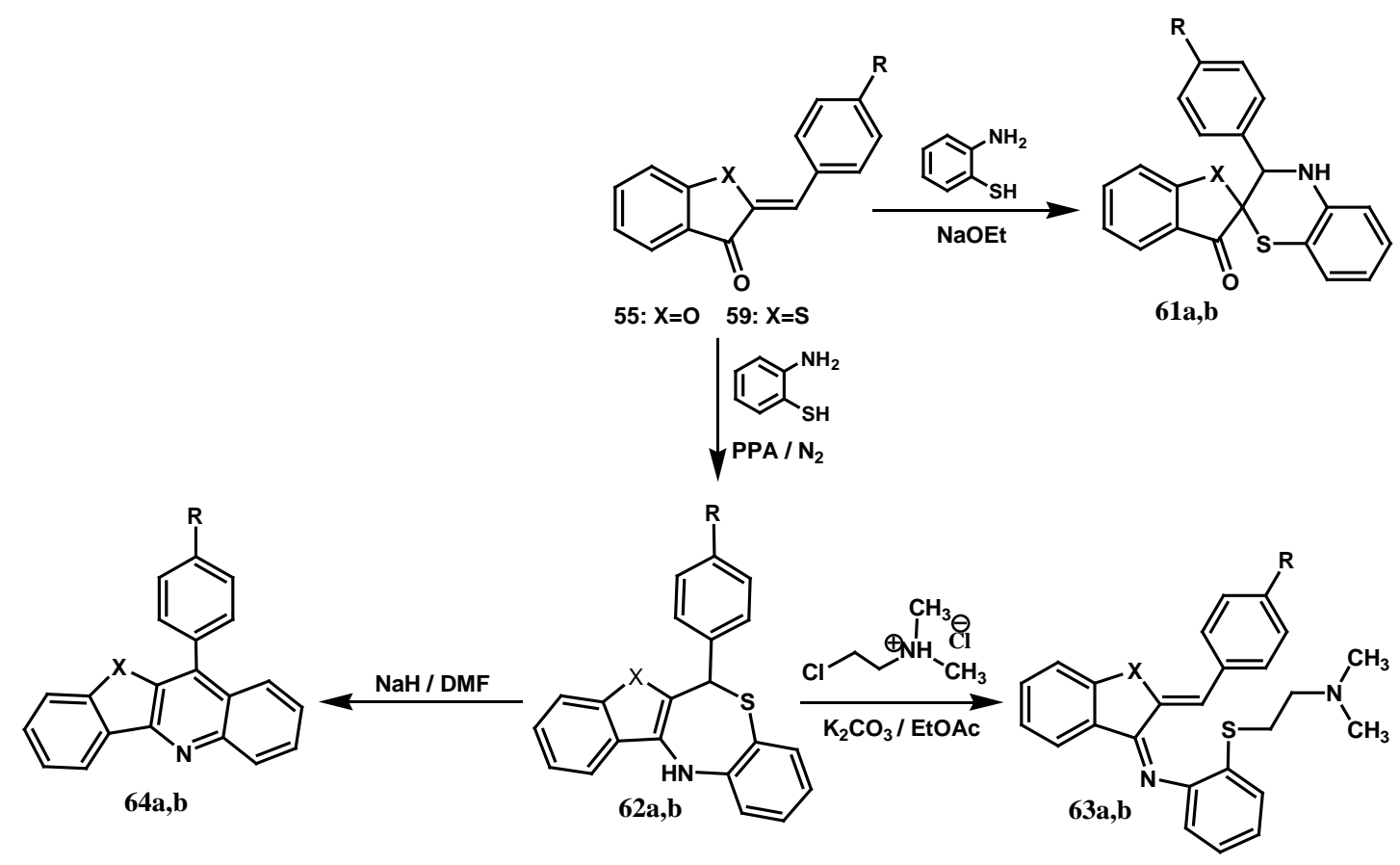

Scheme 31. Preparation of compounds 61-64.

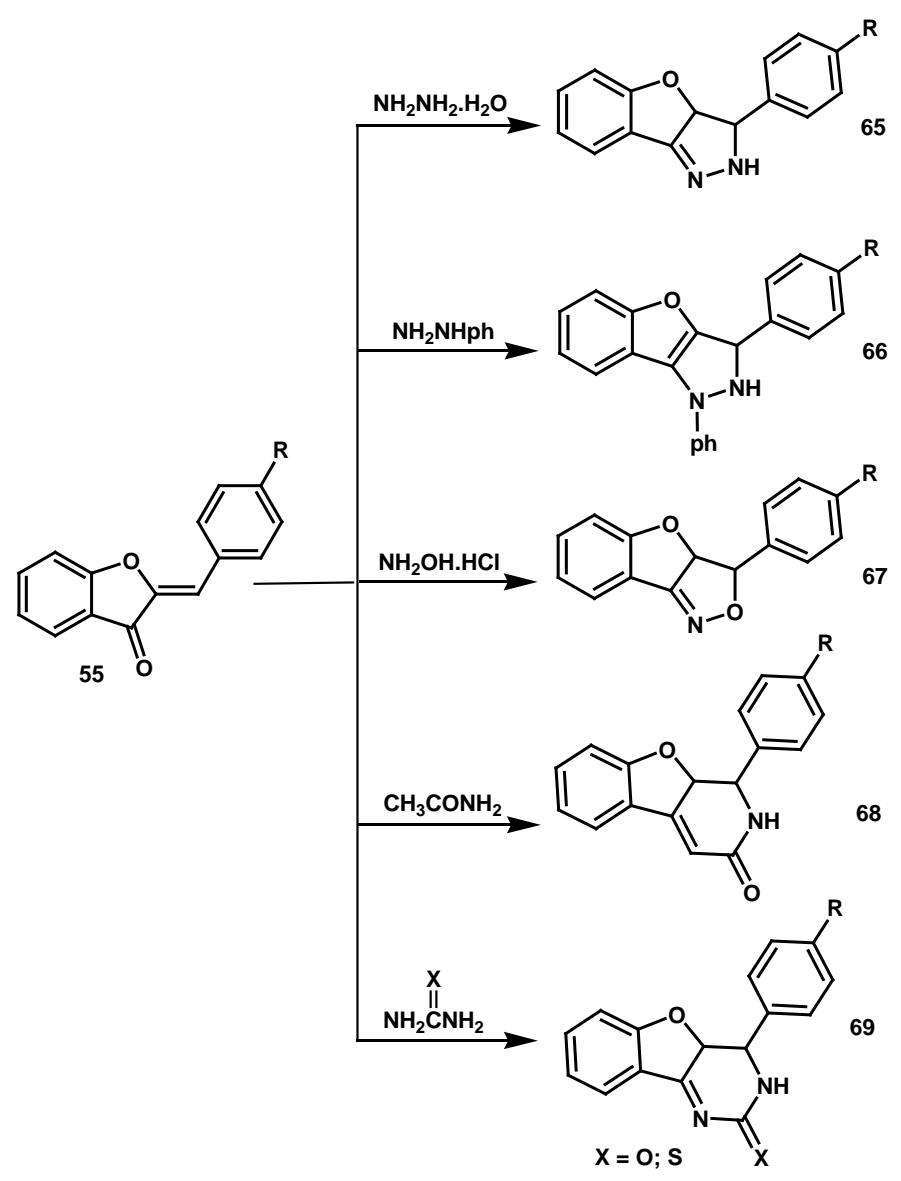

Scheme 32. Preparation of compounds 65-69. 
condensation of different aromatic aldehydes with 4-chromanones $\mathbf{7 0}$ using amberlyst-15 as a catalyst under microwave irradiation in solvent-free conditions [191]. However, it should be mentioned that in case of using piperidine as a catalyst, an exo-endo double bond migration takes place if the aldehyde has strong electron-withdrawing substituents [188] [192]. In such a case, 3-arylmethyl-4-chromenone (homoisoflavone) 72 is the product instead of the expected 3-arylidene-4-chromanone 71 (Scheme 34). Basavaiah et al. [107] [193] synthesized 3-arylidene-4-chromanones $\mathbf{7 1}$ by ring closure of the acrylic acid derivatives $\mathbf{7 3}$ with TFAA in methylene chloride (Scheme 35).

\section{Reactivity of 3-Arylidene-4-Chromanone Derivatives}

Refluxing a solution of 3-arylidene-4-chromanone 71, isatin (49) and sarcosine (74) afforded 4-aryl- $\mathrm{N}$-methyl-spiro[2.3'](2-oxoindoline)-spiro[3.3"](substituted 4-chromanone)pyrrolidines 75 [194] (Scheme 36). Whereas, refluxing a solution of 71, isatin (49) and L-proline (76) in aqueous methanol gave 4-aryl-spiro[2.3'](2oxoindoline)-spiro[3.3"]-(substituted 4-chromanone)hexahydropyrrolizines 77 . The reaction proceeded via formation of an azomethine ylide which readily undergoes 1,3-dipolar cycloaddition reaction with 3-arylidene-4chromanones to give a single cycloadduct [194] (Scheme 36).

\subsection{Synthesis of 3-Arylidene-1-Thio-4-Chromanone Derivatives}

The synthesis of 3-arylidene-1-thio-4-chromanones $\mathbf{7 9}$ is based on the condensation of 1-thio-4-chromanones $\mathbf{7 8}$ with aromatic aldehydes under acidic conditions [195]-[199]. The same condensation was accomplished using piperidine as a catalyst [187]-[189], or amberlyst-15 under microwave irradiation [191] (Scheme 37). As described for the condensation of 4-chromanone $\mathbf{7 0}$ with aromatic aldehydes [187] [188], in case of aromatic aldehydes bearing strongly electron-withdrawing substituents, an exo-endo double bond transposition also takes place, resulting in the formation of 3-arylmethyl-1-thio-4-chromenones $\mathbf{8 0}$ instead of 3-arylidene-1-thio-4chromanones 79 [188] (Scheme 38).

\subsection{Synthesis of 3-Arylideneflavanone Derivatives}

3-Arylideneflavanones (flavindognides) 82 are well known flavanone derivatives. They were first synthesized by Katschalowsky and von Kostanecki in 1904 [200]. They were also synthesized by the acid-catalyzed condensation<smiles>O=C1C[CH+]Oc2ccccc21</smiles>

Scheme 33. Preparation of compounds 71 through condensation of 4-chromanones $\mathbf{7 0}$ with aromatic aldehydes.

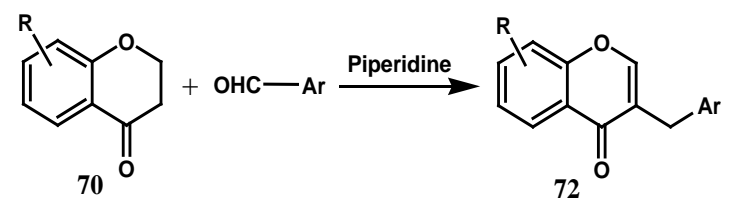

$\mathrm{ArCHO}=$ Aromatic aldehydes substituted with electron-withdrawing groups

Scheme 34. Preparation of compounds 72.<smiles>[R]c1cccc(OC/C(=C\[Al])C(=O)O)c1</smiles>

73<smiles>[R]c1ccc2c(c1)OC/C(=C\Br)C2=O</smiles>

Scheme 35. Preparation of compounds 71 through cyclization of acrylic acid derivatives 73 with TFAA. 


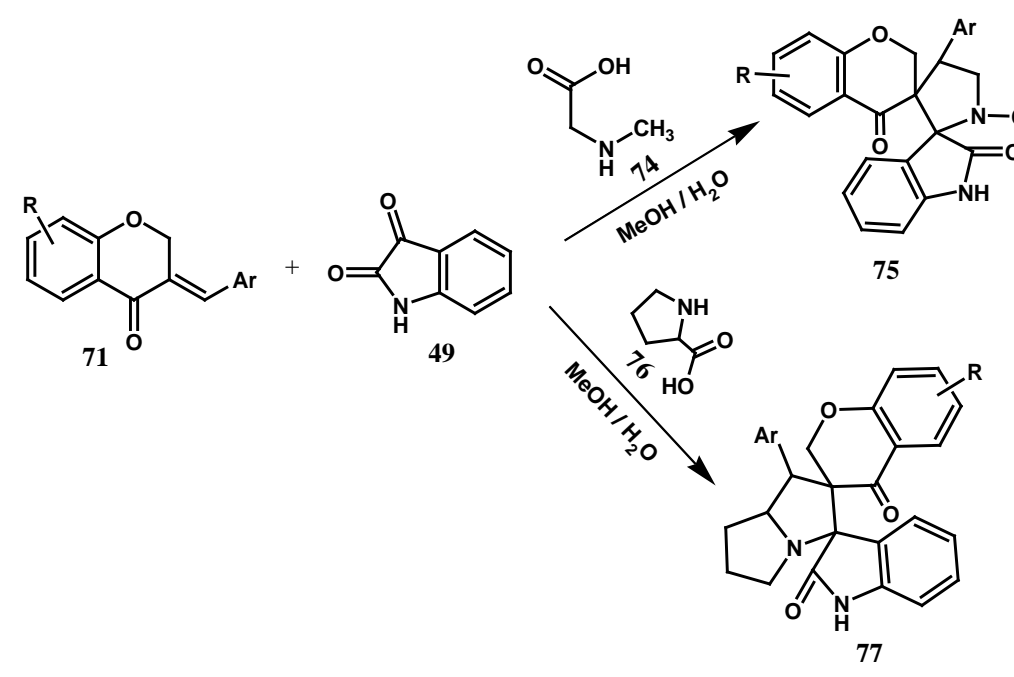

Scheme 36. Preparation of compounds $\mathbf{7 5}$ and $\mathbf{7 7 .}$

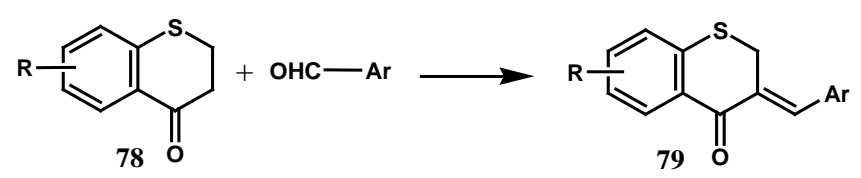

$\mathrm{ArCHO}=$ Aromatic aldehydes substituted with electron-donating groups

Scheme 37. Preparation of compounds 79.

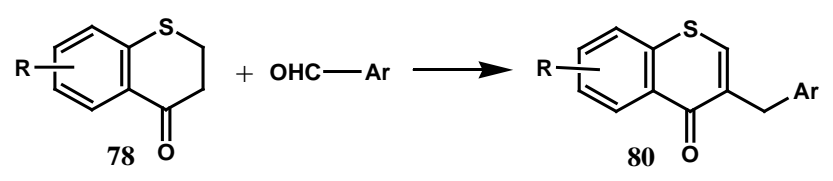

$\mathrm{ArCHO}=$ Aromatic aldehydes substituted with electron-withdrawing groups

Scheme 38. Preparation of compounds 80.

of flavanones $\mathbf{8 1}$ with aromatic aldehydes [200]-[204] (Scheme 39). In addition, glycine was described as a catalyst for this condensation [205]. It was reported that in some cases the base catalyzed condensation of hydroxyacetophenone with benzaldehyde gave 3-benzylideneflavanone as a coproduct of the corresponding hydroxychalcone [206]-[208]. Furthermore, the synthesis of $\mathbf{8 2}$ via base-catalyzed condensation of flavanone $\mathbf{8 1}$ with aromatic aldehydes was reported [189] [209]. It is worth mentioning that if aldehydes with strong electron-withdrawing substituents are used, 3-arylmethylflavones $\mathbf{8 3}$ are obtained instead of 3-arylideneflavanones 82 [210] (Scheme 40). 3-Arylmethylflavones 83 were also obtained via treatment of 82 with pyridinium chlorochromate (PCC) (5.0 equivalent) in DMF [211] (Scheme 41).

\subsection{Synthesis of 3-Arylidene-1-Thioflavanone Derivatives}

3-Arylidene-1-thioflavanones 85 were synthesized by the acid-catalyzed condensation of 1-thioflavanones 84 with aromatic aldehydes [212] [213] (Scheme 42). Also, base catalyzed condensation of thioflavanones 84 with aromatic aldehydes using piperidine was reported [214]. However, this procedure can be used only for the synthesis of 3-arylidene-1-thioflavanones substituted with electron-donating or slightly electron-withdrawing substituents in the arylidene moiety. When aromatic aldehydes substituted with strongly electron-withdrawing substituents were used, 3-arylmethyl-1-thioflavones 86 were obtained [214] [215] (Scheme 43).

\section{Reactivity of 3-Arylidene-1-Thioflavanone Derivatives}

Reaction of 3-arylidene-1-thioflavanones $\mathbf{8 5}$ with sodium oxychloride and hydrogen peroxide gave 3-arylidene- 


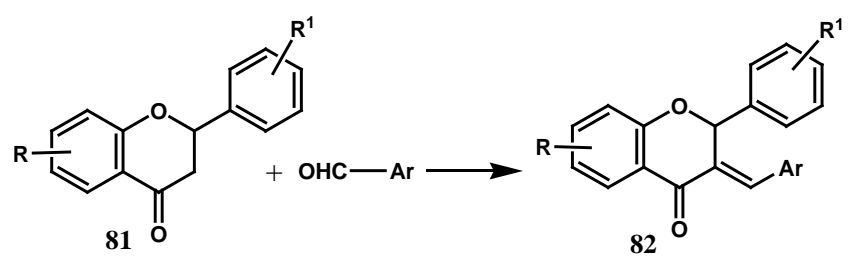

$\mathrm{ArCHO}=$ Aromatic aldehydes substituted with electron-donating groups

Scheme 39. Preparation of compounds 82 through condensation of flavanones $\mathbf{8 1}$ with aromatic aldehydes substituted with electron-donating groups.<smiles>[R][R]1ccc2c(c1)O[C@H](c1ccc([R1])cc1)CC2=O</smiles>

ArCHO = Aromatic aldehydes substituted with electron-withdrawing groups

Scheme 40. Preparation of compounds 83 through condensation of flavanones $\mathbf{8 1}$ with aromatic aldehydes substituted with strong electron-withdrawing groups.

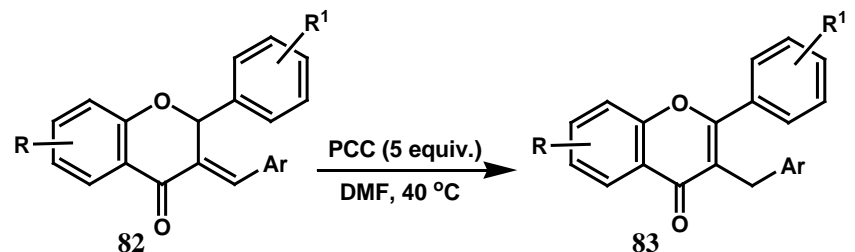

Scheme 41. Preparation of compounds 83 through treatment of 3-arylideneflavanones $\mathbf{8 2}$ with pyridinium chlorochromate (PCC).

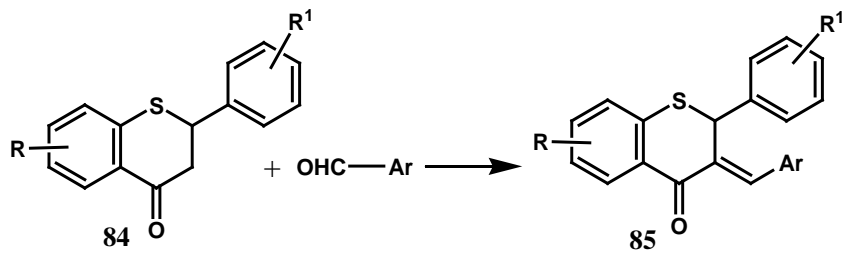

$\mathrm{ArCHO}=$ Aromatic aldehydes substituted with electron-donating groups

Scheme 42. Preparation of compounds 85 through condensation of 1-thioflavanones $\mathbf{8 4}$ with aromatic aldehydes substituted with electron-donating groups.<smiles>[R][R]1ccc(C2CC(=O)c3ccccc3S2)cc1</smiles>

$\mathrm{ArCHO}=$ Aromatic aldehydes substituted with electron-withdrawing groups

Scheme 43. Preparation of compounds 86 through condensation of 1-thioflavanones $\mathbf{8 4}$ with aromatic aldehydes substituted with strong electron-withdrawing groups. 
1-thioflavanone epoxides 87 [216]. Reaction of epoxide derivatives 87 with dimethyldioxirane (DMD) yielded the sulfoxide and sulfone derivatives $\mathbf{8 8}$ and $\mathbf{8 9}$ [216] (Scheme 44).

\subsection{Synthesis of Arylideneaniline Derivatives (Schiff Bases)}

Schiff bases are typically formed by the condensation of primary amines with aldehydes. Schiff bases are important intermediates for the synthesis of various bioactive compounds. Literature survey revealed that these compounds have been associated with diverse chemotherapeutic activities, including antimalarial [217], anticancer [218], antibacterial [219], antifungal [220], antitubercular [221], anti-inflammatory [222], antimicrobial [222] and antiviral [223] activities. On the other hand, they are fundamental materials for the synthesis of various Schiff base ligands which are used as chiral auxiliaries in asymmetric synthesis [224]. Metal complex Schiff bases have also been used in oxidation reactions [225].

\subsubsection{Various Reaction Conditions Have Been Used in the Synthesis of Schiff Bases}

Schiff bases are compounds containing an azomethine group ( $-\mathrm{C}=\mathrm{N}-)$. They are usually formed by condensation of primary amines with carbonyl compounds according to the following equation [226]; $\mathrm{R}^{-\mathrm{NH}_{2}}+\mathrm{R}^{1}-\mathrm{CHO} \rightarrow$ $\mathrm{R}-\mathrm{N}=\mathrm{CH}-\mathrm{R}^{1}+\mathrm{H}_{2} \mathrm{O}$, where $\mathrm{R}, \mathrm{R}^{1}$ may be an aliphatic or aromatic group. Schiff bases of aromatic aldehydes have an effective conjugated system and are more stable [227]. They are prepared under various reaction conditions, the use of organic solvents such as THF and 1,2-dichloroethane (DCE) was reported [228]. The reaction was also carried out in ethanol at room temperature [229] [230], in refluxing ethanol [231], in refluxing ethanol and in the presence of a catalytic amount of glacial acetic acid [222] [232], in refluxing methanol and in the presence of a catalytic amount of glacial acetic acid [233], in methanol at room temperature and in the presence of a catalytic amount of concentrated hydrochloric acid [234], in refluxing ethanol and in the presence of a catalytic amount of concentrated sulfuric acid [235], in refluxing mixture of ethanol/dioxane and in the presence of a catalytic amount of glacial acetic acid [236], in refluxing ethanol and in the presence of a catalytic amount of anhydrous zinc chloride [237], in refluxing benzene [238], in dichloromethane (DCM) at room temperature and in the presence of anhydrous magnesium sulfate [238], using DCM and a catalytic amount of neutral alumina under microwave irradiation [238], under solvent-free conditions in the presence of lemon juice as natural acid catalyst [239], in refluxing methanol and in the presence of a catalytic amount of nickel nitrate [240], and using phosphorus pentoxide/silica gel $\left(\mathrm{P}_{2} \mathrm{O}_{5} / \mathrm{SiO}_{2}\right)$ [241]. In addition, a green and efficient method for the synthesis of Schiff bases in aqueous media was described [242].

\subsubsection{Mechanism}

Concerning the mechanism of the transformation of aldehydes and amines into Schiff bases 90, two possible pathways are illustrated (Scheme 45 and Scheme 46) [239]. In Scheme 45, there is nucleophilic attack of a primary amine on carbonyl carbon that affords hydroxyl compound which on dehydration gives Schiff bases. The

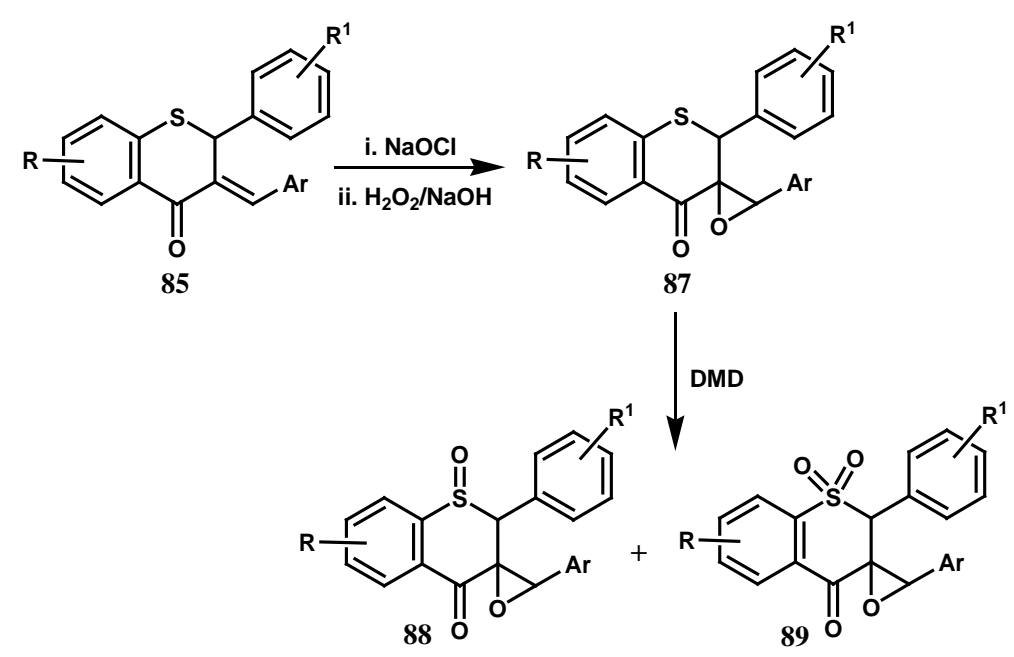

Scheme 44. Preparation of compounds 87-89. 


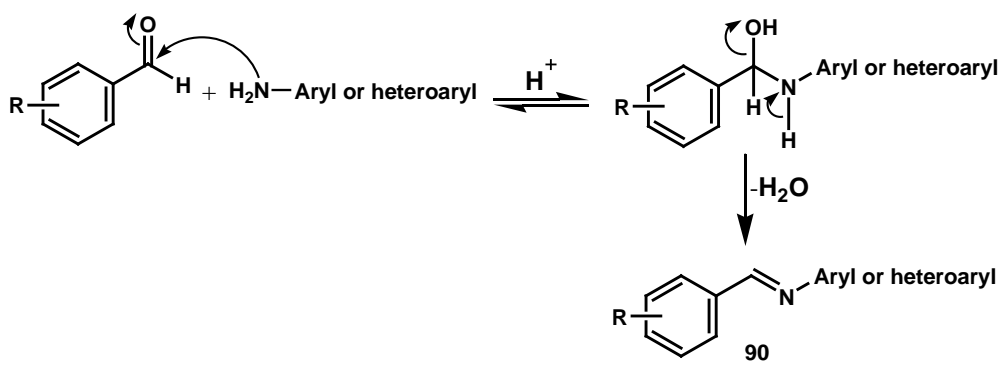

Scheme 45. Mechanism of condensation of benzaldehyde derivatives with primary amines without using Lewis acid as a catalyst.

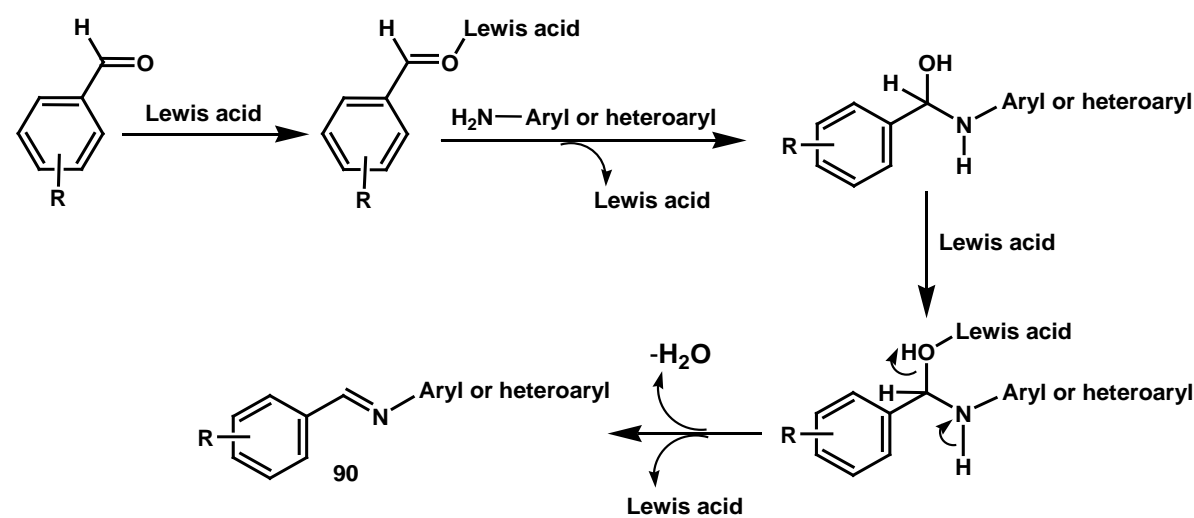

Scheme 46. Mechanism of condensation of benzaldehyde derivatives with primary amines using Lewis acid as a catalyst.

formation of Schiff bases $\mathbf{9 0}$ in this method largely depends on the rate of removal of water from the reaction mixture. Originally, the classical synthetic route for preparation of Schiff bases was reported by Schiff [243] which involves the condensation of primary amines with carbonyl compounds under azeotropic distillation [244] with the simultaneous removal of water. The removal of water during this condensation was conventionally facilitated by using molecular sieves [245] or a Dean-Stark apparatus [246]. In literature, the removal of water in situ has been accomplished by using dehydrating solvents such as tetramethyl orthosilicate [247] and trimethyl orthoformate [248] [249].

To overcome the difficulties in the removal of water, an alternative method has been employed in which Lewis acid is used as a catalyst that accelerates nucleophilic attack of amines on carbonyl carbon as well as serving as a dehydrating agent for removal of water in the second step (Scheme 46). Several modified methods for synthesis of Schiff bases have been reported in literature in which Lewis acids were used as catalysts such as $\mathrm{ZnCl}_{2}$ [250], $\mathrm{TiCl}_{4}$ [251], alumina [252], $\mathrm{P}_{2} \mathrm{O}_{5}$ [253] and also by using hydrotalcite [254].

\subsubsection{Reactivity of Schiff Bases}

Schiff bases are important intermediates for the synthesis of many heterocyclic compounds. Condensation of $\mathbf{9 0}$ with indole in basic medium afforded $N$-substituted indoles 91 [255]-[258]. The thiazolidin-4-one derivatives 92a,b were obtained via reaction of $\mathbf{9 0}$ with thioglycolic [259]-[268] and thiolactic acids [269], respectively. Reaction of Schiff bases $\mathbf{9 0}$ with chloroacetyl chloride in dioxane and in the presence of triethylamine gave chloroacetamido derivatives 93 [266] or the azetidin-2-ones 94 [265] [270]. Similarly, reaction of 91 with phenylacetyl chloride in dioxane and in the presence of triethylamine produced the azetidinones 95 [271]. The pyrrol-2-one derivatives $\mathbf{9 6}$ can be synthesized by reaction of $\mathbf{9 0}$ with maleic anhydride [272]-[275] (Scheme 47).

\subsection{Synthesis of Arylidenemalononitrile Derivatives}

The Knoevenagel reaction is the most simple and straightforward method used to produce the substituted alkenes [276]. Classically, the process consists of condensation of aldehydes or ketones with active methylene 


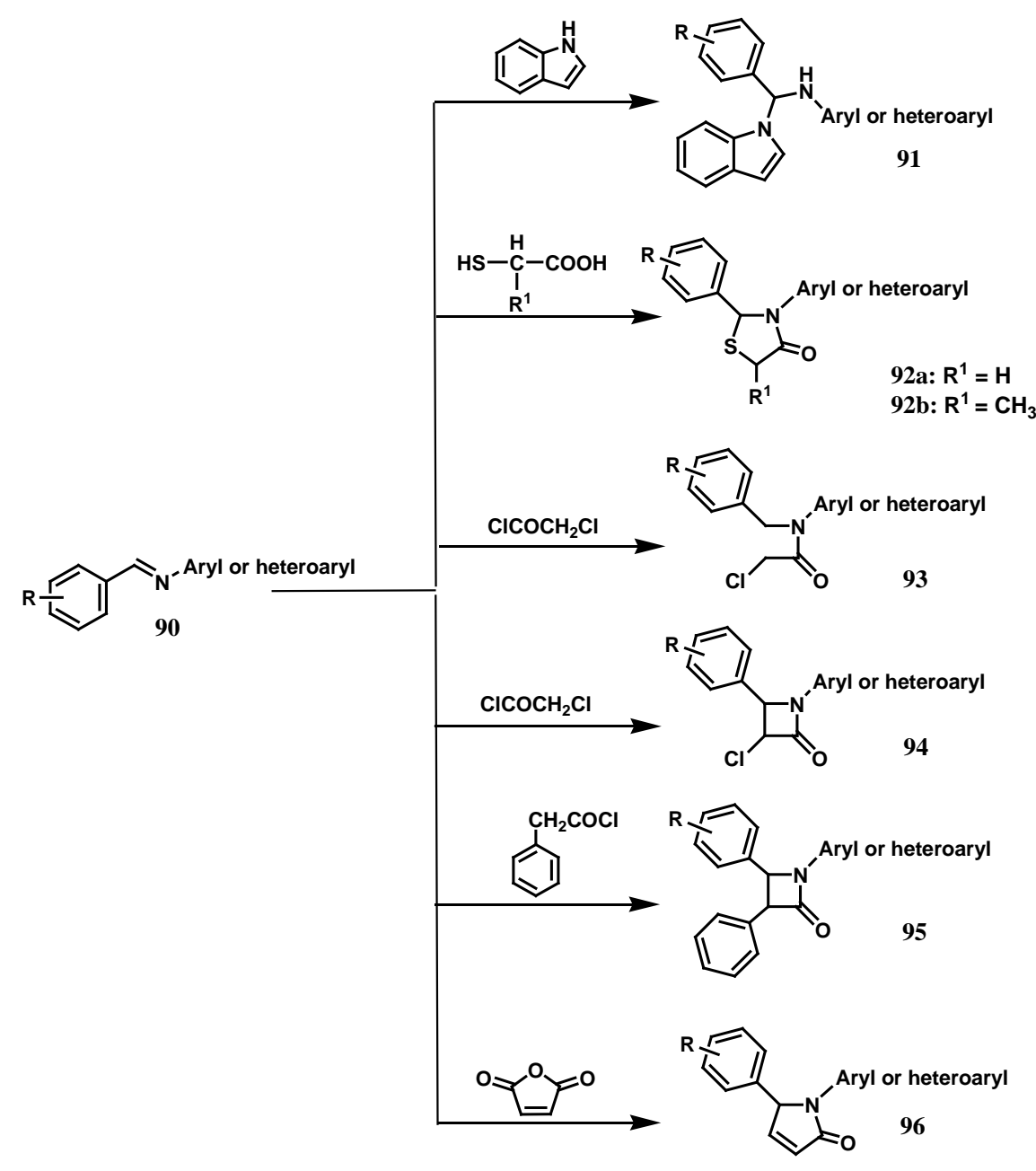

Scheme 47. Preparation of compounds 91-96.

compounds in the presence of a variety of reagents. Several bases [276]-[279], Lewis acids [280] [281] or heterogeneous media [282]-[289] were used as catalysts in Knoevenagel condensation reaction for the synthesis of arylidenemalononitriles $\mathbf{9 7}$. In addition, a simple and more efficient procedure was developed for the condensation of malononitrile with aromatic, heteroaromatic and aliphatic aldehydes in water [290] (Scheme 48).

\section{Reactivity of Arylidenemalononitrile Derivatives}

The arylidenemalononitriles $\mathbf{9 7}$ are useful intermediates for the synthesis of a variety of heterocyclic compounds, 2-aminobenzo[h]chromene-3-carbonitrile derivatives $\mathbf{9 8}$ were synthesized via condensation of $\mathbf{9 7}$ with $\alpha$-naphthol in the presence of $\mathrm{Mg} / \mathrm{Al}$ hydrotalcite under single-mode microwave irradiation [291] (Scheme 49). On the other hand, 3-aminobenzo[f]chromene-2-carbonitrile derivatives 99 were obtained through condensation of $\mathbf{9 7}$ with $\beta$-naphthol [292] (Scheme 49). Pyrano[3,2-c]chromenes 100 were prepared by heating 4-hydroxycoumarin with 97 in pyridine [293], in ethanol and in the presence of triethylamine as a catalyst [294] or in water [295] (Scheme 49). Acid hydrolysis of pyrano[3,2-c]chromenes 100 produced compound 101, which is subsequently transformed into warfarin 102 (Ar = phenyl) [293] [296]-[298] (Scheme 50). Several pyrano[3,2-c]quinolines 103 were prepared via reaction of 4-hydroxyquinolin-2(1H)-ones with arylidenemalononitriles 97 [299] [300] (Scheme 49). Three component reaction between arylidenemalononitriles 97, 1,3-indanedione and thioglycolic acid under microwave irradiation afforded indeno[1,2-b]pyridine derivatives 104 [301] (Scheme 49). The analogous three-component reaction of $\mathbf{9 7}$ with 1,3-indanedione and 4-methylbenzenethiol, or aromatic amine under microwave irradiation afforded indeno[1,2-b]pyridines 105 [301] (Scheme 49). A series of dihydropyrrolo[1,2-f]phenanthridines 106 was prepared via reaction between 97, isocyanides and phenanthridine in dry diethyl ether [302] 
(Scheme 49). Condensation of $\mathbf{9 7}$ with 5-methylresorcinol monohydrate in ethanol afforded the chromene derivatives 107 [303] (Scheme 49). Hexahydroquinolin-5-ones 108 were synthesized through reaction of 3-aminocyclohex-2-en-1-ones with 97 [304] (Scheme 49). The thiazolopyridine derivatives 109 were obtained using 2:1 molar ratio of 97 and 2-(4,5-dihydro-4-oxothiazol-2-yl)acetonitrile or ethyl 2-(4,5-dihydro-4-oxothiazol-2yl)acetate [305] [306] (Scheme 49). Reaction of 2-isoxazolin-5-ones with 97 was reported to yield pyrazolo[2,3-c]isoxazole derivatives 110 [307] (Scheme 49). Condensation of $\mathbf{9 7}$ with 3-methylpyrazol-5-ones gave the pyranopyrazole derivatives 111 [292] (Scheme 49). Whereas, pyrano[2,3- $d$ ]thiazole derivatives 112 were prepared through reaction of $\mathbf{9 7}$ with $\alpha$-(4-oxothiazolin-2-yl)- $\alpha$-phenylhydrazonoacetamide [308] (Scheme 49). Condensation of 97 with barbituric or thiobarbituric acid afforded the corresponding pyrano[2,3- $d$ ]pyrimidine derivatives 113 [308] (Scheme 49). In addition, the pyrido[1,2-a]quinazoline derivatives 114 were synthesized via condensation of $\mathbf{9 7}$ with 2-(2-cyanoacetamido)benzoic acid [309] (Scheme 49). It was found that 3-phenyl2-thiohydantoin reacts with $\mathbf{9 7}$ to give the corresponding pyrrolo[1,2-c]imidazole derivatives 115 [310] (Scheme 49). Reaction of 3-oxo-3-phenyl- $N$-(pyridin-3-yl)propanamide with $\mathbf{9 7}$ in ethanol gave tetrahydropyridines 116 [311] (Scheme 49). In addition, 6-acetyl-3-amino-2,5-diphenyl-2,3,4,5-tetrahydropyridazine-4-carbonitrile derivatives 117 were obtained through reaction of $\mathbf{9 7}$ with 1-(phenylhydrazono)propan-2-one in pyridine [312]

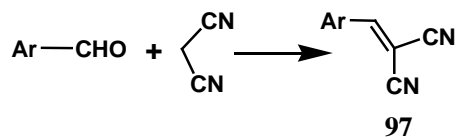

Scheme 48. Preparation of compounds 97.
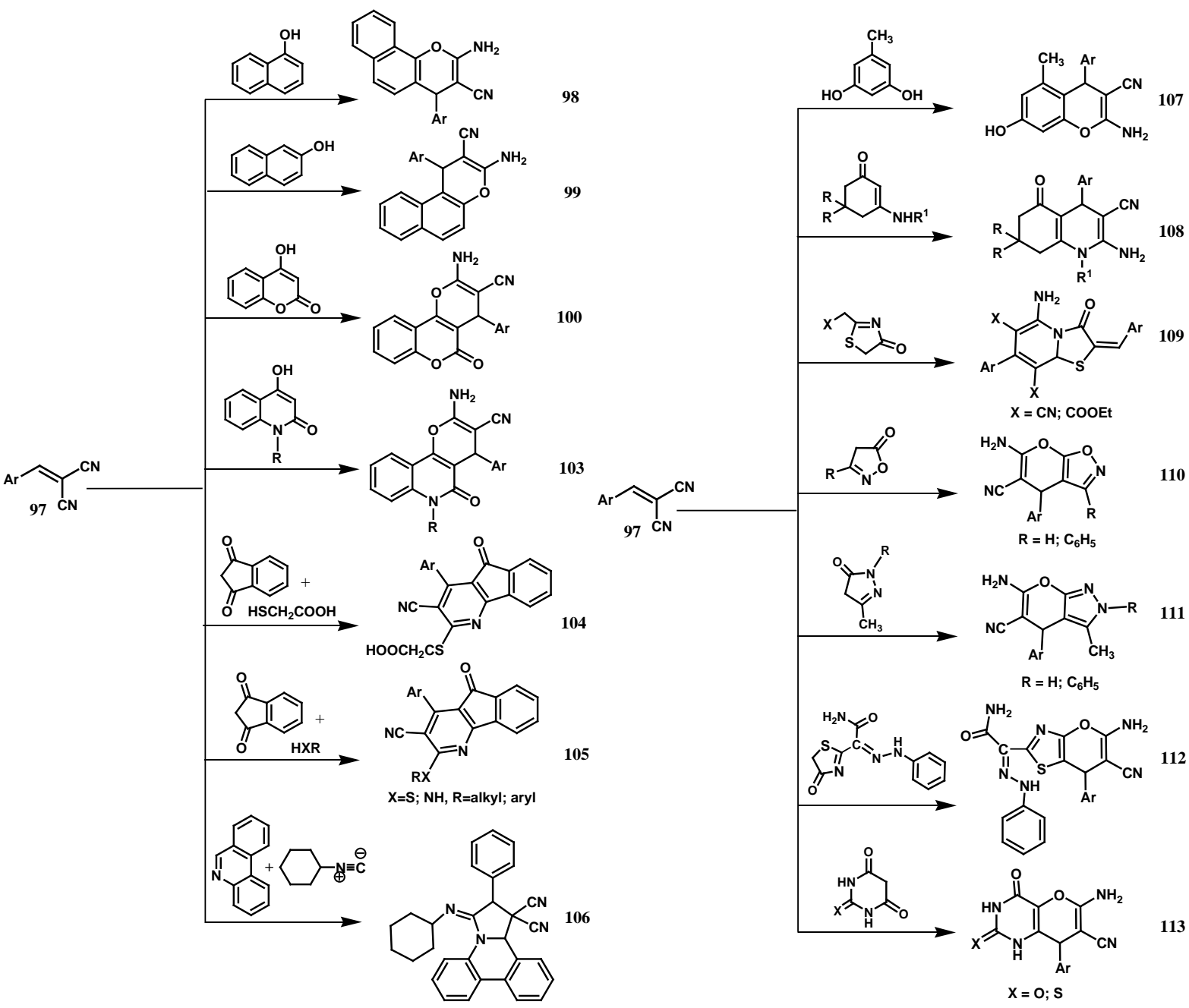


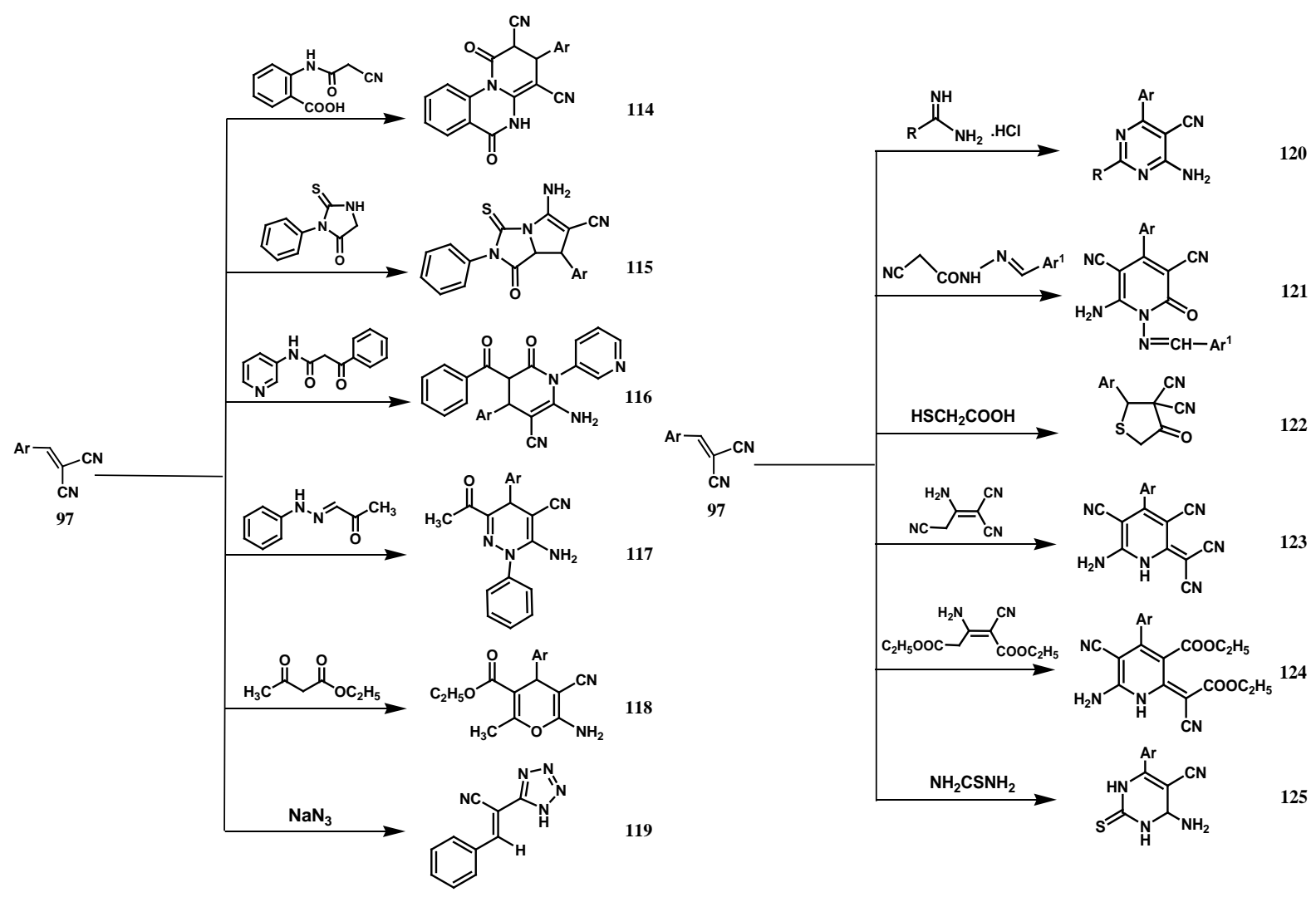

Scheme 49. Preparation of compounds 98-100 and 103-125.

(Scheme 49). Reaction of 97, ethyl acetoacetate and aqueous solution of ammonium hydroxide afforded $4 \mathrm{H}$ pyran derivatives 118 [313] (Scheme 49). Tetrazoles 119 have been prepared through reaction of 97 with sodium azide in water [314] (Scheme 49). Micheal additions of arylidenemalononitriles 97 with amidines in refluxing acetonitrile and in the presence of a catalytic amount of magnesium oxide produced the pyrimidine derivatives 120 [289] (Scheme 49). Reaction of 97 with hydrazide-hydrazone derivatives in dioxane and in the presence of triethylamine as a catalyst gave 6-amino-2-oxopyridine-3,5-dicarbonitriles 121 [315] (Scheme 49). The synthesis of thiophene derivatives 122 was accomplished through the condensation of $\mathbf{9 7}$ with thioglycolic acid [316] [317] (Scheme 49). 2-Amino-1,1,3-tricyanoprop-2-ene reacts with $\mathbf{9 7}$ to yield the pyridine derivatives 123 [318] [319] (Scheme 49). Similary, diethyl 3-amino-2-cyanopent-2-ene-1,5-dicarboxylate was reacted with 97 to yield the pyridine derivatives 124 [319] [320] (Scheme 49). Treatment of 97 with thiourea in DMF and in the presence of a catalytic amount of piperidine resulted in the formation of the thioxopyrimidine derivatives 125 [321] (Scheme 49).

Reaction of arylidenemalononitriles 97 with 2-cyanothioacetamide in ethanol and in the presence of piperidine as a basic catalyst afforded 1,6-dihydro-6-thioxopyridine-2,3,5-tricarbonitriles 126. Reaction of thioxopyridines 126 with (2-acetoxyethoxy)methyl bromide in DMF and in the presence of sodium hydride afforded 6-[(2-acetoxyethoxy)methylthio]pyridine-2,3,5-tricarbonitriles $\mathbf{1 2 7}$ that is further reacted with ammonia in methanol to produce 6-[(2-hydroxyethoxy)methylthio]pyridine-2,3,5-tricarbonitriles $\mathbf{1 2 8}$. Reaction of $\mathbf{1 2 6}$ with ethoxymethyl chloride in DMF and in the presence of sodium hydride gave 6-(ethoxymethylthio)pyridine-2,3,5tricarbonitriles 129 [322] (Scheme 51).

It was reported that thermal Michael addition reaction takes place when 6,7-dimethoxyisochromanone 130 was treated with arylidenemalononitriles $\mathbf{9 7}$ at $190^{\circ} \mathrm{C}$ to afford $\mathbf{1 3 1}$ which underwent elimination of malononitrile producing 132 [323] (Scheme 52).

\subsection{Synthesis of Diethyl Arylidenemalonate Derivatives}

Diethyl arylidenemalonates $\mathbf{1 3 3}$ are easily accessible by Knoevenagel condensation [324] [325] (Scheme 53). 
<smiles>CC(C)[C@H]1C(C#N)=C(N)Oc2c1c(=O)oc1ccccc21</smiles>

100<smiles>O=C(O)CC(Br)c1c(O)c2ccccc2oc1=O</smiles>

101<smiles>CC(=O)CC(Br)c1c(OCC#N)c2ccccc2oc1=O</smiles>

102

\section{Scheme 50. Preparation of compounds 101 and 102.}

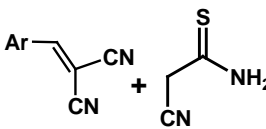

97<smiles>N#Cc1[nH]c(=S)c(C#N)c(C#N)c1C#N</smiles>

126<smiles>COCOCCOCCO</smiles><smiles>CCOCSc1nc(C#N)c(C#N)c(Br)c1C#N</smiles>

129<smiles>CC(=O)OCCOC(CBr)C(=O)O[Na]</smiles><smiles>CC(=O)COCSc1nc(SCOC(C)=O)c(Br)c(C#N)c1C#N</smiles>

127<smiles>CN(C)O</smiles><smiles>N#Cc1nc(SCOCCO)c(C#N)c(Br)c1C#N</smiles>

128

Scheme 51. Preparation of compounds 126-129.

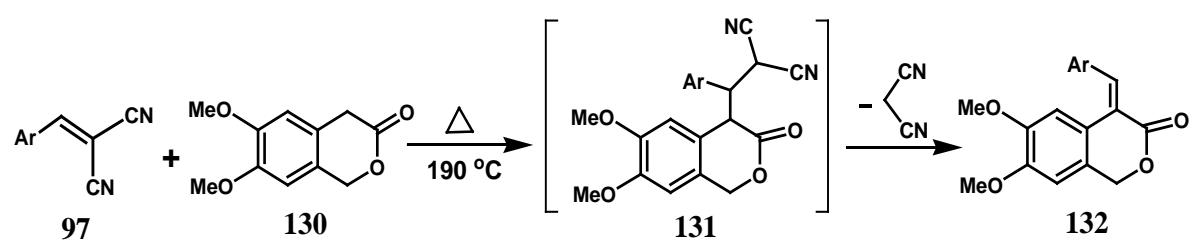

Scheme 52. Preparation of compounds 132.

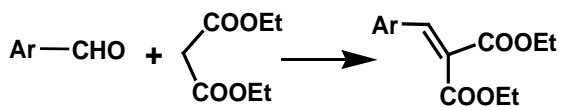

133

\section{Scheme 53. Preparation of compounds 133.}

Various reaction conditions were reported for the preparation of diethyl arylidenemalonates $\mathbf{1 3 3}$. The reaction was performed in water or ethanol without catalyst [326], in refluxing dry xylene and in the presence of a catalytic amount of piperidine/glacial acetic acid (3:1) [327], in refluxing ethanol and in the presence of a catalytic amount of piperidine/glacial acetic acid (2:1) [328] or in refluxing pyridine [329]. In addition, Knoevenagel condensations of benzaldehyde or substituted benzaldehydes with diethyl malonate was carried out in Lewis acidic 1-butyl-3-methylimidazolium chloroaluminate, $[\mathrm{bmim}] \mathrm{Cl} \cdot \mathrm{xAlCl}_{3}$ and 1-butylpyridinium chloroaluminate, 
[bpy]Cl·xAlCl 3 ionic liquids [330].

Reactivity of Diethyl Arylidenemalonate Derivatives

Reaction of diethyl arylidenemalonates 133 with indole 134 in isobutanol at room temperature, employing $\mathrm{Cu}(\mathrm{OTf})_{2}$-bis(oxazoline) complexes under nitrogen afforded ethyl 3-aryl-2-ethoxycarbonyl-3-(3-indolyl) propanoates 135 [331] (Scheme 54). Reaction of diethyl 4-methoxybenzylidenemalonate 136 with but-2-yne1,4-diol $\mathbf{1 3 7}$ in the presence of sodium hydride $(\mathrm{NaH})$ in THF at room temperature for five minutes afforded ethyl 3-(4-methoxyphenyl)-4-oxo-3,3a,4,6-tetrahydro-1H-furo[3,4-c]pyran-3a-carboxylate 138 [332]-[335] (Scheme 55).

\subsection{Synthesis of Ethyl Arylidenecyanoacetate Derivatives}

Ethyl arylidenecyanoacetates $\mathbf{1 3 9}$ are prepared via Knoevenagel condensation of aldehydes with ethyl cyanoacetate (Scheme 56). Several publications were reported for the synthesis of ethyl arylidenecyanoacetates. The reaction was carried out in aqueous medium at room temperature [336], in refluxing ethanol and in the presence of piperidine/glacial acetic acid (2:1) [328], in refluxing ethanol and in the presence of Trizma [337]. Also, this condensation was performed in ethanol/water mixture and in the presence of sodium or potassium hydroxide at $50^{\circ} \mathrm{C}-60^{\circ} \mathrm{C}$ [279]. The same reaction was carried out using magnesium bromide diethyl etherate $\left(\mathrm{MgBr}_{2} \cdot \mathrm{OEt}_{2}\right)$ as Lewis acid in the presence of triethylamine [338]. In addition, poly(4-methyl vinylpyridinium hydroxide)/ SBA-15, a novel basic polymeric composite was applied as a recyclable catalyst for the Knoevenagel condensation reaction of aromatic aldehydes with ethyl cyanoacetate in water at $95^{\circ} \mathrm{C}$ [339]. Furthermore, they were prepared via heating a mixture of aldehyde and ethyl cyanoacetate at $80^{\circ} \mathrm{C}-85^{\circ} \mathrm{C}$ in an oil bath and in the presence of rare earth triflates as $\mathrm{Yb}(\mathrm{OTf})_{3}$ [340]. The same reaction was performed in distilled water and in the presence of hydroxyapatite supported caesium carbonate as a recyclable solid base catalyst $\left(\mathrm{HAP}-\mathrm{Cs}_{2} \mathrm{CO}_{3}\right)$ [278] or under microwave irradiation [341].

\section{Reactivity of Ethyl Arylidenecyanoacetate Derivatives}

The thiazolopyridine derivatives 109 were also obtained using 2:1 molar ratio of ethyl arylidenecyanoacetates 139 and 2-(4,5-dihydro-4-oxothiazol-2-yl)acetonitrile or ethyl 2-(4,5-dihydro-4-oxothiazol-2-yl)acetate [305] [306] (Scheme 57). Reaction of ethyl arylidenecyanoacetates 139 with hydrazide-hydrazone derivatives in dioxane and in the presence of a catalytic amount of triethylamine produced ethyl 2-amino-5-cyano-6-oxopyridine3-carboxylates 140 [298] (Scheme 57). The synthesis of thiophene derivatives 141 was accomplished through the condensation of $\mathbf{1 3 9}$ with thioglycolic acid [316] [317] (Scheme 57). Reaction of $\mathbf{1 3 9}$ with 2-cyanoacetic

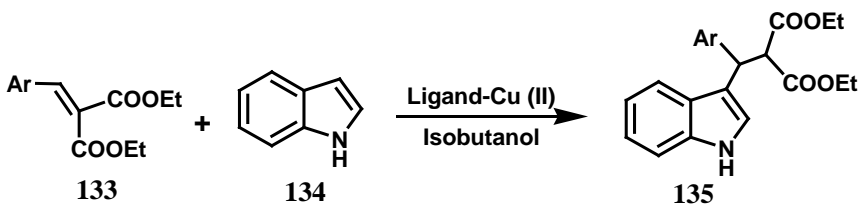

133

134

135

Scheme 54. Preparation of compounds 135.

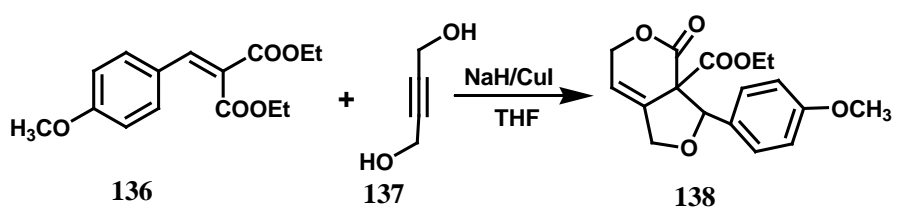

Scheme 55. Preparation of compounds 138.

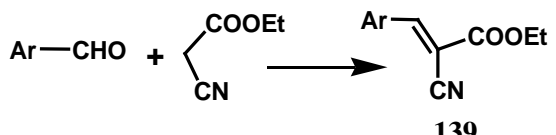

Scheme 56. Preparation of compounds 139. 


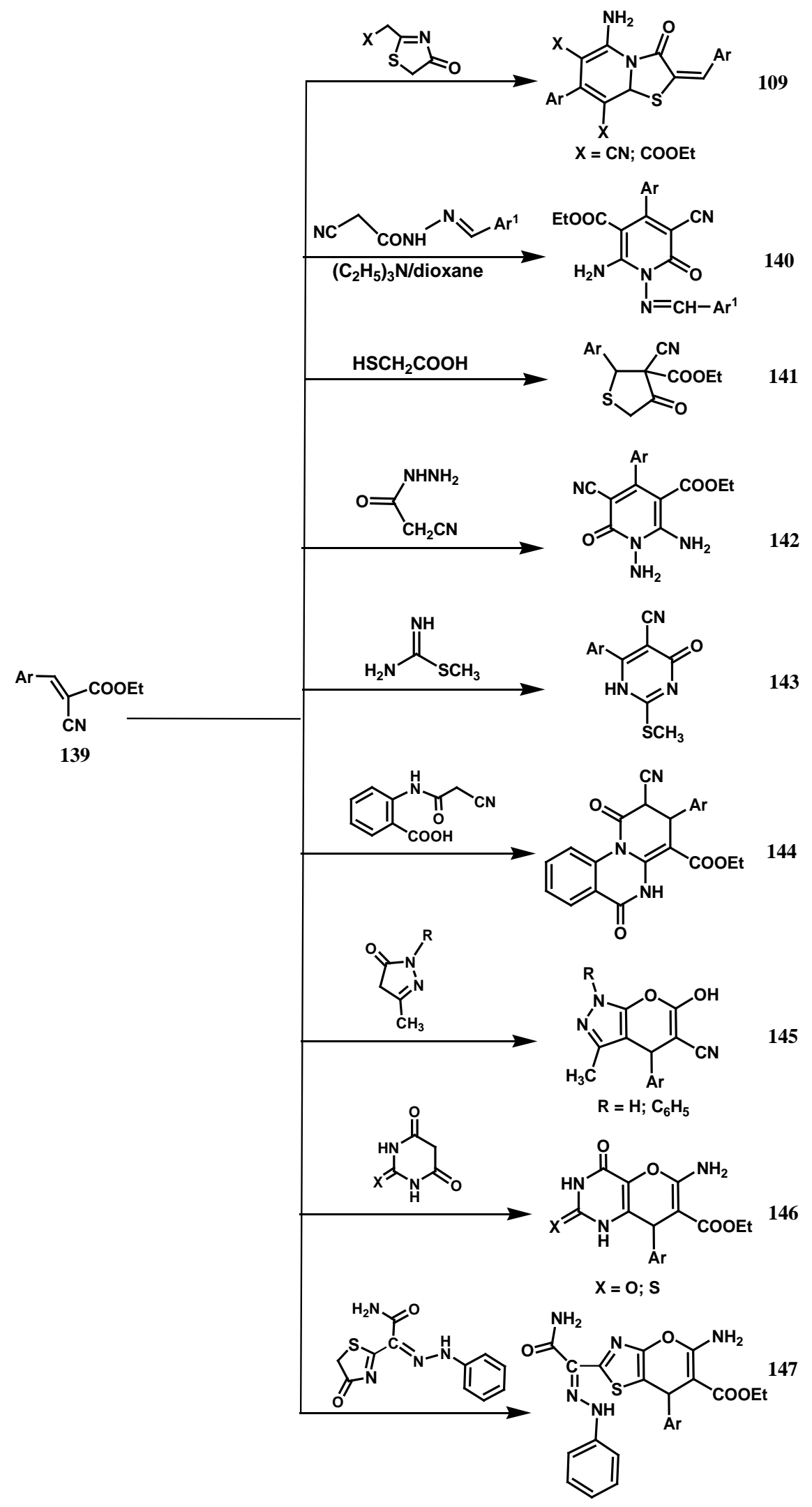

Scheme 57. Preparation of compounds 109 and 140-147. 
acid hydrazide gave the pyridine derivatives 142 [342] (Scheme 57). The reaction of 139 with S-methylthiourea in pyridine produced the pyrimidine derivatives 143 [343]. In addition, the pyrido[1,2-a]quinazoline derivatives 144 were synthesized via condensation of 139 with 2-(2-cyanoacetamido)benzoic acid [309] (Scheme 57). Moreover, the pyrano[2,3-c]pyrazole derivatives 145 were obtained through condensation of 139 with 3-methylpyrazolone derivatives [344] [345] (Scheme 57). Condensation of $\mathbf{1 3 9}$ with barbituric or thiobarbituric acids afforded the corresponding pyrano[3,2-d]pyrimidine derivatives 146 [308] (Scheme 57). Whereas, pyrano[2,3-d] thiazole derivatives 147 were prepared through reaction of 139 with $\alpha$-(4-oxothiazolin-2-yl)- $\alpha$-phenylhydrazonoacetamide [308] (Scheme 57).

Reaction of $\mathbf{1 3 9}$ with 2-cyanothioacetamide in ethanol and in the presence of a catalytic amount of piperidine afforded ethyl 3,5-dicyano-1,6-dihydro-6-thioxopyridine-2-carboxylates 148. Reaction of 6-thioxopyridines 148 with (2-acetoxyethoxy)methyl bromide in DMF and in the presence of sodium hydride afforded ethyl 3,5-dicyano-6-[(2-acetoxyethoxy)methylthio]pyridine-2-carboxylates 149 that is further reacted with ammonia in methanol to produce ethyl 3,5-dicyano-6-[(2-hydroxyethoxy)methylthio]pyridine-2-carboxylates 150. Reaction of 148 with ethoxymethyl chloride in DMF and in the presence of sodium hydride gave ethyl 3,5-dicyano-6(ethoxymethylthio)pyridine-2-carboxylates 151 [322] (Scheme 58).

\subsection{Synthesis of Arylidenecyanoacetamide Derivatives}

Arylidenecyanoacetamides 152 are prepared via Knoevenagel condensation of aldehydes with cyanoacetamide derivatives (Scheme 59). The reaction was carried out under solvent-free conditions [346], in water and in the presence of triethylbenzylammonium chloride (TEBA) [347], in aqueous medium at room temperature [326], or via grinding of aldehydes with cyanoacetamide derivatives at room temperature and in the presence of a catalytic amount of 1,8-diazabicyclo[5.4.0]undec-7-ene (DBU) [348].

\section{Reactivity of Arylidenecyanoacetamides}

The benzylidenecyanoacetamide derivative $\mathbf{1 5 3}$ has been extensively utilized in heterocyclic synthesis. Reaction of $\mathbf{1 5 3}$ with hydrazine hydrate or phenylhydrazine in refluxing ethanol and in the presence of a catalytic amount of piperidine produced the pyrazole derivatives 154 (Scheme 60) [349]. The 2-oxopyrimidine derivative 155 was prepared through condensation of $\mathbf{1 5 3}$ with urea in refluxing ethanol and in the presence of a catalytic amount of piperidine (Scheme 60) [349]. In addition, the 2-thioxopyrimidine derivative 156 was obtained through

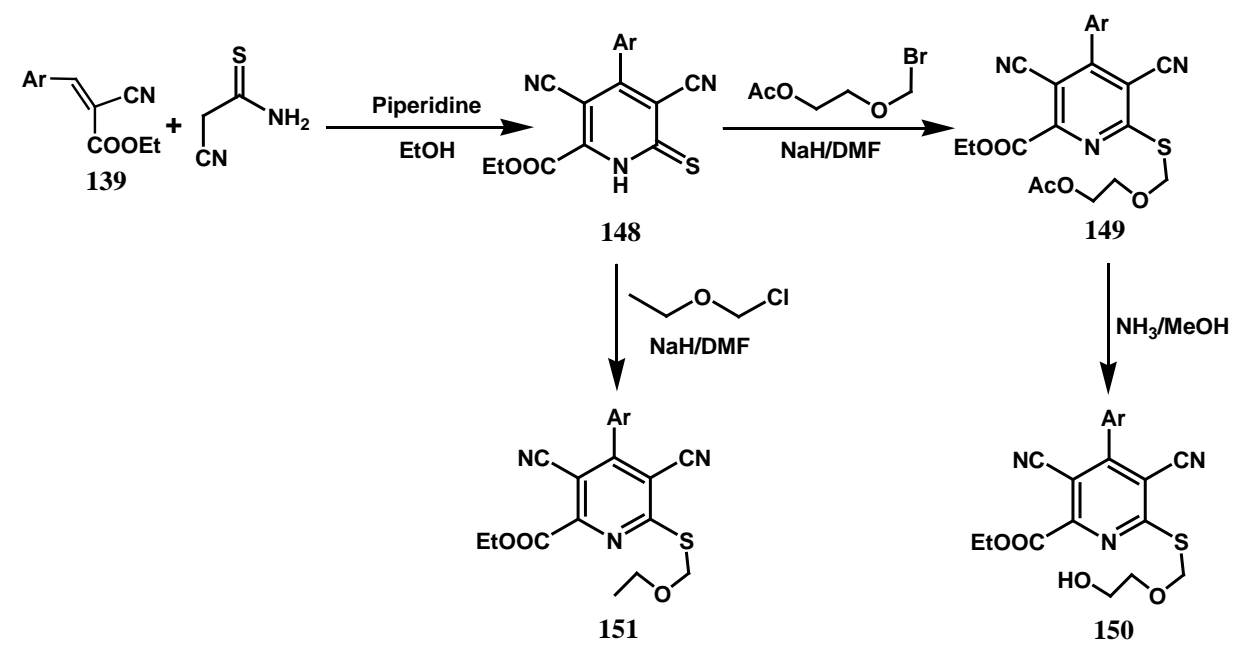

Scheme 58. Preparation of compounds 148-151.

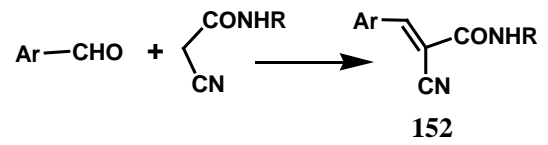

Scheme 59. Preparation of compounds 152. 


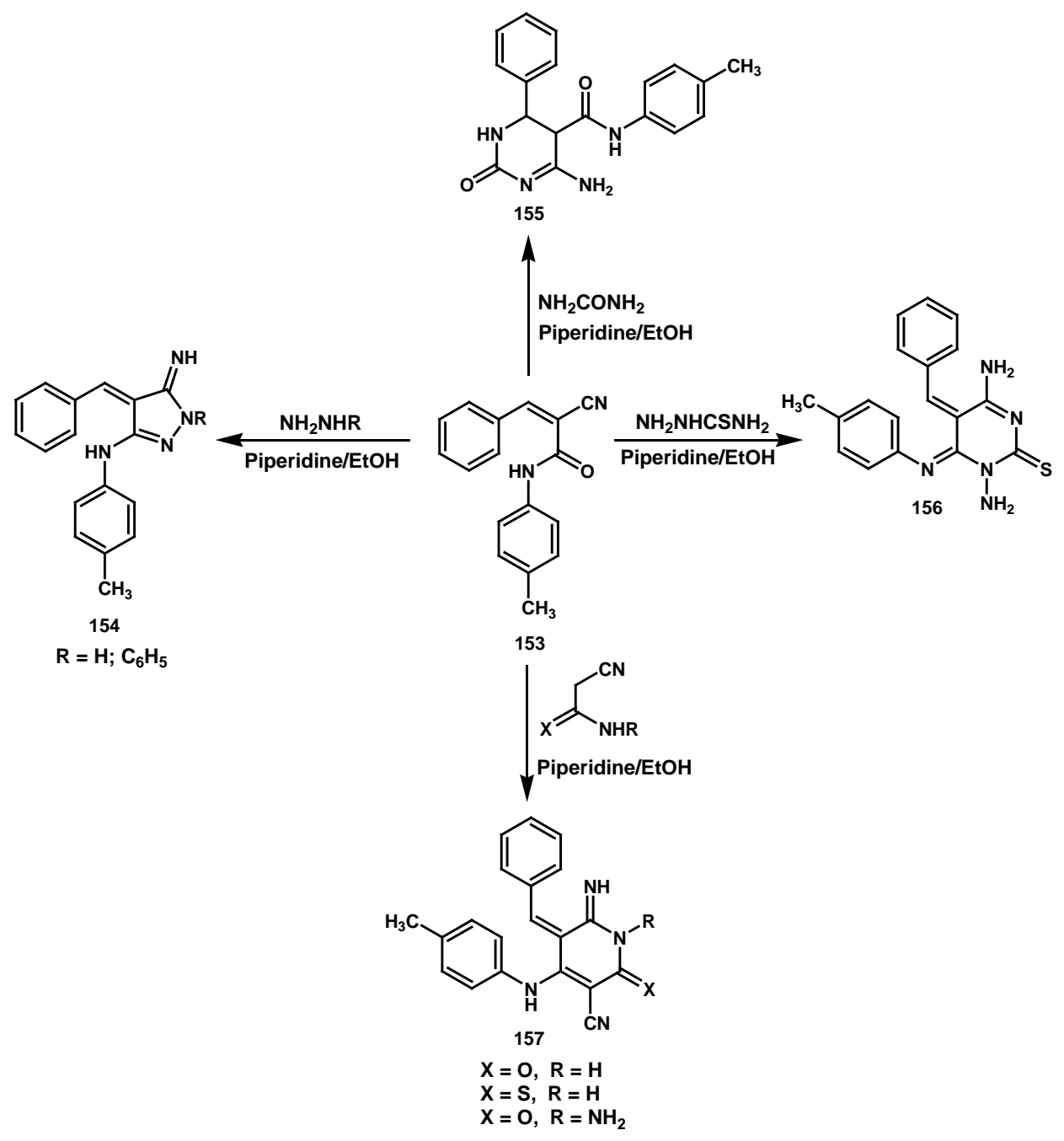

Scheme 60. Preparation of compounds 154-157.

condensation of $\mathbf{1 5 3}$ with thiosemicarbazide in refluxing ethanol and in the presence of a catalytic amount of piperidine (Scheme 60) [349]. Moreover, reaction of 153 with cyanoacetamide, cyanothioacetamide or cyanoacetic acid hydrazide afforded the cyanopyridine derivatives 157 (Scheme 60) [349].

\subsection{Synthesis of 5-Arylidene Derivatives of Barbituric and Thiobarbituric Acids}

Barbituric and thiobarbituric acids have attracted the attention of medicinal chemists for over hundred years due to their therapeutic values [350] [351]. 5-Arylidenebarbiturate/thiobarbiturate derivatives are important members of the pyrimidine family. The major importance of these compounds has been centered on their application as useful precursors in the preparation of new heterocyclic compounds [293] and as selective oxidizing agents [352]-[354]. Barbituric acid and its derivatives exhibited different biological activities such as antibacterial, hypotensive and tranquilizing activities [355]. The clinical use of barbiturates in neurological disorders has also been investigated [356]. 5-Arylidenebarbiturates/thiobarbiturates 158 (Scheme 61) have been synthesized by Knoevenagel reaction of barbituric acid with different aldehydes under various conditions. The reaction was carried out under aqueous reflux using acetic acid as a catalyst [357]. Villemin and Labiad [358] synthesized 5-arylidenebarbiturates under microwave irradiation and in the presence of montmorillonite KSF clay. Dewan and Singh [359] reported various catalysts like $\mathrm{NH}_{4} \mathrm{OAc} / \mathrm{AcOH}$, montmorillonite K-10, silica gel, basic alumina, $\mathrm{NaCl}$, montmorillonite $\mathrm{KSF}$, and $\mathrm{KSF} / \mathrm{NaCl}$ for the synthesis of 5-arylidenebarbiturates/thiobarbiturates $\mathbf{1 5 8}$. A grinding method has also been employed for the synthesis of $\mathbf{1 5 8}$ [360]. The same reaction was promoted by 
infrared irradiation in absence of solvent [361]. Also, it was carried out on basic alumina in a conventional microwave oven in the absence of solvent [362]. In addition, the same reaction has been achieved by employing bismuth chloride under solvent-free conditions [363]. Reddy et al. [364] reported the same reaction under microwave irradiation in absence of solvent and catalyst. In addition, Khan et al. [365] reported an improved, rapid and convenient method under eco-benign conditions i.e., using water as a solvent and bismuth chloride as a catalyst at room temperature. Recently, 5-arylidenebarbiturate/thiobarbiturate derivatives 158 were obtained in excellent yields and high purity through condensation of barbituric or thiobarbituric acid with aromatic aldehydes in distilled water at room temperature and in the presence of a catalytic amount of ethanolamine [366] or L-tyrosine [367].

\section{Reactivity of Arylidenebarbiturates and Thiobarbiturates}

Reaction of 158 with malononitrile in ethanol and in the presence of a catalytic amount of piperidine afforded 7-amino-5-aryl-2-oxo(thioxo)-4-oxo-2,3,4,5-tetrahydro-1H-pyrano[2,3- $d$ ]pyrimidine-6-carbonitriles 159 [366] (Scheme 62). Cycloaddition reactions of 5-arylidenebarbiturate derivatives 158 with a tenfold excess of ethyl vinyl ether in methylene chloride at room temperature afforded $2 H$-pyrano[2,3- $d$ ]pyrimidine-2,4-(3H)-diones 160 [368] (Scheme 63).

\subsection{Synthesis of Arylidene Derivatives of Meldrum's Acid}

2,2-Dimethyl-1,3-dioxane-4,6-dione (Meldrum's acid) undergoes standard Knoevenagel condensation with aromatic and heteroaromatic aldehydes furnishing the corresponding arylidene derivatives 161 (Scheme 64), which are versatile substrates for different kinds of reactions [369]. In addition, they are useful intermediates for cycloaddition reaction and for the synthesis of heterocyclic compounds with potential pharmacological activity [370]. The Knoevenagel condensation of aldehydes with Meldrum's acid is generally catalyzed by bases, such as pyridine [371] or by piperidine/glacial acetic acid in benzene [372]. Uncatalyzed reaction was reported in literature using DMF or DMSO as solvent [373]. In addition, anhydrous zinc chloride was reported to promote the reaction in absence of any solvent [374]. The same reaction was also carried out in water [375]. In addition, the Knoevenagel condensation of aromatic aldehydes with Meldrum's acid proceeded efficiently in the recyclable

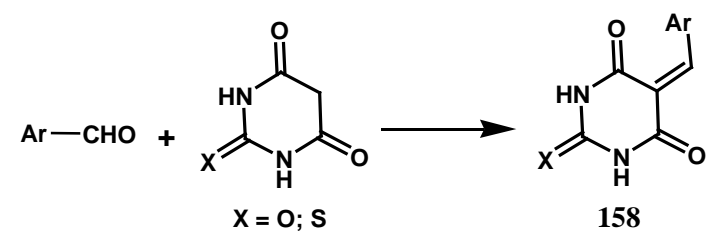

Scheme 61. Preparation of compounds 158.

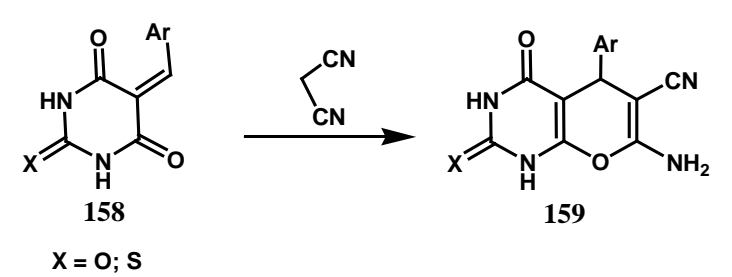

Scheme 62. Preparation of compounds 159.

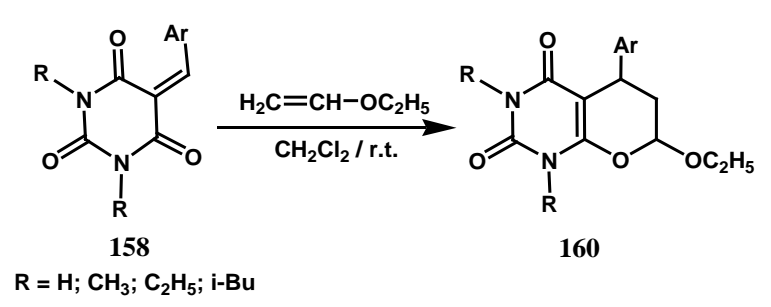

Scheme 63. Preparation of compounds $\mathbf{1 6 0 .}$ 
ionic liquid [bmim] $\mathrm{BF}_{4}$ at room temperature and in the presence of a catalytic amount of piperidine [376]. Also, the same condensation was carried out in methanol at room temperature [377].

\section{Reactivity of Arylidene Derivatives of Meldrum's Acid}

The epoxide analogues of arylidene Meldrum's acid $\mathbf{1 6 2}$ were prepared through reaction of $\mathbf{1 6 1}$ with hydrogen peroxide in acetonitrile at room temperature [378] [379] (Scheme 65).

Rhodium-catalyzed additions of arylboron reagents to $\mathbf{1 6 1}$ in dioxane at room temperature gave compounds 163 [380] (Scheme 66). The condensation of 161 with 3-amino-1,2,4-triazole in nitrobenzene afforded 4,5,6,7tetrahydro-1,2,4-triazolo[1,5-a]pyrimidin-5-ones 164. In DMF, the reaction proceeds with the formation of arylsubstituted $N$-(2H-1,2,4-triazol-3-yl)-3-(2H-1,2,4-triazol-3-ylamino)propionamides 165, in addition, the amide 166 and the aldehydes were present in the reaction mixture [381] (Scheme 67).

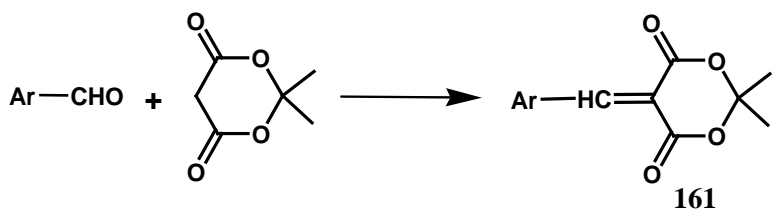

Scheme 64. Preparation of compounds $\mathbf{1 6 1 .}$

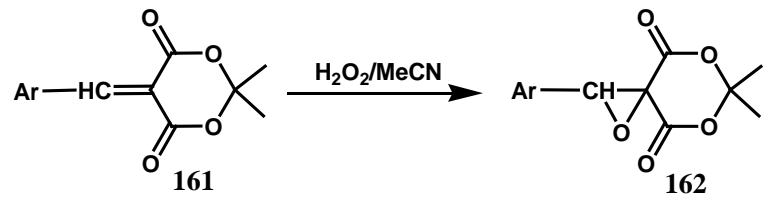

Scheme 65. Preparation of compounds $\mathbf{1 6 2 .}$

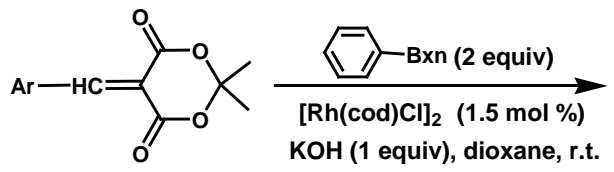

161

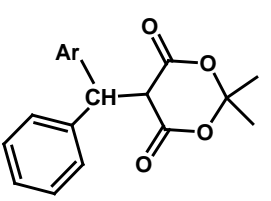

163

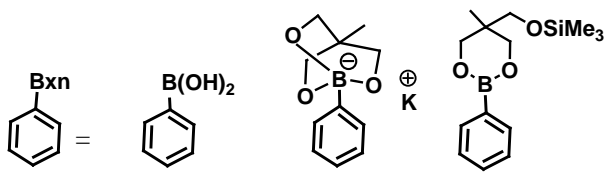

Scheme 66. Preparation of compounds $\mathbf{1 6 3 .}$

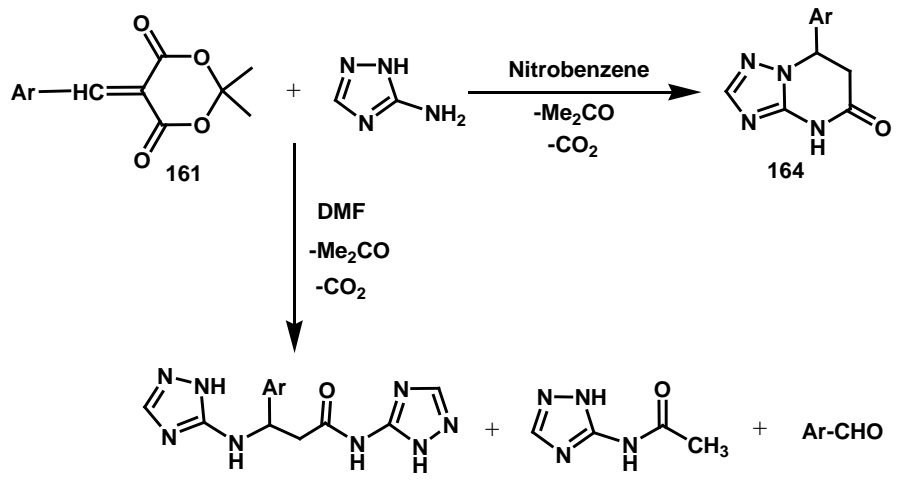

165

166

Scheme 67. Preparation of compounds 164 and 165. 


\subsection{Synthesis of 2-Arylidene Dimedone and Bisdimedone Derivatives}

5,5-Dimethylcyclohexane-1,3-dione (dimedone) was condensed with aromatic aldehydes in equimolar ratio and in presence of bases such as potassium hydroxide [382] [383] or piperidine [383] to give 2-arylidene-5,5-dimethylcyclohexane-1,3-dione derivatives 167 (Scheme 68). The same products were obtained through fusion of equimolar amounts of the aromatic aldehydes and dimedone in an oil bath at $150^{\circ} \mathrm{C}$ [384]. On the other hand, reaction of dimedone with aromatic aldehydes in 2:1 molar ratio afforded the bisdimedone derivatives $\mathbf{1 6 8}$ (Scheme 68), several reaction conditions were reported for this reaction. The reaction was performed in refluxing aqueous ethanol and in the presence of a catalytic amount of piperidine [385], under solvent-free conditions [346], in aqueous ethanol at room temperature and in the presence of a catalytic amount of piperidine [386], in water at $100^{\circ} \mathrm{C}$ and in the presence of a catalytic amount of iodine [387], $\mathrm{HClO}_{4}-\mathrm{SiO}_{2}$ or $\mathrm{PPA}-\mathrm{SiO}_{2}$ [388], in refluxing aqueous methanol [389], in aqueous media at room temperature [390] or in refluxing acetonitrile and in the presence of of zinc oxide as a catalyst [391], also it was carried out in dry methylene chloride and in the presence of silica chloride nano particle (nano $\mathrm{SiO}_{2}-\mathrm{Cl}$ ) [392] to afford the corresponding 2,2'-(arylmethylene)bis(3-hydroxy-5,5-dimethyl-2-cyclohexen-1-one) (bisdimedone derivatives) 168. The same reaction was performed using ytterbium triflate $\left[\mathrm{Yb}(\mathrm{OTf})_{3}-\mathrm{SiO}_{2}\right]$ and amine as a catalytic system under solvent-free conditions

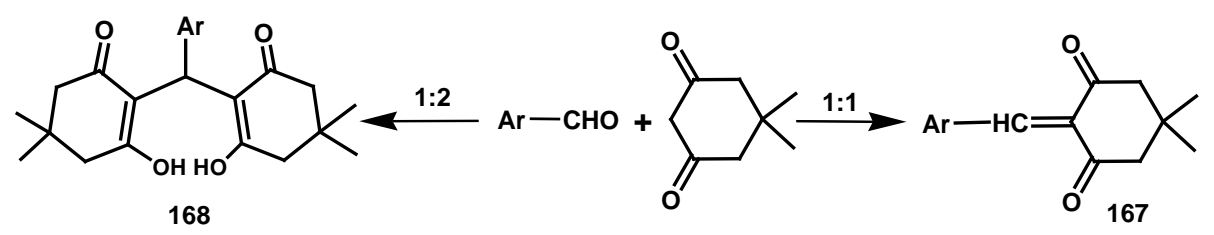

Scheme 68. Preparation of compounds 167 and 168.

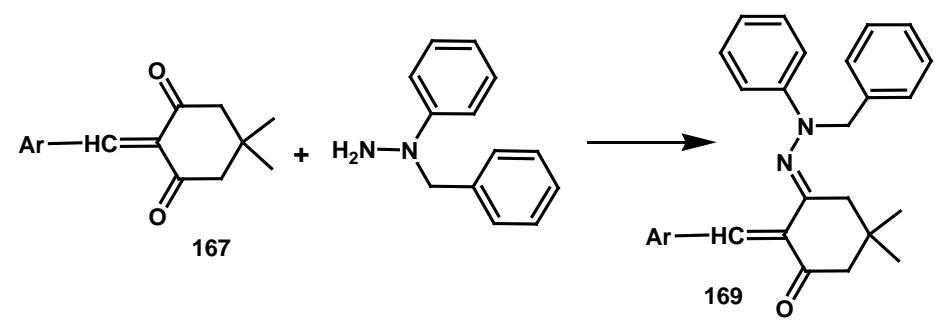

Scheme 69. Preparation of compounds 169.<smiles>CC1(C)CC(=O)C(C(Br)C2=C(O)CC(C)(C)CC2=O)=C(O)C1</smiles><smiles>[R]OC(=O)c1ccc(N)c(OCC)c1</smiles><smiles>CC1(C)CC(=O)C2=C(C1)NC1=C(C(=O)CC(C)(C)C1)C2Br</smiles>
168<smiles>CC1(C)CC(=O)C2=C(C1)N(NC(N)=S)C1=C(C(=O)CC(C)(C)C1)C2Br</smiles>

172

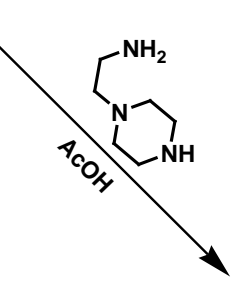

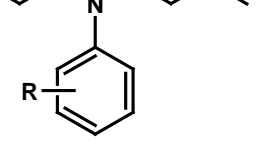

170<smiles>CC(=O)N1CCN(CCN2C3=C(C(=O)CC2(C)C)C(Br)C2=C(C3)CC(C)(C)CC2=O)CC1</smiles>

171

Scheme 70. Preparation of compounds 170-172. 
[393]. This method is advantageous as being eco-friendly, non-corrosive, and allows reutilization of the catalytic system. Recently, bisdimedone derivatives 168 were obtained through reaction of dimedone with aromatic aldehydes in 2:1 molar ratio in ethylene glycol and in presence of nickel nanoparticles [394].

\section{Reactivity of 2-Arylidene Dimedone and Bisdimedone Derivatives}

Reaction of arylidenedimedone derivatives 167 with $N$-benzyl- $N$-phenylhydrazine in $50 \%$ acetic acid produced compounds 169 [384] (Scheme 69).

When bisdimedone derivatives 168 were reacted with different amines in ethanol and in the presence of a catalytic amount of $\mathrm{P}_{2} \mathrm{O}_{5}, 10$-(substituted phenyl)-3,4,6,7,9,10-hexahydro-1,8(2H, 5H)-acridinedione derivatives 170 were obtained. The condensation of $N$-(2-aminoethyl)piperazine with bisdimedones 168 in acetic acid afforded the acridinediones $\mathbf{1 7 1}$ in which the $\mathrm{N}$-acetylation of the piperazine ring has also occurred. The reaction of bisdimedones 168 with thiosemicarbazide gave $N$-(3,3,6,6-tetramethyl-3,4,6,7,9,10-hexahydro-1,8-dioxo-( $2 \mathrm{H}$, 5H)-acridin-10-yl)thiourea derivatives 172 [395] (Scheme 70).

\section{Conclusion}

Literature data have been summarized to help chemists to find information appropriate for the high synthetic potential of different arylidene derivatives. Syntheses of many biologically active heterocyclic compounds belonging to these compounds have also been reported.

\section{References}

[1] Choudary, B.M., Lakshmi Kantam, M., Kavita, B., Venkat Reddy, Ch. and Figueras, F. (2000) Catalytic C-C Bond Formation Promoted by Mg-Al-O-t-Bu Hydrolacite. Tetrahedron, 56, 9357-9364. http://dx.doi.org/10.1016/S0040-4020(00)00906-6

[2] Prajapati, D., Lekhok, K.C., Sandhu, J.S. and Ghosh, A.C. (1996) Magnesium Perchlorate as Efficient Lewis Acid for the Knoevenagel Condensation between $\beta$-Diketones and Aldehydes. Journal of the Chemical Society, Perkin Transactions 1, 959-960. http://dx.doi.org/10.1039/p19960000959

[3] Khan, R.H., Mathur, R.K. and Ghosh, A.C. (1996) Tellurium (IV) Tetrachloride Catalyzed Facile Knoevenagel Reaction. Synthetic Communications, 26, 683-686. http://dx.doi.org/10.1080/00397919608086741

[4] Tanaka, K. (2003) Solvent-Free Organic Synthesis. Chapter 3.2, Wiley-VCH, Weinheim, 93-136. http://dx.doi.org/10.1002/3527601821

[5] Tanaka, K. and Toda, F. (2000) Solvent-Free Organic Synthesis. Chemical Reviews, 100, 1025-1074. http://dx.doi.org/10.1021/cr940089p

[6] Obrador, E., Castro, M., Tamariz, J., Zepeda, G., Miranda, R. and Delgado, F. (1998) Knoevenagel Condensation in Heterogeneous Phase Catalyzed by IR Radiation and Tonsil Actisil FF. Synthetic Communications, 28, 4649-4663. http://dx.doi.org/10.1080/00397919808004530

[7] Balalaie, S. and Nemati, N. (2001) One-Pot Preparation of Coumarins by Knoevenagel Condensation in Solvent-Free Condition under Microwave Irradiation. Heterocyclic Communications, 7, 67-72. http://dx.doi.org/10.1515/HC.2001.7.1.67

[8] Loupy, A., Song, S., Sohn, S., Lee, Y. and Known, T. (2001) Solvent-Free Bentonite-Catalyzed Condensation of Malonic Acid and Aromatic Aldehydes under Microwave Irradiation. Journal of the Chemical Society, Perkin Transactions 1, 1220-1222. http://dx.doi.org/10.1039/b009803p

[9] Maggi, R., Bigi, F., Carloni, S. and Mazzoc, A. (2001) Uncatalysed Reactions in Water: Part 2. Preparation of 3Carboxycoumarins. Green Chemistry, 3, 173-174. http://dx.doi.org/10.1039/b101822c

[10] Bigi, F., Conforti, M.L., Maggi, R., Piccinno, A. and Sartori, G. (2000) Clean Synthesis in Water: Uncatalysed Preparation of Ylidenemalononitriles. Green Chemistry, 2, 101-103. http://dx.doi.org/10.1039/b001246g

[11] Bigi, F., Carloni, S., Ferrari, L., Maggi, R., Mazzacani, A. and Sartori, G. (2001) Clean Synthesis in Water. Part 2: Uncatalysed Reactions of Meldrum's Acid and Aldehydes. Tetrahedron Letters, 42, 5203-5205. http://dx.doi.org/10.1016/S0040-4039(01)00978-9

[12] Rupe, H. and Wasserzug, D.J. (1901) Chemische Berichte, 34, 3527-3531. http://dx.doi.org/10.1002/cber.19010340342

[13] Hermes, S.A. (1969) Chemische Berichte, 70, Article ID: 96422h.

[14] Breslow, D.S. and Houser, C.R. (1940) Chemische Berichte, 62, 2385.

[15] Kazauki, K., Hitayama, K., Yokomor, S. and Soki, T. (1976) Chemical Abstracts, 85, 591. 
[16] Obara, H., Onodera, J. and Kurihara, Y. (1971) The Synthesis of 2',3',4,4',6'-Pentahydroxychalcone. Bulletin of the Chemical Society of Japan, 44, 289. http://dx.doi.org/10.1246/bcsj.44.289

[17] Gaissman, T.A. and Clinton, R.O. (1946) Flavanones and Related Compounds. I. The Preparation of Polyhydroxychalcones and Flavanones. Journal of the American Chemical Society, 68, 697-700. http://dx.doi.org/10.1021/ja01208a051

[18] Martin, G.J., Beler, J.M. and Avakian, S. (1956) Therapeutic Substituted Chalcones. US Patent No. 2769817.

[19] El.Hashah, M.A., El-Kady, M., Saiyed, M.A. and Elaswy, A.A. (1985) Egyptian Journal of Chemistry, 27, 715.

[20] Crawley, L.S. and Fanshawe, W.J. (1977) Neighboring Group Participation in Cyclodehydration. A Regiospecific Isoxazole Synthesis. Journal of Heterocyclic Chemistry, 14, 531-534. http://dx.doi.org/10.1002/jhet.5570140339

[21] Patil, C.B., Mahajan, S.K. and Katti, S.A. (2009) Chalcone: A Versatile Molecule. Journal of Pharmaceutical Sciences and Research, 1, 11-22.

[22] Taylor, E.C. and Morrison, R.W. (1967) An Unusual Molecular Rearrangement of an N-Aminopyrimidine. The Journal of Organic Chemistry, 32, 2379-2382. http://dx.doi.org/10.1021/jo01283a004

[23] Utale, P.S., Raghuvanshi, P.B. and Doshi, A.G. (1998) Synthesis of Some New 1-Carbamoyl-3-(substituted 2-hydroxyphenyl)-5-aryl-2-pyrazolines. Asian Journal of Chemistry, 10, 597-599.

[24] Doan, T.N. and Tran, D.T. (2011) Synthesis, Antioxidant and Antimicrobial Activities of a Novel Series of Chalcones, Pyrazolic Chalcones, and Allylic Chalcones. Pharmacology \& Pharmacy, 2, 282-288. http://dx.doi.org/10.4236/pp.2011.24036

[25] Jyoth, M.V., Prasad, Y.R., Venkatesh, P. and Sureshreddy, M. (2012) Synthesis and Antimicrobial Activity of Some Novel Chalcones of 3-Acetyl Pyridine and Their Pyrimidine Derivatives. Chemical Science Transactions, 1, 716-722. http://dx.doi.org/10.7598/cst2012.223

[26] Lyle, R.E. and Paradis, L.P. (1955) Acid-Catalyzed Condensations. II.1 The Condensation of Benzaldehyde with Substituted Acetophenones. Journal of the American Chemical Society, 77, 6667-6668. http://dx.doi.org/10.1021/ja01629a094

[27] Marathey, M.G. (1952) Journal of the University of Poona, 1.

[28] Younis, F.M. (2011) Preparation of Number of Chalcone Compounds from 6-Formyl-5-methoxy-1,3-benzoxathiol. College of Basic Education Researchers Journal, 11, 711-721.

[29] Raval, A.A. and Shah, N.M. (1962) Journal of Scientific Research (India), 21, 234.

[30] Szell and Sipos (1961) Neue Nitro-chalkone, V. Justus Liebigs Annalen der Chemie, 641, 113-115.

[31] Reichel, L. (1944) Nalanxlissenchaften, 33, 215.

[32] Jadhav, G.V. and Kulkami, V.G. (1951) Borax as a new Condensing Agent for the Synthesis of Chalcones. Current Science (India), 20, 42-43.

[33] Vlasov, V.M. (1971) Izvestiya Sibirskogo Otdeleniya Akademii Nauk SSSR, Seriya Khimicheskikh Nauk, 2, 96.

[34] Cheng, P.L., Fournari, P. and Triouflet, J. (1963) Reserches en série hétérocyclique. VII. Syntèse de chromannones et o-hydroxychalcones substituées sur le differents cycles. Bulletin de la Societe Chimique de France, 10, 2248-2251.

[35] Breslow, D.S. and Hauser, C.R. (1940) Condensations. XI. Condensations of Certain Active Hydrogen Compounds Effected by Boron Trifluoride and Aluminum Chloride. Journal of the American Chemical Society, 62, 2385-2388. http://dx.doi.org/10.1021/ja01866a035

[36] Fujise, S. and Tatsuta, H. (1942) Journal of the Chemical Society of Japan, 63, 932.

[37] Guthrit J.L. and Rabjohn, N. (1957) Some Reactions Effected by Means of Bromomagnesium t-Alkoxides. The Journal of Organic Chemistry, 22, 176-179. http://dx.doi.org/10.1021/jo01353a022

[38] Jayapal, M.R., Sreenivasa Prasad, K. and Sreedhar, N.Y. (2010) Synthesis and Characterization of 2,4-Dihydroxy Substituted Chalcones Using Aldol Condensation by $\mathrm{SOCl}_{2} /$ EtOH. Journal of Chemical and Pharmaceutical Research, 2 , 127-132.

[39] Ameta, K.L., Rathore, N.S. and Kumar, B. (2011) Synthesis of Some Novel Chalcones and Their Facile One-Pot Conversion to 2-Aminobenzene-1,3-dicarbonitriles Using Malononitrile. Analele Universităţii din Bucuresti-Chimie (serie nouă), 20, 15-24.

[40] Tiwari, V., Singh, J.P., Sharma, P., Dangi, L. and Dulawat, S.S. (2011) Microwave Assisted Improved Synthesis of Chalcones under Microwave Irradiation and Their Antibacterial Activity. Journal of Chemical, Biological and Physical Sciences, 1, 22-27.

[41] Funiss, B.S., Hannford, A.J., Smith, P.W.G. and Tatchell, A.R. (2004) Vogel's Textbook of Practical Organic Chemistry. 5th Edition, Longman, London, 1032-1035.

[42] Mukherji, S.M., Singh, S.P. and Kapoor, R.P. (2003) Organic Chemistry. Vol II, International (P) Limited, 586-587. 
[43] Toche, R.B., Kazi, M.A., Jachak, M.N. and Desai, A.E. (2009) Synthesis and Molluscicidal Activities of Quinolone Substituted Pyrazoline and Isoxazoline Derivatives. Journal of Applied Sciences Research, 6, 637-641.

[44] Agarwal, P.K., Sharma, S.K., Sawant, D. and Kundu, B. (2009) Application of the Pictet-Spengler Reaction to Aryl Amine-Based Substrates Having Pyrimidine as a $p$-Nucleophile: Synthesis of Pyrimidoquinolines with Structural Analogy to Benzonaphthyridines Present in Alkaloids. Tetrahedron, 65, 1153-1161. http://dx.doi.org/10.1016/j.tet.2008.11.067

[45] Kalirajan, R., Sivakumar, S.U., Jubie, S., Gowramma, B. and Suresh, B. (2009) Synthesis and Biological Evaluation of Some Heterocyclic Derivatives of Chalcones. International Journal of ChemTech Research, 1, 27-34.

[46] Crawley, L.S. and Fanshawe, W.J. (1977) Neighboring Group Participation in Cyclodehydration. A Regiospecific Isoxazole Synthesis. Journal of Heterocyclic Chemistry, 14, 531-534. http://dx.doi.org/10.1002/jhet.5570140339

[47] Azarifar, D. and Shaebanzadeh, M. (2002) Synthesis and Characterization of New 3,5-Dinaphthyl Substituted 2-Pyrazolines and Study of Their Antimicrobial Activity. Molecules, 7, 885-895. http://dx.doi.org/10.3390/71200885

[48] Samshuddin, S., Narayana, B., Sarojini, B.K., Khan, M.T.H., Yathirajan, H.S., Raj, C.G.D. and Raghavendra, R. (2012) Antimicrobial, Analgesic, DPPH Scavenging Activities and Molecular Docking Study of Some 1,3,5-Triaryl2-pyrazolines. Medicinal Chemistry Research, 21, 2012-2022. http://dx.doi.org/10.1007/s00044-011-9735-9

[49] Samshuddina, S., Narayana, B., Sarojini, B.K., Yathirajan, H.S. and Raghavendra, R. (2012) Synthesis, Characterization and Biological Evaluation of Functionalized Derivatives of Versatile Synthon 4,4'-Difluoro Chalcone. Der Pharma Chemica, 4, 1445-1457.

[50] Loh, W.-S., Quah, C.K., Chia, T.S., Fun, H.-K., Sapnakumari, M., Narayana, B. and Sarojini, B.K. (2013) Synthesis and Crystal Structures of $N$-Substituted Pyrazolines. Molecules, 18, 2386-2396. http://dx.doi.org/10.3390/molecules18022386

[51] Sammour, A., Akhnookh, Y. and Jahine, H. (1970) Studies on Chalcones. Condensation with Ethyl Cyanoacetate and Malononitrilie in Presence of Ammonium Acetate. United Arab Republic Journal of Chemistry, 13, 421-437.

[52] Goda, F.E., Abdel-Aziz, A.A.-M. and Attef, O.A. (2004) Synthesis, Antimicrobial Activity and Conformational Analysis of Novel Substituted Pyridines: $\mathrm{BF}_{3}$-Promoted Reaction of Hydrazine with 2-Alkoxy Pyridines. Bioorganic \& Medicinal Chemistry, 12, 1845-1852. http://dx.doi.org/10.1016/j.bmc.2004.01.040

[53] Ahmed, M.G., Ahmed, S.A., Roman, U.K.R., Touchy, A.S., Badal, M.R., Hossain, M.A. and Uddin, M.K. (2005) Synthesis of Substituted and Unsubstituted 2,4-Diaryl-5-oxo-5,6,7,8-tetrahydro-2-chromens. Indian Journal of Chemistry, 44B, 622-624.

[54] Jin, H., Zhao, H., Zhao, F., Li, Sh., Liu, W., Zhou, G., Tao, K. and Hou, T. (2009) Efficient Epoxidation of Chalcones with Urea-Hydrogen Peroxide under Ultrasound Irradiation. Ultrasonics Sonochemistry, 16, 304-307. http://dx.doi.org/10.1016/j.ultsonch.2008.10.013

[55] Sharshira, E.M. and Hamada, N.M.M. (2011) Synthesis and in Vitro Antimicrobial Activity of Some Pyrazolyl-1-Carboxamide Derivatives. Molecules, 16, 7736-7745. http://dx.doi.org/10.3390/molecules16097736

[56] Chandrashekhar, C.H., Latha, K.P., Vagdevi, H.M. and Vaidya, V.P. (2011) Synthesis and Antimicrobial Activity of Chalcones of Naphtho[2,1-b]furan Condensed with Barbituric Acid. Der Pharma Chemica, 3, 329-333.

[57] Sangani, H.G., Bhimani, K.B., Khunt, R.C. and Parikh, A.R. (2006) Synthesis and Characterization of Barbitones as Antimicrobial Agents. Journal of the Serbian Chemical Society, 71, 587-591. http://dx.doi.org/10.2298/JSC0606587S

[58] Al-Issa, S.A. (2007) Synthesis of 3,5-Diaryl Azoline and [1,4]Diazepine Derivatives via Microwave Irradiation. Journal of King Saud University-Science, 19, 67-77. http://dx.doi.org/10.4197/Sci.19-1.6

[59] Ameta, K.L., Rathore, N.S. and Kumar, B. (2012) Synthesis and in Vitro Anti-Breast Cancer Activity of Some Novel 1,5-Benzothiazepine Derivatives. Journal of the Serbian Chemical Society, 77, 725-731. http://dx.doi.org/10.2298/JSC110715219A

[60] Yadav, J.S. and Srivastava, Y.K. (2010) An Efficient Microwave Assisted Synthesis of Some Novel 1,4-Dizepine Derivatives as Possible Antimicrobial Agents. Rasayan Journal of Chemistry, 3, 726-730.

[61] Joung, M.E. (1976) A Review of Annulation. Tetrahedron, 32, 3-31. http://dx.doi.org/10.1016/0040-4020(76)80016-6

[62] Hathaway, B.A. (1987) An Aldol Condensation Experiment Using a Number of Aldehydes and Ketones. Journal of Chemical Education, 64, 367-368. http://dx.doi.org/10.1021/ed064p367

[63] Rajanarendar, E., Kalyan Rao, E. and Raju, S. (2009) Microwave Assisted Rapid and Efficient Synthesis of New 3Ethoxy-4,6-diaryl-4,5-dihydro-2,1-benzisoxazoles. Indian Journal of Chemistry, 48B, 749-753.

[64] Nakano, T., Irifune, S., Umano, S., Inada, A., Ishii, Y. and Ogawa, M. (1987) Cross-Condensation Reactions of Cycloalkanones with Aldehydes and Primary Alcohols under the Influence of Zirconocene Complexes. The Journal of Organic Chemistry, 52, 2239-2244. http://dx.doi.org/10.1021/jo00387a025

[65] Li, J.T., Yang, W.Z., Chen, G.F. and Li, T.S. (2003) A Facile Synthesis of $\alpha, \alpha$-Bis(substituted benzylidene)cycloalka- 
nones Catalyzed by $\mathrm{KF} / \mathrm{Al}_{2} \mathrm{O}_{3}$ under ultrasound Irradiation. Synthetic Communications, 33, 2619-2625. http://dx.doi.org/10.1081/SCC-120021982

[66] Yadav, J.S., Reddy, B.V.S., Nagaraju, A. and Sarma, J.A.R.P. (2002) Microwave Assisted Synthesis of $\alpha, \alpha^{\prime}-$ Bis(benzylidene)ketones in Dry Media. Synthetic Communications, 32, 893-896. http://dx.doi.org/10.1081/SCC-120002700

[67] Zhang, X.Y., Fan, X.S., Niu, H.Y. and Wang, J.J. (2003) An Ionic Liquid as a Recyclable Medium for the Green Preparation of $\alpha$, $\alpha^{\prime}$-Bis (substituted benzylidene)cycloalkanones Catalyzed by $\mathrm{FeCl}_{3} \cdot 6 \mathrm{H}_{2} \mathrm{O}$. Green Chemistry, 5, 267-269. http://dx.doi.org/10.1039/b212155g

[68] Wang, L., Sheng, J., Tian, H., Han, J., Fan, Z. and Qian, C. (2004) A Convenient Synthesis of $\alpha, \alpha$ '-Bis(substituted benzylidene)cycloalkanones Catalyzed by $\mathrm{Yb}(\mathrm{OTf})_{3}$ under Solvent-Free Conditions. Synthesis, 2004, 3060-3064. http://dx.doi.org/10.1055/s-2004-834900

[69] Bigdeli, M.A., Mahdavinia, G.H., Jafari, S. and Hazarkhani, H. (2007) Wet 2,4,6-Trichloro[1,3,5]triazine (TCT) an Efficient Catalyst for Synthesis of $\alpha, \alpha$-Bis(substituted-benzylidene)cycloalkanones under Solvent-Free Conditions. Catalysis Communications, 8, 2229-2231. http://dx.doi.org/10.1016/j.catcom.2007.05.010

[70] Singh, N., Pandey, J., Yadav, A., Chaturvedi, V., Bhatnagar, Sh., Gaikwad, A.N., Sinha, S.K., Kumar, A., Shukla, P.K. and Tripathi, R.P. (2009) A Facile Synthesis of $\alpha, \alpha^{\prime}-(E E)$-bis(benzylidene)-cycloalkanones and Their Antitubercular Evaluations. European Journal of Medicinal Chemistry, 44, 1705-1709. http://dx.doi.org/10.1016/j.ejmech.2008.09.026

[71] Mahdavinia, G.H. and Mirzazadeh, M. (2012) Facile and Convenient Synthesis of $\alpha, \alpha$ '-Bis(substituted-arylidene)cycloalkanones: An Improved Protocol. E-Journal of Chemistry, 9, 49-54. http://dx.doi.org/10.1155/2012/390528

[72] Rahman, A.F.M.M., Ali, R., Jahng, Y. and Kadi, A.A. (2012) A Facile Solvent Free Claisen-Schmidt Reaction: Synthesis of $\alpha, \alpha^{\prime}$-Bis-(substituted-benzylidene)cycloalkanones and $\alpha, \alpha^{\prime}$-Bis-(substituted-alkylidene)cycloalkanones. Molecules, 17, 571-583.

[73] Teimouri, F., Hadi Khezri, S., Miri, Z., Eftekhari-Sis, B. and Azizian, J. (2009) Ammonium Chloride Catalyzed Aldol Condensation: A Facile Synthesis of $\alpha, \alpha$-Bis(substituted benzylidene) Cycloalkanones. Journal of Sciences (Islamic Azad University) (JSIAU), 19, 103-108.

[74] Mahdavinia, Gh.H. and Peikarporsan, S. (2011) Crossed Aldol Condensation Reaction Catalyzed by NBS as an Efficient and Almost Neutral Catalyst: Preparation of $\alpha, \dot{\alpha}$-Bis(substituted-benzylidene)cycloalkanones. Trends in Modern Chemistry TMC, 1, 5-10.

[75] Kumar, S., Kumar, P. and Makrandi, J.K. (2012) A Simple, Improved and Solvent Free Synthesis of $\alpha, \alpha^{\prime}-B i s(\operatorname{aryli}-$ dene)cycloalkanones. Der Chemica Sinica, 3, 269-273.

[76] Singh, N., Pandey, J., Yadav, A., Chaturvedi, V., Bhatnagar, Sh., Gaikwad, A.N., Sinha, S.K., Kumar, A., Shukla, P.K. and Tripathi1, R.P. (2009) A Facile Synthesis of $\alpha, \alpha^{\prime}-(E E)$-bis(benzylidene)-cycloalkanones and Their Antitubercular Evaluations. European Journal of Medicinal Chemistry, 44, 1705-1709. http://dx.doi.org/10.1016/j.ejmech.2008.09.026

[77] Zou, Q., Zhao, Y., Makarov, N.S., Campo, J., Yuan, H., Fang, D.-C., Perry, J.W. and Wu, F. (2012) Effect of Alicyclic Ring Size on the Photophysical and Photochemical Properties of Bis(arylidene)cycloalkanone Compounds. Physical Chemistry Chemical Physics, 14, 11743-11752. http://dx.doi.org/10.1039/c2cp41952a

[78] Colonge, J. and Sibeud, J. (1952) Bulletin de la Societe Chimique de France, 786-789.

[79] Emerson, W.S., Birum, G.H. and Longley Jr., R.I. (1953) Bicyclic Dihydropyrans by the Diels-Alder Reaction. Journal of the American Chemical Society, 75, 1312-1313. http://dx.doi.org/10.1021/ja01102a013

[80] Jaitak, V., Kaul, V.K. and Das, P. (2013) Environmentally Benign Michael and Claisen Schmidt Reaction of Aromatic Carbonyl Compounds by Alkaline Polyionic Resin. Indian Journal of Chemistry, 52B, 1137-1145.

[81] Huitric, A.C. and Kumler, W.D. (1956) The Dipole Moments, Spectra and Structure of Some New 2-Phenyl-, 2-Benzyl-, 2-(p-Halobenzylidene)- and 2,6-Bis-( $p$-halobenzylidene)-cyclohexanones. Journal of the American Chemical Society, 78, 614-622. http://dx.doi.org/10.1021/ja01584a026

[82] Fringuelli, F., Pani, G., Piermatti, O. and Pizzo, F. (1994) Condensation Reactions in Water of Active Methylene Compounds with Arylaldehydes. One-Pot Synthesis of Flavonols. Tetrahedron, 50, 11499-11508. http://dx.doi.org/10.1016/S0040-4020(01)89287-5

[83] Kang, L.-Q., Song, G.-H., Wang, J.-Y. and Wei, B.-G. (2008) Synthesis of $\alpha$, $\alpha$-Bis(substituted benzylidene)cycloalkanones catalyzed by Amino-Functionalized Ionic Liquid. Journal of the Chinese Chemical Society, 55, 1125-1128.

[84] Sheikhhosseini, E., Ahmadi, S.A. and Sadeghi, S. (2014) P-Dodecylbenzenesulfonic Acid (DBSA), a Brønsted AcidSurfactant Catalyst for Synthesis of $\alpha$, $\dot{\alpha}$-Bis(substituted benzylidene)cycloalkanones with Electron-Withdrawing Substituent in Aqueous Media. Journal of Applied Chemical Research, 8, 25-30.

[85] Wang, X.X. and Zhang, Y.M. (2004) Formation of $\alpha, \alpha$ '-Bis(substituted benzylidene)cycloalkanones from Masked Aldehydes Promoted by Samarium (III) Triiodide. Chinese Chemical Letters, 15, 511-514. 
[86] Singh, N., Pandey, J. and Tripathi, R.P. (2008) $d$-Glucosamine, a Natural Aminosugar as Organocatalyst for an Ecofriendly Direct Aldol Reaction of Ketones with Aromatic Aldehydes in Water. Catalysis Communications, 9, 743-746. http://dx.doi.org/10.1016/j.catcom.2007.08.014

[87] Fehnel, E.A. and Carmack, M. (1948) Studies in the Thiapyran Series. The Preparation, Properties and Reactions of 1,4-Thiapyrone-1-Dioxide. Journal of the American Chemical Society, 70, 1813-1817. http://dx.doi.org/10.1021/ja01185a048

[88] Chardwell, H.M.E. (1949) Experiments on the synthesis of Substances Related to Sterols. Part XLVII. The Synthetic Use of thia Cyclohexan-4-One Methiodide. Journal of the Chemical Society, 715-719. http://dx.doi.org/10.1039/jr9490000715

[89] Cornubert, R., Delmas, R., Monteil, S. and Viriot, J. (1950) Bulletin de la Societe Chimique de France, 36.

[90] Leonard, N.J. and Choudhury, D. (1957) $\gamma$-Pyrones by Isomerization. Substituted 3,5-Dibenzyl-4H-pyran-4-ones. Journal of the American Chemical Society, 79, 156-160. http://dx.doi.org/10.1021/ja01558a042

[91] Puar, M.S., Rovnyak, G.C., Cohen, A.I., Toeplitz, B. and Gougoutas, J.Z. (1979) Orientation of the Sulfoxide Bond as a Stereochemical Probe. Synthesis and Proton and Carbon-13 NMR of Substituted Thiopyrano[4,3-c]pyrazoles. The Journal of Organic Chemistry, 44, 2513-2518. http://dx.doi.org/10.1021/jo01328a040

[92] Rovnyak, G.C. and Shu, V. (1979) Preparation of Thiopyrano- and Pyrano[4,3-c]pyrazoles. Structure Elucidation of Dehydro Coproducts. The Journal of Organic Chemistry, 44, 2518-2522. http://dx.doi.org/10.1021/jo01328a041

[93] Turk, C.F. (1975) Pyrazoline Derivatives, Their N-Oxides, and Salts. Ger Offen Patent No. 2520171.

[94] Krapcho, J. and Schawartz, J. (1976) CNS Active Compounds. US Patent No. 3969527.

[95] Krapcho, J., and Turk, F. (1975) 2-Amino-4,5-Dihydro-4-Arylidenopyrimidines. US Patent No. 3925384.

[96] Sohár, P., Perjési, P., Törnroos, K.W., Husebye, S., Vértes, A., Vankó, G. and Bozak, R. (2000) Study on Ferrocenes, Part 7. E-2-Ferrocenemethylene-1-benzocyclanones. Synthesis, Stereostructure, NMR, IR, X-Ray, and Mössbauer Spectroscopic Investigation. Journal of Molecular Structure, 524, 297-304. http://dx.doi.org/10.1016/S0022-2860(00)00380-X

[97] Gupta, R., Gupta, A.K., Paul, S. and Kachroo, P.L. (1995) Improved Microwave-Induced Synthesis of Chalcones and Related Enones. Indian Journal of Chemistry, 34B, 61-62.

[98] Mandal, S.K. and Sarkar, A. (2002) endo-Selective Allylation at the Benzylic Centre of a Cr(CO) $)_{3}$ Complexed Aromatic Ring. Journal of the Chemical Society, Perkin Transactions 1, 669-674. http://dx.doi.org/10.1039/b109291j

[99] Asiri, A.M. and Rasul, M.G. (2009) Synthesis of (2E)-2-(2,4,6-trimethoxybenzylidene)indan-1-one. Molbank, 2009, M588.

[100] Witschard, G. and Griffin, C.E. (1964) The Wittig Reaction with Five- and Six-Membered Cyclic Ketones and Their Benzylidene Derivatives. The Journal of Organic Chemistry, 29, 2335-2340. http://dx.doi.org/10.1021/jo01031a057

[101] Lankin, D.C. and Zimmer, H. (1973) Synthesis of Condensed Heterocyclic Systems V: 1H-indeno[1,2-b]quinolines from Photochemical and Acid-Calalyzed Rearrangements of Trans-2-(2-aminobenzylidene)-indanones. Journal of Heterocyclic Chemistry, 10, 1035-1038. http://dx.doi.org/10.1002/jhet.5570100630

[102] Kumbharek, R. and Sridhar, M. (2012) Trifluoromethanesulfonic Acid Promoted Dakin-West Reaction: An Efficient and Convenient Synthesis of $\hat{~}^{2}$-Acetamido Ketones. Journal of Chemical Sciences, 124, 495. http://dx.doi.org/10.1007/s12039-011-0183-3

[103] Murray, R.J. and Cromwell, N.H. (1976) Mobile Keto Allyl Systems. 18. Synthesis and Charge-Transfer Interactions of 2-(Alpha-aminobenzyl)-1-Indenones. The Journal of Organic Chemistry, 41, 3540-3545. http://dx.doi.org/10.1021/jo00884a011

[104] Wagner, H., Horn, B., Eppner, H. and Kühmstedt, H. (1979) Pharmazie, 34, 56.

[105] Berthelote, C., McCooye, C., Leblanc, Y. and Trimble, L.A. (1997) Studies on the Dimerization of 2-Benzylidene-1Indanone. The Journal of Organic Chemistry, 62, 4339-4342. http://dx.doi.org/10.1021/jo970402y

[106] Singh, G. and Ray, J.N. (1930) Journal of the Indian Chemical Society, 7, 637.

[107] Basavaiah, D. and Reddy, R.M. (2001) One-Pot Inter- and Intramolecular Friedel-Crafts Reactions in Baylis-Hillman Chemistry: A Novel Facile Synthesis of (E)-2-arylideneindan-1-ones. Tetrahedron Letters, 42, 3025-3027. http://dx.doi.org/10.1016/S0040-4039(01)00354-9

[108] Coombs, R.W. and Houlihan, W.J. (1974) Process for Preparing Substituted Indeno, Naphtho and Cycloheptapyrazoles. US Patent No. 3843665.

[109] Boudriga, S., Wannassi, N., Askri, M., El Baker Rammah, M. and Strohman, C.J. (2009) Journal de la Société Chimique de Tunisie, 11, 29-36.

[110] Thadhaney, B., Sain, D. and Joshi, A. and Talesara, G.L. (2009) Synthesis and Biological Evaluation of Some Ethox- 
yphthalimide Derivatives of Benzo ( $g$ ) Indazoles. International Journal of Chemical Sciences, 7, 1185-1194.

[111] Sohár, P., Perjési, P., Törnroos, K.W., Husebye, S., Vértes, A., Vankó, G. and Bozak, R. (2000) Study on Ferrocenes, Part 7. E-2-Ferrocenemethylene-1-benzocyclanones. Synthesis, Stereostructure, NMR, IR X-Ray, and Mossbauer Spectroscopic Investigation. Journal of Molecular Structure, 524, 297-304. http://dx.doi.org/10.1016/S0022-2860(00)00380-X

[112] Gupta, R., Gupta, A.K., Paul, S. and Kachroo, P.L. (1995) Indian Journal of Chemistry, 34B, 61-62.

[113] Orlov, V.D., Borovoi, I.A. and Lavrushin, V.F. (1976) Zhurnal Strukturnoi Khimii, 17, 691.

[114] Schwender, C.F. and Shavel Jr., J. (1974) 1-Oxo-Substituted-Tetrahydronaphthalenes (Substituted-Tetralones). US Patent No. 3833726.

[115] Ansell, L.L., Webb, T.E., Burnham, J.W., Eisenbraun, E.J., Hamming, M.C. and Keen, G.W. (1976) Synthesis of 2-(1-Naphthylmethyl)-3,4-dihydronaphthalene, 2-(1-Naphthylmethyl)-1,2,3,4-tetrahydronaphthalene, 7a,8,9,13b-Tetrahydro-7H-dibenz $[a, k L]$ Anthracene, and 5,6-Dihydro-4H-dibenz $[a, k L]$ anthracene. Organic Preparations and Procedures International, 8, 125-132. http://dx.doi.org/10.1080/00304947609355605

[116] Aizenshtat, Z., Hausmann, M., Pickholtz, Y., Tal, D. and Blum, J. (1977) Chlorocarbonylbis(triphenylphosphine)iridium-Catalyzed Isomerization, Isoaromatization, and Disproportionation of Some Cycloalkanones Having Exocyclic Double Bonds. The Journal of Organic Chemistry, 42, 2386-2394. http://dx.doi.org/10.1021/jo00434a010

[117] Kerbal, A., Tshiamala, K., Cerutti, E., Laude, B. and Vebrel, J. (1990) Bulletin de la Societe Chimique de France, 127, 252.

[118] D’Auria, M., D’Onofrio, F. and Vantaggi, A. (1990) Benzophenone Sensitized Rearrangement of Furylidenetetralones. Tetrahedron, 46, 7831-7840. http://dx.doi.org/10.1016/S0040-4020(01)90080-8

[119] D’Auria, M., D’Annibale, A. and Ferri, T. (1992) Photochemical Behaviour of Furylidene Carbonyl Compounds. Tetrahedron, 48, 9323-9336.

[120] Sur, S., Ganesh, S., Puranik, V.G. and Sarkar, A. (1998) Remote Stereocontrol as a Synthetic Strategy: Diastereoselective Annulations on an Arene Tricarbonylchromium Template. Journal of the Chemical Society, Perkin Transactions 1, 977-982. http://dx.doi.org/10.1039/a705285e

[121] Arora, S., Yadav, S., Agrawal, N. and Nagori, Dr., B.P. (2013) International Journal of Pharmaceutics, 1, 456.

[122] Kamakshi, R., Swarna Latha, S. and Reddy, B.S.R. (2010) An Efficient Synthesis of Bio-Active Fluorescent Benzylidine Tetralones. Indian Journal of Chemistry, 49B, 944-947.

[123] Bayer, H. and Hartmann, R.W. (1991) Pyridyl-Substituted Tetralone Derivatives: A New Class of Nonsteroidal Aromatase Inhibitors. Archiv der Pharmazie (Weinheim), 324, 815-820. http://dx.doi.org/10.1002/ardp.2503241008

[124] Bayer, H. and Hartmann, R.W. (1991) New Inhibitors of Aromatase: Synthesis and Biological Activity of PyridylSubstituted Phenanthrenone Derivatives. Archiv der Pharmazie (Weinheim), 324, 833-836. http://dx.doi.org/10.1002/ardp.2503241102

[125] Bayer, H., Baltz, C., Hartmann, R.W. and Mannschreck, A. (1991) New Aromatase Inhibitors. Synthesis and Biological Activity of Pyridyl-Substituted Tetralone Derivatives. Journal of Medicinal Chemistry, 34, 2685-2691. http://dx.doi.org/10.1021/jm00113a004

[126] Wächter, G.A., Harmtmann, R.W., Sergejew, T., Grün, G.L. and Ledergerber, D. (1996) Tetrahydronaphthalenes: Influence of Heterocyclic Substituents on Inhibition of Steroidogenic Enzymes P450 Arom and P450 17. Journal of Medicinal Chemistry, 39, 834-841. http://dx.doi.org/10.1021/jm950377t

[127] Azzolina, O., Desimoni, G., Di Toro, V., Ghislandi, V. and Tacconi, G. (1975) Gazzetta Chimica Italiana, $105,971$.

[128] Wagner, H., Horn, B., Eppner, H. and Kühmstedt, H. (1979) Pharmazie, 34, 56.

[129] Kaur, R., Bansal, M. and Kaur, B. (2011) Synthesis of Some New Quinazoline Derivatives and Theoretical Studies of Their Geometries. Chemical Sciences Journal, 2011, 1-9.

[130] Muthusamy, S., Babu, S.A. and Gunanathan, C. (2000) Novel chemoselective 1,3-dipolar cycloaddition of rhodium generated carbonyl ylides with arylidenetetralones. Tetrahedron Letters, 41, 8839-8842. http://dx.doi.org/10.1016/S0040-4039(00)01560-4

[131] Quiroga, J., Portilla, J., Serrano, H., Abonia, R., Insuasty, B., Nogueras, M. and Cobo, J. (2007) Regioselective Synthesis of Fused Benzopyrazolo[3,4-b]quinolines under Solvent-Free Conditions. Tetrahedron Letters, 48, 1987-1990.

[132] Jayashankaran, J., Manian, R.D.R.S. and Raghunathan, R. (2005) ARKIVOC, xi, 32.

[133] Xu, W.-Z., Huang, Z.-T. and Zheng, Q.-Y. (2008) Synthesis of Benzo[c]xanthones from 2-Benzylidene-1-tetralones by the Ultraviolet Radiation-Mediated Tandem Reaction. The Journal of Organic Chemistry, 73, 5606-5608. http://dx.doi.org/10.1021/j08008929

[134] El-Rayyes, N.R. and Bahtiti, N.H. (1989) Synthesis of New Substituted 2,3,3a,4,5,6-Hexahydrobenzo[6,7]cyclohep- 
ta[1,2-c]pyrazoles and related compounds. Journal of Heterocyclic Chemistry, 26, 209-214. http://dx.doi.org/10.1002/jhet.5570260137

[135] El-Rayyes, N.R. and Ramadan, H.M. (1987) Heterocycles. PartX. Synthesis of New Pyrimidine Systems. Journal of Heterocyclic Chemistry, 24, 589-596. http://dx.doi.org/10.1002/jhet.5570240310

[136] Wagner, G., Garbe, C., Vieweg, H., Brunn, M. and Dittrich, A. (1979) Pharmazie, 34, 55.

[137] Cummins, B., Donnelly, D.M.X., Eades, J.F., Fletcher, H., O’Cinneide, F., Philbin, E.M., Swirski, J., Wheeler, T.S. and Wilson, R.K. (1963) Oxidation of Chalcones (AFO reaction). Tetrahedron, 19, 499-512. http://dx.doi.org/10.1016/S0040-4020(01)98539-4

[138] Dean, F.M. and Podimuang, V. (1965) The Course of the Algar-Flynn Oyamada (A.F.O.). Journal of the Chemical Society, 3978-3987. http://dx.doi.org/10.1039/jr9650003978

[139] Fougerousse, A., Gonzalez, E. and Brouillard, R. (2000) A Convenient Method for Synthesizing 2-Aryl-3-hydroxy-4oxo-4H-1-benzopyrans or flavonols. The Journal of Organic Chemistry, 65, 583-586. http://dx.doi.org/10.1021/jo990735q

[140] Donnelly, J.A. and Higginbotham, C.L. (1990) Flavone Formation in the Wheelerb Aurone Synthesis. Tetrahedron, 46, 7219-7226. http://dx.doi.org/10.1016/S0040-4020(01)87902-3

[141] Donnelly, J.A., Emerson, G.M. (1990) Amine-Effected Cyclization of Chalcone Dihalides to Aurones. Tetrahedron, 46, 7227-7236. http://dx.doi.org/10.1016/S0040-4020(01)87903-5

[142] von Auwerws, K. and Müller, K. (1908) Umwandlung von Benzal-cumaranonen in Flavonole. Berichte der deutschen chemischen Gesellschaft, 41, 4233-4241. http://dx.doi.org/10.1002/cber.190804103137

[143] Brady, B.A., Geoghegan, M. and O’Sullivan, W.I. (1981) Flavonoid Epoxides. Part 16. Synthesis and Base-Catalysed Rearrangement of Aurone Epoxides. Journal of the Chemical Society, Perkin Transactions 1, 119-123. http://dx.doi.org/10.1039/p19810000119

[144] Haudecoeur, R., Belkacem, A.A., Yi, W., Fortuné, A., Brillet, R., Belle, C., Nicolle, E., Pallier, C., Pawlotsky, J.-M. and Boumendjel, A. (2011) Discovery of Naturally Occurring Aurones That Are Potent Allosteric Inhibitors of Hepatitis C Virus RNA-Dependent RNA Polymerase. Journal of Medicinal Chemistry, 54, 5395-5402. http://dx.doi.org/10.1021/jm200242p

[145] Hadj-Esfandiari, N., Navidpour, L., Shadnia, H., Amini, M., Samadi, N., Faramarzi, M.A. and Shafiee, A. (2007) Synthesis, Antibacterial Activity, and Quantitative Structure-Activity Relationships of New (Z)-2-(nitroimidazolylmethylene)-3(2H2H)-benzofuranone Derivatives. Bioorganic \& Medicinal Chemistry Letters, 17, 6354-6363.

[146] von Auwers, K. and Poh, P. (1914) Ann., 405, 243.

[147] Wagner, G. and Eppner, B. (1979) Pharmazie, 34, 527.

[148] Farkas, L., Nógrádi, M. and Pallos, L. (1963) The Correct Structure and Synthesis of Rengasine. Tetrahedron Letters, 4, 1999-2000. http://dx.doi.org/10.1016/S0040-4039(01)90957-8

[149] Farkas, L., Nógrádi, M. and Pallos, L. (1964) Aurone und Auronglucoside, VI. Die endgültige Konstitutionsaufklärung und die Synthese des Rengasins. Chemische Berichte, 97, 1044-1046. http://dx.doi.org/10.1002/cber.19640970415

[150] Farkas, L., Pallos, L. and Nógrádi, M. (1965) Magyar Kémiai Folyóirat, 71, 270.

[151] Jong, T.T. and Leu, S.J. (1990) Intramolecular Cyclisation Catalysed by Silver(I) Ion; a Convenient Synthesis of Aurones. Journal of the Chemical Society, Perkin Transactions 1, 423-424. http://dx.doi.org/10.1039/p19900000423

[152] Agrawal, N.N. and Soni, P.A. (2006) A New Process for the Synthesis of Aurones by Using Mercury (II) Acetate in Pyridine and Cupric Bromide in Dimethyl Sulfoxide. Indian Journal of Chemistry, 45B, 1301-1303.

[153] Detsi, A., Majdalani, M., Christos, A., Dimitra, K., Hadjipavlou-Litina, D. and Kefalas, P. (2009) Natural and Synthetic 2'-Hydroxy-Chalcones and Aurones: Synthesis, Characterization and Evaluation of the Antioxidant and Soybean Lipoxygenase Inhibitory Activity. Bioorganic \& Medicinal Chemistry, 17, 8073-8085. http://dx.doi.org/10.1016/j.bmc.2009.10.002

[154] Dawane, B.S., Konda, S.G., Khandare, N.T., Chobe, S.S., Shaikh, B.M., Bodade, R.G. and Joshi, V.D. (2010) Synthesis and Antimicrobial Evaluation of 2-(2-Butyl-4-chloro- $1 H$-imidazol-5-yl-methylene)-substituted-benzofuran-3-ones. Chemical Communications, 3, 22-29.

[155] Bhasker, N. and Reddy, M.K. (2011) Synthesis and Characterization of New Series of Prenyloxy Chalcones, Prenyloxy Aurones and Screening for Anti-Bacterial Activity. International Journal of Research in Pharmaceutical and Biomedical Sciences, 2, 1266-1272.

[156] Harkat, H., Blanc, A., Weibel, J.-M. and Pale, P. (2008) Versatile and Expeditious Synthesis of Aurones via Au-Catalyzed Cyclization. The Journal of Organic Chemistry, 73, 1620-1623. http://dx.doi.org/10.1021/jo702197b

[157] Alcaide, B., Almendros, P. and Alonso, J.M. (2011) Gold-Catalyzed Cyclizations of Alkynol-Based Compounds: Syn- 
thesis of Natural Products and Derivatives. Molecules, 16, 7815-7843.

[158] Kamila, S., Mukherjee, C., Pradhan, T.K. and De, A. (2006) Synthetic Studies in Sulfur Heterocycles. One-Pot Synthesis of "Thioaurones" and their Conversion into [1]benzothieno[3,2-b]pyrans via Tandem Reactions. ARKIVOC, II, 45-60.

[159] Yamaguchi, T., Seki, T., Tamaki, T. and Ichimura, K. (1992) Preparation and Photochemical Properties in Organic Solvents. Bulletin of the Chemical Society of Japan, 65, 649-656. http://dx.doi.org/10.1246/bcsj.65.649

[160] Seki, T., Tamaki, T., Yamaguchi, T. and Ichimura, K. (1992) Photochromism of Hemithioindigo Derivatives. II. Photochromic Behaviors in Bilayer-Membranes and Related Systems. Bulletin of the Chemical Society of Japan, 65, 657663. http://dx.doi.org/10.1246/bcsj.65.657

[161] Cabiddu, M.G., Cabiddu, S., Cadoni, E., De Montis, S., Fattuoni, C., Melis, S. and Usai, M. (2002) One-Step Synthesis of Thioaurones. Synthesis, 2002, 875-878. http://dx.doi.org/10.1055/s-2002-28523

[162] Boughaleb, A., Al Houari, G., Bennani, B., Daoudi, M., Garrigues, B., Kerbal, A. and El Yazidi, M. (2010) N-phenyl$C$-arylnitrilimines sur des derives de la 2-benzylidenebenzo[b]thiophen-3(2H)-one (Thioaurones). Société Chimique de Tunisie, 12, 109-115.

[163] Pradhan, T.K., Dea, A. and Mortier, J. (2005) Application of Directed Metalation in Synthesis. Part 8: Interesting Example of Chemoselectivity in the Synthesis of Thioaurones and Hydroxy Ketones and a Novel Anionic Ortho-Fries Rearrangement Used as a Tool in the Synthesis of Thienopyranones and Thiafluorenones. Tetrahedron, 61, 9007-9017. http://dx.doi.org/10.1016/j.tet.2005.07.050

[164] Wichers, M. and Görlitzer, K. (2012) Strategies for the Synthesis of Tetracyclic Diltiazem Analogues. Institute of Pharmaceutical Chemistry, Technical University of Braunschweig, Braunschweig.

[165] Eisa, M.A. (2006) Synthesis of Some New Fused Heterocyclic Rings Derived from 3-Benzofuranone. Raf. Jour. Sci., 17, 76-85.

[166] Rajan, Y.C. and Kanakam, C.C. (2008) Synthesis and Characterization of Chiral Enantiopure Bis-Chromanones: A Baylis-Hillman Approach. Tetrahedron Letters, 49, 3023-3026. http://dx.doi.org/10.1016/j.tetlet.2008.02.124

[167] Foroumadi, A., Samzadeh-Kermani, A., Emami, S., Dehghan, G., Sorkhi, M., Arabsorkhi, F., Heidari, M.R., Abdollahi, M. and Shafiee, A. (2007) Synthesis and Antioxidant Properties of Substituted 3-Benzylidene-7-alkoxychroman4-ones. Bioorganic \& Medicinal Chemistry Letters, 17, 6764-6769. http://dx.doi.org/10.1016/j.bmcl.2007.10.034

[168] Harborne, J.B. and Williams, C.A. (2000) Advances in Flavonoid Research since 1992. Phytochemistry, 55, $481-504$. http://dx.doi.org/10.1016/S0031-9422(00)00235-1

[169] Gupta, A., Dwivedy, A., Keshri, G., Sharma, R., Balapure, A.K., Singh, M.M. and Ray, S. (2006) Rapid Synthesis of 4-Benzylidene and 4-[Bis-(4-methoxyphenyl)-methylene-2-subsituted phenyl-benzopyrans as Potential Selective Estrogen Receptor Modulators (SERMs) Using McMurry Coupling Reaction. Bioorganic \& Medicinal Chemistry Letters, 16, 6006-6012. http://dx.doi.org/10.1016/j.bmcl.2006.08.126

[170] Buston, G.W., Doba, T., Gabe, E.J., Huges, L., Lee, F., Prasad, L. and Ingold, K.U. (1985) Autoxidation of Biological Molecules. 4. Maximizing the Antioxidant Activity of Phenols. Journal of the American Chemical Society, 107, 70537065. http://dx.doi.org/10.1021/ja00310a049

[171] Ibrahim, M.A., Ali, T.E., Alnamer, Y.A. and Gabr, Y.A. (2010) Synthesis and Chemical Reactivity of 2-Methylchromones. ARKIVOC, i, 98-135. http://dx.doi.org/10.3998/ark.5550190.0011.103

[172] Ghosh, C.K. and Patra, A. (2008) Chemistry and Application of 4-Oxo-4H-1-benzopyran-3-carboxaldehyde. Journal of Heterocyclic Chemistry, 45, 1529-1547. http://dx.doi.org/10.1002/jhet.5570450601

[173] Sangwan, N.K. and Rastogi, S.N. (1981) Indian Journal of Chemistry, 20B, 135.

[174] Evans, D. and Lockhart, I.M. (1966) Reaction of Aromatic Aldehydes and Nitroso-Compounds with 4-Chromanones. Journal of the Chemical Society, 711-712.

[175] Albrecht, R., Kessler, H.J. and Schröder, E. (1971) Bull. Chim. Thér., 352.

[176] Wright, G.C. (1976) The Condensation Products of 6-Methoxy-2,3-dihydro-4H-benzopyran-4-one and 6-Nitroveratraldehyde. Part I. Journal of Heterocyclic Chemistry, 13, 1177-1179. http://dx.doi.org/10.1002/jhet.5570130606

[177] Chatterjea, J.N., Shaw, S.C., Lal, P.K. and Singh, R.P. (1979) Journal of the Indian Chemical Society, 56, $1006-1007$.

[178] Naurikoshi, M., Nakata, H., Yamada, H., Nagai, M. and Saitoh, T. (1987) Homoisoflavonoids and Related Compounds. II. Isolation and Absolute Configurations of 3,4-Dihydroxylated Homoisoflavans and Brazilins from Caesalpinia sappan L.Chemical and Pharmaceutical Bulletin, 35, 2761-2773. http://dx.doi.org/10.1248/cpb.35.2761

[179] Roberts, J.F., Alhassan, M., Xicluna, A., Ombetta, J.E., Mercier, M.F., Mercier, R. and Laude, B. (1993) Bulletin de la Societe Chimique de France, 130, 788.

[180] Letafat, B., Shakeri, R., Emami, S., Noushini, S., Mohammadhosseini, N., Shirkavand, N., Ardestani, S. K., Safavi, M., 
Samadizadeh, M., Letafat, A., Shafiee, A. and Foroumadi, A. (2013) Iranian Journal of Basic Medical Sciences, 16, 1155.

[181] Farkas, L., Gottsegen, Á. and Nógrádi, M. (1968) Synthesis of Encomin and ( \pm ) Eucomol. Tetrahedron Letters, 9, 4099-4100. http://dx.doi.org/10.1016/S0040-4039(00)72872-3

[182] Farkas, L., Gottsegen, Á. and Nógrádi, M. (1970) The Synthesis of Encomin and ( \pm ) Eucomol. Tetrahedron, 26, 2787-2790. http://dx.doi.org/10.1016/S0040-4020(01)92854-6

[183] Farkas, L., Gottsegen, Á. and Nógrádi, M. (1971) Synthesis of Homoisoflavanones-II: Constituents of Eucomis Autumn Alis and E. Punctata. Tetrahedron, 27, 5049-5054. http://dx.doi.org/10.1016/S0040-4020(01)98209-2

[184] Pfeiffer, P. and Emmer, H.J. (1920) Zur Kenntnis der Chromanone, II. (II. Mitteilung zur Brasilin- und HämatoxylinFrage). Berichte der deutschen chemischen Gesellschaft (A and B Series), 53, 945-953.

[185] Pfeiffer, P., Oberlin, H. and Konermann, E. (1925) Über Methoxychromonole und das Schall-Drallesche Abbauprodukt des Brasilins. (IV. Mitteilung zur Brasilin- und Hämatoxylin-Frage). Berichte der deutschen chemischen Gesellschaft (A and B Series), 58, 1947-1958.

[186] Woods, L.L. and Dix, P.A. (1959) Notes: Reactions of Several 4-Pyrones Catalyzed by Potassium Acetate and Trifluoroacetic Acid. The Journal of Organic Chemistry, 24, 1126-1128. http://dx.doi.org/10.1021/jo01090a604

[187] Gopaul, K., Shaikh, M.M., Koobanally, N.A., Ramjugernath, D. and Omondi, B. (2012) (E)-3-(4-Cyclohexyl-3-fluorobenzylidene)chroman-4-one. Acta Crystallographica Section E: Structure Reports, 68, 01972.

[188] Lévai, A., Dinya, Z., Schág, J.B., Tóth, G. and Szöllősy, Á. (1981) Pharmazie, 36, 465.

[189] Lévai, A. and Szabó, Z. (1992) Pharmazie, 47, 56.

[190] Chambers, R.J., Koch, K., Biggers, M.S. and Ramchandani, M. (1998) Synthetic Approaches to 2-(4-Hydroxy-7-chromanyl)benzoic Acids as Antagonists of Leukotriene $\mathrm{B}_{4}$. Bioorganic \& Medicinal Chemistry Letters, 8, 1787-1790. http://dx.doi.org/10.1016/S0960-894X(98)00276-5

[191] Mandal, T.K., Pal, R., Mondal, R. and Mallik, A.K. (2011) Facile Condensation of Aromatic Aldehydes with Chroman-4-Ones and 1-Thiochroman-4-Ones Catalysed by Amberlyst-15 under Microwave Irradiation Condition. E-Journal of Chemistry, 8, 863-869.

[192] Dawood, K.M. and Fuchigami, T. (2001) Electrolytic Partial Fluorination of Organic Compounds. 55. Highly Regioand Stereoselective Anodic Monofluorination of 2,3-Dihydrochroman-4-One and Chromone Derivatives. The Journal of Organic Chemistry, 66, 7691-7695. http://dx.doi.org/10.1021/jo0105437

[193] Basavaiah, D., Bakthadoss, M. and Pandiaraju, S. (1998) A New Protocol for the Syntheses of (E)-3-Benzylidenechroman-4-ones: A Simple Synthesis of the Methyl Ether of Bonducellin. Chemical Communications, 16, 1639-1640. http://dx.doi.org/10.1039/a804796k

[194] Scholastica, M., Vithiya, B., Shanmugapriya, A. and Augustine, A.P.T. (2013) A Highly Regioselective Synthesis of Spiro[oxindole-chromanone]pyrrolidines and Pyrrolizines through 1,3-Dipolar Cycloaddition Protocol. Der Pharma Chemica, 5,184-188.

[195] Wagner, G., Garbe, C., Vieweg, H., Brunn, M. and Dittrich, A. (1979) Pharmazie, 34, 55.

[196] Hofmann, H. and Westernacher, H. (1969) Synthese von Derivaten des 1-Benzoxepins, 1-Benzothiepins und 1-Benzothiepin-1.1-dioxids. Chemische Berichte, 102, 205-222. http://dx.doi.org/10.1002/cber.19691020126

[197] Nishibata, K., Nishio, M., Ishii, T. and Ito, S. (1971) 3-Arylidenethiochromanone Derivatives. Japan Patent No. 7139865.

[198] Orlov, V.D., Nadelman, O.A. and Mihedkina, E.I. (1981) Zhurnal Organicheskoi Khimii, 51, 1153.

[199] Fang, L., Guo, C. and Zhang, Q.B. (1997) Studies on the Synthesis and Antifungal Activity of Thiochromanone Derivatives. Chinese Chemical Letters, 8, 939-942.

[200] Katschalowsky, A. and von Kostanecki, S. (1904) Ueber Flavindogenide. chte der deutschen chemischen Gesellschaft, 37, 3169-3172. http://dx.doi.org/10.1002/cber.190403703113

[201] Széll, T. and Unyi, R.É.M. (1963) Condensation of Hydroxynitroacetophenones with Aromatic Aldehydes in the Presence of Hydrogen Chloride. The Journal of Organic Chemistry, 28, 1146-1147. http://dx.doi.org/10.1021/jo01039a515

[202] Széll, T. and Zarándy, K. (1968) Synthesis of Benzylidene-Flavanones. Canadian Journal of Chemistry, 46, 15711572. http://dx.doi.org/10.1139/v68-257

[203] Reichel, L. and Grytzka, H. (1968) Chemie und Biochemie der Pflanzenstoffe, XXIII ${ }^{1)}$ Bildung und Reaktionen von 3-Benzyliden-flavanonen. Liebigs Annalen der Chemie, 720, 154-160. http://dx.doi.org/10.1002/jlac.19687200114

[204] Keane, D.D., Marathe, K.G., O’Sulivan, W.I., Philbin, E.M., Simons, R.M. and Teague, P.C. (1970) Configuration and Conformation of 3-Arylideneflavanones. The Journal of Organic Chemistry, 35, 2286-2290. http://dx.doi.org/10.1021/j000832a039 
[205] Reichel, L. and Hempel, G. (1966) Chemie und Biochemie der Pflanzenstoffe, XVII. Synthesen und Reaktionen Amino-substituierter Flavonoide. Liebigs Annalen der Chemie, 693, 216-224. http://dx.doi.org/10.1002/jlac.19666930123

[206] Seikel, M.K., Lounsbury, M.J. and Wang, S.C. (1962) Identification of a 3-Benzylideneflavanone as a By-Product of a Chalcone Synthesis. The Journal of Organic Chemistry, 27, 2952-2954. http://dx.doi.org/10.1021/jo01055a528

[207] Shah, P.R. and Shah, N.M. (1964) Untersuchungen über Chalkone. Kondensation von Chinacetophenen mit Benzaldehyd. Chemische Berichte, 97, 1453-1457. http://dx.doi.org/10.1002/cber.19640970531

[208] Dhara, M.G., Mallik, U.K. and Mallik, A.K. (1996) Alkali-Catalysed Condensation of Flavanones and Aromatic Aldehydes: Synthesis of E-3-Arylideneflavanones and Related Compounds. Indian Journal of Chemistry Section B, 35, 1214-1217.

[209] Lévai, A. and Hetey, E.H. (1978) A Simple Convenient Synthesis of 3-Benzylideneflavanones. Pharmazie, 33, 378379.

[210] Lévai, A. and Szabó, Z. (1992) Journal of Chemical Research(S), 380.

[211] Sosnovskikh, V.Y., Irgashev, R.A. and Kodess, M.I. (2008) One-Pot Three-Component Reaction of 3-(Polyfluoroacyl)chromones with Active Methylene Compounds and Ammonium Acetate: Regioselective Synthesis of Novel RF-Containing Nicotinic Acid Derivatives. Tetrahedron, 64, 2997-3004. http://dx.doi.org/10.1016/j.tet.2008.01.076

[212] von Auwers, K. and Arndt, F. (1909) Umwandlung von Thiophenoläthern in Thioflavanon-Derivate. Berichte der deutschen chemischen Gesellschaft, 42, 2706-2712. http://dx.doi.org/10.1002/cber.190904202190

[213] Beirne, J.J. and O’Sullivan, W.I. (1977) The Preparation, Configuration and Conformation of 3-Arylmethylenethioflavanone Epoxides. Proceedings of the Royal Irish Academy. Section B: Biological, Geological, and Chemical Science, 77, 337-342.

[214] Lévai, A., Szöllősy, Á. and Tóth, G. (1991) Acta Chimica Academiae Scientiarum Hungaricae, 128, 359.

[215] Lévai, A. and Szabó, Z. (1991) Bulletin de la Societe Chimique de France, 128, 976.

[216] Kovacs, J. (2002) Structure Elucidation of Natural Steroid-Glycosides and Products of 3-Arylidene-1-thioflavan-4-one Oxidation by NMR Methods, Ph.D. Dissertation, Budapest University of Technology and Economics Institute for General and Analytical Chemistry, Budapest.

[217] Li, Y., Yang, Z.S., Zhang, H., Cao, B.J. and Wang, F.D. (2003) Artemisinin Derivatives Bearing Mannich Base Group: Synthesis and Antimalarial Activity. Bioorganic \& Medicinal Chemistry, 11, 4363-4368. http://dx.doi.org/10.1016/S0968-0896(03)00499-1

[218] Villar, R., Encio, I., Migliaccio, M., Gil, M.G. and Martinez-Merino, V. (2004) Synthesis and Cytotoxic Activity of Lipophilic Sulphonamide Derivatives of the Benzo[b]thiophene-1,1-dioxide. Bioorganic \& Medicinal Chemistry, 12, 963-968. http://dx.doi.org/10.1016/j.bmc.2003.12.012

[219] Venugopal, K.N. and Jayashree, B.S. (2008) Microwave-Induced Synthesis of Schiff Bases of Bromocoumarins as Antibacterials. Indian Journal of Pharmaceutical Sciences, 70, 88-91. http://dx.doi.org/10.4103/0250-474X.40338

[220] Pandey, S.N., Lakshmi, V.S. and Pandey, A. (2003) Biological Activity of Mannich Bases. Indian Journal of Pharmaceutical Sciences, 65, 213-222.

[221] Bhat, M.A., Imran, M., Khan, S.A. and Yeole, P.G. (2009) Synthesis and Biological Evaluation of Schiff Base of Dapsone and Their Derivative as Antimicrobial Agents. International Journal of PharmTech Research, 1, 22-23.

[222] Santosh, K., Niranjan, M.S., Chaluvaraju, K.C., Jamakhandi, C.M. and Dayanand, K. (2010) Synthesis and Antimicrobial Study of Some Schiff Bases of Sulfonamides. Journal of Current Pharmaceutical Research, 1, 39-42.

[223] Karthikeyan, M.S., Prasad, D.J., Subrahmanya, B.P., Bhat, K. and Holla, B.Sh. (2006) Synthesis and Biological Activity of Schiff and Mannich Bases Bearing 2,4-Dichloro-5-Fluorophenyl Moiety. Bioorganic \& Medicinal Chemistry, 14, 7482-7489. http://dx.doi.org/10.1016/j.bmc.2006.07.015

[224] Jiang, Y., Zhou, X., Hu, W., Wu, L. and Mi, A. (1995) Asymmetric Synthesis XXVII: Asymmetric Catalytic Trimethylsilylcyanation of Aldehydes by Novel Ti-Chiral Schiff Base Complexes. Tetrahedron: Asymmetry, 6, 2915-2916. http://dx.doi.org/10.1016/0957-4166(95)00385-1

[225] Jarrahpour, A.A. and Rezaei, S. (2006) Synthesis of N,N'-Bis (a-methylsalicylidene) 4,4'-Diaminodiphenylmethane as a Novel Complexing Agent. Molbank, 2006, M456.

[226] Bell, S.C., Conklin, G.L. and Childress, S.J. (1963) The Separation of Ketimine Isomers. Journal of the American Chemical Society, 85, 2868-2869. http://dx.doi.org/10.1021/ja00901a057

[227] Munir, C., Yousaf, S.M. and Ahmad, N. (1985) Journal of the Chemical Society of Pakistan, 7, 301.

[228] Abdel-Magid, A.F., Carson, K.G. and Harris, B.D. (1996) Reductive Amination of Aldehydes and Ketones with Sodium Triacetoxyborohydride. Studies on Direct and Indirect Reductive Amination Procedures. The Journal of Organic Chemistry, 61, 3849-3862. http://dx.doi.org/10.1021/j0960057x 
[229] Raman, N., Raja, J.D. and Sakthivel, A. (2007) Synthesis, Spectral Characterization of Schiff Base Transition Metal Complexes: DNA Cleavage and Antimicrobial Activity Studies. Journal of Chemical Sciences, 119, 303-310. http://dx.doi.org/10.1007/s12039-007-0041-5

[230] Mekheimer, R.A., Abdel Hameed, A.M. and Sadek, K.U. (2008) First Synthesis and Isolation of the E- and Z-Isomers of Some New Schiff Bases. Reactions of 6-Azido-5-formyl-2-pyridone with Aromatic Amines. Molecules, 13, 195203. http://dx.doi.org/10.3390/molecules13010195

[231] Asiri, A.M. and Badahdah, Kh.O. (2007) Synthesis of Some New Anils: Part 1. Reaction of 2-Hydroxy-Benzaldehyde and 2-Hydroxynaphthaldehyde with 2-Aminopyridene and 2-Aminopyrazine. Molecules, 12, 1796-1804. http://dx.doi.org/10.3390/12081796

[232] Gor, D., Patel, P., Shah, M. and Patel, P.S. (2012) Synthesis and Characterization of 3-(4-\{[(Substituted phenyl)methylene]amino\}phenyl)-6-bromo-2-methylquinazoline-4-one. Journal of Chemical and Pharmaceutical Research, 4, 19471949.

[233] Al-Kahraman, Y.M.S.A., Madkour, H.M.F., Sajid, M., Azim, M.K., Bukhari, I. and Yasinzai, M. (2011) Nematicidal Efficacy of Schiff Bases Derived from Aryl and/or Heteroaryl Carboxaldehydes. World Journal of Chemistry, 6, 19-24.

[234] Sharma, C.S., Gunjan, J.H., Singh, P., Ankalgi, A.D., Ranawat, M.S. and Diwaker, A.K. (2012) Synthesis, Characterization and Biological Evaluation of Some Novel Hydrazones. International Journal of Advance Pharmaceutical and Biological Sciences, 1, 25-30.

[235] Wadher, S.J., Puranik, M.P., Karande, N.A. and Yeole, P.G. (2009) Synthesis and Biological Evaluation of Schiff Base of Dapsone and Their Derivative as Antimicrobial Agents. International Journal of PharmTech Research, 1, 22-23.

[236] Mrunmayee, P.T., Vilasrao, J.K. and Vithal, M.K. (2009) Synthesis and Antifungal Activity of Some Azetidinones. International Journal of ChemTech Research, 1, 1194-1199.

[237] Shreenivas, M.T., Chetan, B.P. and Bhat, A.R. (2009) Synthesis and Pharmacological Evaluation of Certain Schiff Bases and Thiazoldine Derivatives as AT1 Angiotension-II (AII) Receptor Antagonists. Journal of Pharmaceutical Science and Technology, 1, 88-94.

[238] Yang, Z. and Sun, P. (2006) Compare of Three Ways of Synthesis of Simple Schiff Base. Molbank, 2006, M514.

[239] Patil, S., Jadhav, S.D. and Patil, U.P. (2012) Natural Acid Catalyzed Synthesis of Schiff Base under Solvent-Free Condition: As a Green Approach. Archives of Applied Science Research, 4, 1074-1078.

[240] Akbar, M., Naser, F. and Mehdi, K. (2010) An Efficient Synthesis of Schiff Bases Containing Benzimidazole Moiety Catalyzed by Transition Metal Nitrates. Turkish Journal of Chemistry, 34, 367-373.

[241] Devidas, Sh.M., Quadri, Sh.H., Kamble, S.A., Syed, F.M. and Vyavhare, D.Y. (2011) Novel One-Pot Synthesis of Schiff Base Compounds Derived from Different Diamine \& Aromatic Aldehyde Catalyzed by $\mathrm{P}_{2} \mathrm{O}_{5} / \mathrm{SiO}_{2}$ under FreeSolvent Condition at Room Temperature. Journal of Chemical and Pharmaceutical Research, 3, 489-495.

[242] Bhagat, S., Sharma, N. and Chundawat, T.S. (2013) Synthesis of Some Salicylaldehyde Based Schiff Bases in Aqueous Media. Journal of Chemistry, 2013, Article ID: 909217. http://dx.doi.org/10.1155/2013/909217

[243] Schiff, H. (1864) Mittheilungen aus dem Universitätslaboratorium in Pisa: Eine neue Reihe organischer Basen. Justus Liebigs Annalen der Chemie, 131, 118-119. http://dx.doi.org/10.1002/jlac.18641310113

[244] Moffett, R.B. and Rabjohn, N. (1963) Organic Synthesis. Vol. 4, John Wiley \& Sons, Inc., New York, 605.

[245] Taguchi, K. and Westheimer, F.H. (1971) Catalysis by Molecular Sieves in the Preparation of Ketimines and Enamines. The Journal of Organic Chemistry, 36, 1570-1752. http://dx.doi.org/10.1021/jo00810a033

[246] Kuehne, M.E. (1959) The Applications of Enamines to a New Synthesis of $\beta$-Ketonitriles. Journal of the American Chemical Society, 81, 5400-5404. http://dx.doi.org/10.1021/ja01529a037

[247] Love, B.E. and Ren, J. (1993) Synthesis of Sterically Hindered Imines. The Journal of Organic Chemistry, 58, 55565557. http://dx.doi.org/10.1021/j000072a051

[248] Look, G.C., Murphy, M.M., Campbell, D.A. and Gallop, M.A. (1995) Trimethylorthoformate: A Mild and Effective Dehydrating Reagent for Solvation and Solid Phase Imine Formation. Tetrahedron Letters, 36, 2937-2940. http://dx.doi.org/10.1016/0040-4039(95)00442-F

[249] Vaas, R.S., Dudás, J. and Varma, R.S. (1999) Solvent-Free Synthesis of $N$-Sulfonylimines Using Microwave Irradiation. Tetrahedron Letters, 40, 4951-4954. http://dx.doi.org/10.1016/S0040-4039(99)00867-9

[250] Billman, J.H. and Tai, K.M.J. (1958) Reduction of Schiff Bases. II. Benzhydrylamines and Structurally Related Compounds. The Journal of Organic Chemistry, 23, 535-539. http://dx.doi.org/10.1021/jo01098a009

[251] White, W.A. and Weingarten, H. (1967) A versatile New Enamine Synthesis. The Journal of Organic Chemistry, 32, 213-214. http://dx.doi.org/10.1021/jo01277a052

[252] Texier-Boullet, F. (1985) A Simple, Convenient and Mild Synthesis of Imines on Alumina Surface without Solvent. 
Synthesis, 1985, 679-681. http://dx.doi.org/10.1055/s-1985-31308

[253] Naeimi, H., Salimi, F. and Rabiei, K. (2006) Mild and Convenient One Pot Synthesis of Schiff Bases in the Presence of $\mathrm{P}_{2} \mathrm{O}_{5} / \mathrm{Al}_{2} \mathrm{O}_{3}$ as New Catalyst under Solvent-Free Conditions. Journal of Molecular Catalysis A: Chemical, 260, 100104. http://dx.doi.org/10.1016/j.molcata.2006.06.055

[254] Zhu, J., Chen, L., Wu, H. and Yang, J. (2009) Highly Efficient Procedure for the Synthesis of Schiff Bases Using Hydrotalcite-Like Materials as Catalyst. Chinese Journal of Chemistry, 27, 1868-1870. http://dx.doi.org/10.1002/cjoc.200990313

[255] Katritzky, A.R. and Rees (1984) Comprehensive Heterocyclic Chemistry. 1st Edition, Vol. 5, Pergamon Press, New York, 278.

[256] Krein, E.B. and Aizenshat, Z. (1993) Phase-Transfer-Catalyzed Reactions between Polysulfide Anions and Alpha, Beta-Unsaturated Carbonyl Compounds. The Journal of Organic Chemistry, 58, 6103-6108. http://dx.doi.org/10.1021/jo00074a043

[257] Parikh, V.M. (1974) Absorption Spectroscopy of Organic Molecules. Addison-Wesley Publishing Company, Menlo Park, 324.

[258] Said, S.A. (2006) Raf. Jour. Sci., 17, 5.

[259] Abdel-Rahman, R.M. (1986) Selective Reactions with 3-Chloro-5,6-diphenyl-1,2,4-triazine. Communications de la Faculté des Sciences de l'Université d'Ankara Series B, 32, 87-88.

[260] Seada, M., Fawzy, M.M. and Jahine, H. (1989) Synthesis and Biological Activities of Some New Pyridazine Derivatives. Journal of the Chinese Chemical Society, 36, 241-249.

[261] Vicini, P., Gerenikaki, A., Anastasia, K., Incertia, M. and Zania, F. (2006) Synthesis and Antimicrobial Activity of Novel 2-Thiazolylimino-5-arylidene-4-thiazolidinones. Bioorganic \& Medicinal Chemistry, 14, 3859-3864. http://dx.doi.org/10.1016/j.bmc.2006.01.043

[262] Al-Omar, M.A., El-Azab, A.S., El-Obeid, H.A. and Abdel Hamide, S.G. (2006) Synthesis of Some New 4-(3H)-Quinazoline Analogs as Potential Antioxidant Agents. Journal of Saudi Chemical Society, 10, 111-128.

[263] Subramanian, N.S., Omprakash, G., Anjaneyulu, Y., Gupta, V.R.M. and Ramadevi, M. (2009) Synthesis, Characterization and Antimicrobial Screening of Novel Thiazolidino-Fused Compounds. International Journal of Chemical Sciences, 7, 1537-1552.

[264] Kumar, R., Shukla, A. and Tyagi, D.S. (2012) An Efficient Synthesis of Bioactive Azetidinones and Thiazolidinones of 3-Methyl-1-phenyl-1H-pyrazol-5-ol. International Journal of Environmental Research and Public Health, 2, 1-7.

[265] Kumar, V. and Singh, P. (2010) Novel Pyrimidinone Derivative as Potential Promising Antimicrobial Agent. Der Pharma Chemica, 2, 52-62.

[266] Veerabhadraiah, I.U., Rao, V.R. and Rao, T.V.P. (1990) Reaction of Mercaptoacetic Acid and Chloroacetyl Chloride with Benzalamino Thiazolyl Coumarins. Collection of Czechoslovak Chemical Communications, 55, 535-539. http://dx.doi.org/10.1135/cccc19900535

[267] Cherkupally, S.R., Dasari, C.R., Vookanti, Y. and Adki, N. (2010) Synthesis and Antimicrobial Study of Bis-[thiadiazol2-yl-tetrahydro-2H-pyrazolo[3,4-d][1,3]thiazole]methanes. Organic Communications, 3, 57-69.

[268] El Azab, I.H. and Abd El Latif, F.M. (2012) A Simple and Convenient Synthesis of Isolated-Fused Heterocycles Based on: 2-Imino- $N$-phenyl-2H-chromene-3-carboxamide. Open Journal of Synthesis Theory and Applications, 1, 44-57. http://dx.doi.org/10.4236/ojsta.2012.13008

[269] Desai, K.R. and Mistry, K. (2006) Microwave Assisted Synthesis of Nitrogen and Sulphur Containing Heterocyclic Compounds and Their Pharmacological Evaluation. Indian Journal of Chemistry, 45B, 1762-1766.

[270] Patel, T.M. and Patel, A.M. (2012) Synthesis and Antimicrobial Activity of Newly Azetidinone Derivatives. Der Pharmacia Lettre, 4, 579-583.

[271] Ali, P., Meshram, J. and Tiwari, V. (2010) Microwave Mediated Cyclocondensation of 2-Aminothiazole into $\beta$-Lactam Derivatives: Virtual Screening and in Vitro Antimicrobial Activity with Various Microorganisms. International Journal of ChemTech Research, 2, 956-964.

[272] Patel, T.M. and Patel, A.M. (2012) Study of Novel Pyrrole Derivatives. International Journal of Pharmaceutical Research and Allied Sciences, 1, 36-39.

[273] Parmar, K., Sutariya, Sh., Shukla, M. and Goswami, K. (2012) Synthesis and Antimicrobial Activity of Substituted $2 \mathrm{H}$-pyrrole-2-ones Derivatives Based on 1- $\mathrm{N}$-Phenyl-3-phenyl-4-formyl pyrazole (PFP). Journal of Chemical and Pharmaceutical Research, 4, 3478-3482.

[274] Al-Bayati, R.I., Al-Amiery, A.A.H. and Al-Majedy, Y.K. (2010) Design, Synthesis and Bioassay of Novel Coumarins. African Journal of Pure and Applied Chemistry, 4, 74-86.

[275] Al-Bayati, R.I., Al-Amiery, A.A.H. and Al-Majedy, Y.K. (2010) Novel Quinazolinone Derivatives: Synthesis and An- 
timicrobial (No Journal). 14th International Electronic Conference on Synthetic Organic Chemistry (ECSOC-14). http://www.Sciforum.net\&http://www.usc.es/congresos/ecsoc1-30

[276] Jones, G. (1967) Organic Reactions. Vol. XV, Wiley, New York, 204.

[277] Moison, H., Texier-Boullet, F. and Foucaud, A. (1987) Knoevenagel, Wittig-Horner Reactions in the Presence of Magnesium Oxide or Zinc Oxide. Tetrahedron, 43, 537-542. http://dx.doi.org/10.1016/S0040-4020(01)89986-5

[278] Gupta, M., Gupta, R. and Anand, M. (2009) Hydroxyapatite Caesium Carbonate as a New Recyclable Solid Base Catalyst for the Knoevenagel Condensation in Water. Beilstein Journal of Organic Chemistry, 5, 7 p.

[279] Sheibani, H. and Saljoogi, A.S. (2012) Regioselective Reactions of 3-Alkyl-1-phenyl-2-pyrazolin-5-ones with Acyl Halides in the Presence of Nonosized Magnesium Hydroxide as a Highly Effective Heterogenous Base Catalyst. Heterocyclic Letters, 2, 389.

[280] Lehnert, W. (1974) Knoevenagel-Kondensation Mit TiCl $/$ Base-V, 3-Alkyliden-und-3-Aryliden-2,4-Pentandione aus Aldehyden und Acetylaceton. Synthesis, 1974, 667-669. http://dx.doi.org/10.1055/s-1974-23400

[281] Rao, P.S. and Venkataratnam, R.V. (1991) Zinc Chloride as a New Catalyst for Knoevenagel Condensation. Tetrahedron Letters, 32, 5821-5822. http://dx.doi.org/10.1016/S0040-4039(00)93564-0

[282] Cabello, J.A., Campelo, J.M., Garica, A., Luna, D. and Marinas, J.M. (1984) Knoevenagel Condensation in Heterogeneous Phase Using $\mathrm{AlPO}_{4}-\mathrm{Al}_{2} \mathrm{O}_{3}$ as a New Catalyst. The Journal of Organic Chemistry, 49, 5195-5197. http://dx.doi.org/10.1021/jo00200a036

[283] Angeletti, E., Canepa, C., Martinetti, G. and Venturello, P. (1988) Silica Gel Functionalized with Amino Groups for Knoevenagel Condensation under Heterogeneous Catalysis Conditions. Tetrahedron Letters, 29, 2261-2264. http://dx.doi.org/10.1016/S0040-4039(00)86727-1

[284] Zheng, G.-Z., Lee, Ch.-H., Pratt, J. K., Perner, R.J., Jiang, M.Q., Gomtsyan, A., Matulenko, M.A., Mao, Y., Koenig, J. R., Kim, K.H., Muchmore, S., Yu, H., Kohlhaas, K., Alexander, K.M., McGaraughty, S., Chu, K.L., Wismer, C.T., Mikusa, J., Jarvis, M.F., Marsh, K., Kowaluk, E.A., Bhagwat, Sh.S. and Stewart, A.O. (2001) Pyridopyrimidine Analogues as Novel Adenosine Kinase Inhibitors. Bioorganic \& Medicinal Chemistry Letters, 11, 2071-2074. http://dx.doi.org/10.1016/S0960-894X(01)00375-4

[285] Cao, Y.Q., Dai, Z., Zhang, R. and Chen, B.H. (2004) A Practical Knoevenagel Condensation Catalyzed by PEG400 and Anhydrous $\mathrm{K}_{2} \mathrm{CO}_{3}$ without Solvent. Synthetic Communications, 34, 2965-2971. http://dx.doi.org/10.1081/SCC-200026650

[286] Warea, M., Madjeb, B., Pokalwara, R., Kakadea, G. and Shingarea, M. (2007) DBU: An Efficient Catalyst for Knoevenagel Condensation under Solvent-Free Condition. Bulletin of the Catalysis Society of India, 6, 104-106.

[287] Heravi, M.M., Bakhtiari, Kh., Taheri, Sh. and Oskooie, H.A. (2007) A Straightforward Method for the Synthesis of Functionalized Trisubstituted Alkenes through $\mathrm{Na}_{2} \mathrm{~S}_{/} \mathrm{Al}_{2} \mathrm{O}_{3}$ Catalyzed Knoevenagel Condensation. Journal of the Chinese Chemical Society, 54, 1557-1560.

[288] Gupta, R., Gupta, M., Paul, S. and Gupta, R. (2009) Silica Supported Ammonium Acetate: An Efficient and Recyclable Heterogeneous Catalyst for Knoevenagel Condensation between Aldehydes or Ketones and Active Methylene Group in Liquid Phase. Bulletin of the Korean Chemical Society, 30, 2419-2421. http://dx.doi.org/10.5012/bkcs.2009.30.10.2419

[289] Sheibani, H., Seifi, M. and Bazgir, A. (2009) Three-Component Synthesis of Pyrimidine and Pyrimidinone Derivatives in the Presence of High-Surface-Area MgO, a Highly Effective Heterogeneous Base Catalyst. Synthetic Communications , 39, 1055-1064. http://dx.doi.org/10.1080/00397910802474982

[290] Bigi, F., Conforti, M. L., Maggi, R., Piccinno, A. and Sartori, G. (2000) Clean Synthesis in Water: Uncatalysed Preparation of Ylidenemalononitriles. Green Chemistry , 2, 101-103. http://dx.doi.org/10.1039/b001246g

[291] Surpur, M.P., Kshirsagar, S. and Samant, Sh.D. (2009) Exploitation of the Catalytic Efficacy of Mg/Al Hydrotalcite for the Rapid Synthesis of 2-Aminochromene Derivatives via a Multicomponent Strategy in the Presence of Microwaves. Tetrahedron Letters, 50, 719-722. http://dx.doi.org/10.1016/j.tetlet.2008.11.114

[292] Khalil, Kh., Al-Matar, H. and Elnagdi, M. (2010) Chitosan as an Eco-Friendly Heterogeneous Catalyst for Michael type Addition Reactions. A Simple and Efficient Route to Pyridones and Phthalazines. European Journal of Chemistry, 1, 252-258. http://dx.doi.org/10.5155/eurjchem.1.4.252-258.211

[293] Weiner, C., Liden, N.J. and Schroeder, C.H. (1963) Warfarin Intermediates. US Patent No. 3097213.

[294] Shestopalov, A.A., Rodinovskaya, L.A., Shestopalov, A.M. and Litvinov, V.P. (2004) Cross Reactions of Cyanoacetic Acid Derivatives with Carbonyl Compounds 3. One-Step Synthesis of Substituted 2-Amino-5-oxo-4,5-dihydropyrano[3,2-c]chromenes. Russian Chemical Bulletin, 54, 992-996. http://dx.doi.org/10.1007/s11172-005-0346-9

[295] Khoobi, M., Alipour, M., Moradi, A., Sakhteman, A., Nadri, H., Razavi, S.F., Ghandi, M., Foroumadi, A. and Shafiee, A. (2013) Design, Synthesis, Biological Evaluation and Docking Study of 5-Oxo-4,5-dihydropyrano[3,2-c]chromene 
Derivatives as Acetylcholinesterase and Butyrylcholinesterase Inhibitors. European Journal of Medicinal Chemistry, 68, 260-269. http://dx.doi.org/10.1016/j.ejmech.2013.07.038

[296] Sharanin, Y.A., Goncharenko, M.P. and Litvinov, V.P. (1998) Reactions of Carbonyl Compounds with $\alpha, \beta$-Unsaturated Nitriles as a Convenient Pathway to Carbo- and Heterocycles. Russian Chemical Reviews, 67, 393. http://dx.doi.org/10.1070/RC1998v067n05ABEH000371

[297] Shestopalov, A.M. and Emeliyanova, Y.M. (2003) In: Kartsev, V.G., Ed., Selected Methods for Synthesis and Modification of Heterocycles, Vol. 2, IBS, Moscow, 363.

[298] O’Neil, V.J. (2001) The Merck Index. Merck and Co., Inc., Whitehouse Station, New York, 1818.

[299] El-Gemei, G.E.H., Elecs, S.A., El-Sakka, I. and El-Nagdy, M.H. (1983) Zeitschrift für Naturforschung, 38b, 639-642.

[300] Sowellim, S.Z.A., El-Taweel, F.M.A. and El-Agamey, A.A. (1996) Bulletin de la Société Chimique de France, 133, 229.

[301] Tu, S., Jiang, B., Jiang, H., Zhang, Y., Jia, R., Zhang, J., Shao, Q., Li, Ch., Zhou, D. and Cao, L. (2007) A Novel Three-Component Reaction for the Synthesis of New 4-Azafluorenone Derivatives. Tetrahedron, 63, 5406-5414. http://dx.doi.org/10.1016/j.tet.2007.04.053

[302] Li, M., Qiu, Z.-X., Wen, L.-R. and Zhou, Z.-M. (2011) Novel Regio- and Stereo-Selectivity: Synthesis of Dihydropyrrolo[1,2-f]Phenanthridines via Isocyanide-Based Multicomponent Reaction. Tetrahedron, 67, 3638-3648. http://dx.doi.org/10.1016/j.tet.2011.03.085

[303] Mohammed, F.K., Soliman, A.Y., Ssawy, A. and Badre, M.G. (2009) 2-Amino-7-hydroxy-4-phenyl-5-methyl-4Hchromeno-3-carbonitrile as a Key Precursor for the Synthesis of Several Chromene Based Heterocyclic Systems. Journal of Chemical and Pharmaceutical Research, 1, 213-224.

[304] Lichitsky, B.V., Dudinov, A.A. and Krayushkin, M.M. (2001) Reaction of 3-Aminocyclohex-2-en-1-ones with Arylidenemalononitriles: Synthesis of $N$-Substituted 1,4,5,6,7,8-hexahydroquinolin-5-ones. ARKIVOC, ix, 73-79.

[305] Midorikawa, H., Kambe, S., Saito, K. and Sakurai, A. (1981) Synthetic Studies Using $\alpha, \beta$-Unsaturated Nitriles: Facile Synthesis of Pyridine Derivatives. Synthesis, 1981, 531-532.

[306] Sharanin, Y.A., Goncharenko, M.P. and Litvinov, V.P. (1998) Reactions of Carbonyl Compounds with $\alpha, \beta$-Unsaturated Nitriles as a Convenient Pathway to Carbo- and Heterocycles. Russian Chemical Reviews, 67, 393. http://dx.doi.org/10.1070/RC1998v067n05ABEH000371

[307] Aziz, S.I., Riad, B.Y., Alfahham, H.A. and Elnagdi, M.H. (1982) Activated Nitriles in Heterocyclic Synthesis: A Novel Synthesis of Pyrazolo[5,6:3',4']pyrano[5,4-b]isoxazoles. Heterocycles, 19, 2251-2254. http://dx.doi.org/10.3987/R-1982-12-2251

[308] Ibrahim, M.K.A., Elmoghayer, M.R.H. and Sharaf, M. (1987) Indian Journal of Chemistry, 26B, 216-219.

[309] Zayed, E.M., Khalifa, M.A.E. and Mohamed, M.H. (1983) Symposium on Malononitrile and Other Reactive MalonoSynthons, Cairo, 7 April 1987, 79.

[310] Daboun, H.A.F., Abdou, S.E., Hussein, M.. and El-Elnagdi, M.H. (1982) Activated Nitriles in Heterocyclic Synthesis: Novel Syntheses of Pyrrolo[1,2-c]imidazole and pyrano[2,3- $d$ ]imidazole Derivatives. Synthesis, 1982, 502-504. http://dx.doi.org/10.1055/s-1982-29857

[311] Abdel Hafiz, I.S., Ramiz, M.M.M. and Elian, M.A. (2012) Activated Anilide in Heterocyclic Synthesis: Synthesis of New Hydrazo, Dihydropyridazine, Tetrahydropyridine, Dihydropyridine and Pyranopyridine Derivatives. Journal of Chemical Sciences, 124, 647-655. http://dx.doi.org/10.1007/s12039-012-0259-8

[312] Abdelghani, E., Shehab, W.S., El-Mobayed, M. and Abdel Hamid, A.M. (2012) Synthesis and Electrochemical Behavior of Some New Pyridazine Derivatives. International Journal of Basic and Applied Sciences, 1, 220-236. http://dx.doi.org/10.14419/ijbas.v1i3.87

[313] Sánchez, A., Hernández, F., Cruz, P.C., Alcaraz, Y., Tamariz, J., Delgado, F. and Vázquez, M.A. (2012) Infrared Irradiation-Assisted Multicomponent Synthesis of 2-Amino-3-cyano-4H-pyran Derivatives. Journal of the Mexican Chemical Society, 56, 121-127.

[314] Tisseh, Z.N., Dabiri, M., Nobahar, M., Khavasi, H.R. and Bazgir, A. (2012) Catalyst-Free, Aqueous and Highly Diastereoselective Synthesis of New 5-Substituted $1 \mathrm{H}$-Tetrazoles via a Multi-Component Domino Knoevenagel Condensation/1,3 Dipolar Cycloaddition Reaction. Tetrahedron, 68, 1769-1773.

http://dx.doi.org/10.1016/j.tet.2011.12.044

[315] Wardakhan, W.W., Sherif, S.M., Mohareb, R.M. and Abouzied, A.S. (2012) The Reaction of Cyanoacetylhdrazine with Furan-2-Aldehyde: Novel Synthesis of Thiophene, Azole, Azine and Coumarin Derivatives and Their Antitumor Evaluation. International Journal of Organic Chemistry, 2, 321-331. http://dx.doi.org/10.4236/ijoc.2012.24044

[316] Elnagdi, M.H., Abed, N.M., El-Moghayer, M.R.H. and Fleita, D.H. (1976) Reactivity of $\alpha$-Cyanochelkones as Michael Acceptors. Indian Journal of Chemistry, 14, 422-424. 
[317] Elnagdi, M.H., Elmoghayer, M.R.H., Hammam, A.G. and Khallaf, S.A. (1979) The Reaction of Malononitrile with Thioglycolic Acid. A Novel Procedure for the Synthesis of Thiazolone Derivatives. Journal of Heterocyclic Chemistry, 16, 1541-1543. http://dx.doi.org/10.1002/jhet.5570160804

[318] Fuentes, L., Soto, J.L. and Vaquero, J.J. (1981) 18th International Congress in Heterocyclic Chemistry, Graz, 33.

[319] Fahmy, S.M., Sadek, K.U., Mohareb, R.M. and Elnagdi, M.H. (1983) Symposium on Malononitrile and Other Reactive Malono-Synthons. Cairo, 7 April 1983, 55.

[320] Fahmy, S.M., Abed, N.M., Mohareb, R.M. and Elnagdi, M.H. (1982) Activated Nitriles in Heterocyclic Synthesis: Novel Synthesis of Pyridazines, Pyridines, and Isoxazoles. Synthesis, 1982, 490-493. http://dx.doi.org/10.1055/s-1982-29850

[321] EL-mahdy, K.M., El-Kazak, A.M., Abdel-Megid, M., Seada, M. and Farouka, O. (2013) Journal of Advances in Chemistry, 5, 581.

[322] Attia, A.M.E., El-Hamid, A. and Ismail, A.A. (2003) An Approach to Acyclo-3-Deazapyrimidine S-Nucleosides via 3,5-Dicyano-2(1H)-pyridinethiones. Tetrahedron, 59, 1749-1752. http://dx.doi.org/10.1016/S0040-4020(03)00113-3

[323] Afzal, J., Vairdmani, M., Hazara, B. and Das, K. (1980) A Novel Thermal Knoevenacel Condensation via a Thermal Michael Reaction. Synthetic Communications, 10, 843-850. http://dx.doi.org/10.1080/00397918008062767

[324] Allen, C.F. and Spangler, F.W. (1955) $\alpha, \beta$-Unsaturated Malonates. Organic Syntheses, Coll., 3, 377.

[325] Fones, W.S. (1967) Organic Syntheses, Coll., Vol. IV, 2nd Edition, 293.

[326] Zabicky, J. (1961) The Kinetics and Mechanism of Carbonyl-Methylene Condensation Reactions. Part XI. Stereochemistry of the Products. Journal of the Chemical Society, 683-687. http://dx.doi.org/10.1039/jr9610000683

[327] Gullu, M. and Utly, J.H.P. (1999) A New Class of Pyridopyrimidine Derivatives: Furo[2,3-d]pyrido[1,2-a]pyrimidines. Communications de la Faculté des Sciences de l'Université d'Ankara Series B, 45, 93-99.

[328] Meskini, I., Toupet, L., Daoudi, M., Kerbal, A., Bennani, B., Dixneuf, P.H., Chohan, Z.H., Leite, A.C.L. and Hadda, T.B. (2010) An Efficient Protocol for Accessing $\beta$-Amino Dicarbonyl Compounds through Aza-Michael Reaction. Journal of the Brazilian Chemical Society, 21, S1-S18. http://dx.doi.org/10.1590/S0103-50532010000600025

[329] Magd-El-Din, A.A., Abd-El-All, A.S., Abdel-Rhaman, A.H. and El-Baroudyl, M.M.S. (2010) Antitumor and Synthesis of Furochromenyl Pyrazoles, and Thiosemicarbazide Derivatives. Nature and Science, 8, 12-22.

[330] Harjani, J.R., Nara, S.J. and Salunkhe, M.M. (2002) An Intramolecular Pauson-Khand Approach to the Synthesis of Chiral Cyclopentadienes. Tetrahedron Letters, 43, 1127-1129. http://dx.doi.org/10.1016/S0040-4039(01)02341-3

[331] Jing, L., Hong-Liang, C., Lei, L. and Bin, F. (2010) Synthesis of New $C_{2}$-Symmetric Fluoren-9-Ylidene Malonate Derived Bis(Oxazoline) Ligands and Their Application in Friedel-Crafts Reactions. Molecules, 15, 8582-8592. http://dx.doi.org/10.3390/molecules15128582

[332] Sheldrick, G.M. (1997) SHELXS 97, Program for X-Ray Crystal Structure Solution and Refinement. University of Gottingen, Gottingen.

[333] Bottex, M., Cavicchioli, M., Hartmann, B., Monteiro, N. and Balme, G. (2001) A Versatile Palladium-Mediated ThreeComponent Reactions of the One-Pot Synthesis of Stereodefined 3-Arylidene-(or 3-alkenylidene-)tetrahydrofurans. The Journal of Organic Chemistry, 66, 175-179. http://dx.doi.org/10.1021/jo0012997

[334] Nakamura, M., Liang, C. and Nakamura, E. (2004) Zn(II)/Amine-Catalyzed Coupling Reaction of Alkylidenemalonates WIth Propargyl Alcohol: A One-Pot Synthesis of Methylenetetrahydrofurans. Organic Letters, 6, 2015-2017. http://dx.doi.org/10.1021/ol0493554

[335] Zhong, H.-Y., Wang, T.-T., Zhang, Y.-K., Chen, H., Lv, Z.-L., Zhang, M.-F., Geng, D.-P., Niu, C.-J. and Li, K. (2011) Synthesis, Crystal Structure and Anti-Tumor Activity of Ethyl 3-(4-Methoxyphenyl)-4-oxo-3,3a,4,6-tetrahydro-1Hfuro[3,4-c]pyran-3a-carboxylate. Chinese Journal of Structurnal Chemistry, 30, 1737-1741.

[336] Deb, M.L. and Bhuyan, P.J. (2005) Uncatalysed Knoevenagel Condensation in Aqueous Medium at Room Temperature. Tetrahedron Letters, 46, 6453-6456. http://dx.doi.org/10.1016/j.tetlet.2005.07.111

[337] Mohamed, Sh.K., Abdelhamid, A.A., Maharramov, A.M., Khalilov, A.N., Gurbanovb, A.V. and Allahverdiev, M.A. (2012) Trizma: Efficient Catalyst and Reactant in Knoevenagel Condensation Reaction under Conventional Heat and Microwave Irradiation Conditions. Journal of Chemical and Pharmaceutical Research, 4, 1787-1793.

[338] Abaee, M.S., Mojtahedi, M.M., Zahedi, M.M. and Khanalizadeh, G. (2006) Efficient $\mathrm{MgBr}_{2}$.OEt $\mathrm{OE}_{2}$-Catalyzed Knoevenagel condensation. ARKIVOC, xv, 48-52. http://dx.doi.org/10.3998/ark.5550190.0007.f06

[339] Kalbasi, R.J., Kolahdoozan, M., Massah, A. and Shahabian, K. (2010) Synthesis, Characterization and Application of Poly(4-methyl vinylpyridinium hydroxide)/SBA-15 Composite as a Highly Active Heterogeneous Basic Catalyst for the Knoevenagel Reaction. Bulletin of the Korean Chemical Society, 31, 2618-2626.

http://dx.doi.org/10.5012/bkcs.2010.31.9.2618 
[340] Ilangovan, A., Muralidharan, S. and Maruthamuthu, S. (2011) A Systematic Study on Knoevenagel Reaction and Nazarov Cyclization of Less Reactive Carbonyl Compounds Using Rare Earth Triflates and Its Applications. Journal of the Korean Chemical Society, 55, 1000-1006. http://dx.doi.org/10.5012/jkcs.2011.55.6.1000

[341] Kim, S.-Y., Kwon, P.-S., Kwon, T.-W., Chung, S.-K. and Chang, Y.-T. (1997) Microwave Enhanced Knoevenagel Condensation of Ethyl Cyanoacetate with Aldehydes. Synthetic Communications, 27, 533-541. http://dx.doi.org/10.1080/00397919708003323

[342] El-Moghayer, M.R.H., El-Agamey, A.G.A., Abel, N.M. and Ibrahim, M.K.A. (1985) Anales de Química, 81, 236.

[343] Daboun, H.A. and El-Reedy, A.M. (1983) Symposium on Malononitrile and Other Reactive Malono-Synthons, Cairo, 7 April 1983, 85.

[344] Elnagdi, M.H., Elfahham, H.A. and Elgemeie, G.E. (1983) Utility of $\alpha, \beta$-Unsaturated Nitrirles in Heterocyclic Synthesis. Heterocycles, 20, 519-550. http://dx.doi.org/10.3987/R-1983-03-0519

[345] Fuentes, L., Soto, J.L. and Vaquero, J.J. (1981) 18th International Congress in Heterocyclic Chemistry, Graz, 33.

[346] Kaupp, G., Naimi-Jamal, M.R. and Schmeyers, J. (2003) Solvent-Free Knoevenagel Condensations and Michael Additions in the Solid State and in the Melt with Quantitative Yield. Tetrahedron, 59, 3753-3760. http://dx.doi.org/10.1016/S0040-4020(03)00554-4

[347] Shi, D.Q., Chen, J., Zhuang, Q.Y., Wang, X.Sh. and Hu, H.W. (2003) The Condensation of Aromatic Aldehydes with Acidic Methylene Compounds in Water. Chinese Chemical Letters, 14, 1242-1245.

[348] Ware, M., Madje, B., Pokalwar, R., Kakade, G. and Shingare, M. (2007) DBU: An Efficient Catalyst for Knoevenagel Condensation under Solvent Free Condition. Bulletin of the Catalysis Society of India, 6, 104-106.

[349] El-Rady, E.A. and Khalil, M.A. (2004) 2-Cyanoacetamide in the Synthesis of Heterocyclic Compounds: Synthesis of New Polysubstituted Pyrazole, Pyridine and Pyrimidine Derivatives. Journal of the Chinese Chemical Society, 51, 779784.

[350] Bojarski, J.T., Mokrosz, J.L., Borton, H.J. and Paluchowska, M.H. (1985) Recent Progress in Barbituric Acid Chemistry. Advances in Heterocyclic Chemistry, 38, 229-297. http://dx.doi.org/10.1016/S0065-2725(08)60921-6

[351] Tietze, L.F. and Bartels, C. (1991) Inter- and Intramolecular Hetero-Diels-Alder Reactions, 32. Iridoids, 26. Synthesis of Bridged Homoiridoids from Secologanin by Tandem-Knoevenagel-Hetero-Diels-Alder Reactions. Liebigs Annalen der Chemie, 1991, 155-160. http://dx.doi.org/10.1002/jlac.199119910128

[352] Tanaka, K., Chen, X., Kimura, T. and Yoneda, F. (1987) Oxidation of Thiol by 5-Arylidene 1,3-dimethylbarbituric Acid and Its Application to Synthesis of Unsymmetrical Disulfide. Tetrahedron Letters, 28, 4173-4176. http://dx.doi.org/10.1016/S0040-4039(00)95570-9

[353] Tanaka, K., Chen, X., Kimura, T. and Yoneda, F. (1988) 5-Arylidene 1,3-Dimethylbarbituric Acid Derivatives, Mild Organic Oxidants for Allylic and Benzylic Alcohols. Chemical and Pharmaceutical Bulletin, 36, 60-69. http://dx.doi.org/10.1248/cpb.36.60

[354] Tanaka, K., Chen, X., Kimura, T. and Yoneda, F. (1988) Oxidation of Thiol with 5-Arylidene-1,3-Dimethylbarbituric Acid: Application to Synthesis of Unsymmetrical Disulfide. Tetrahedron, 44, 3241-3249. http://dx.doi.org/10.1016/S0040-4020(01)85957-3

[355] Chaaban, I., Mohsen, A., Omar, M.E. and Maharan, M.A. (1984) Scientia Pharmaceutica, 52.

[356] Smith, M.C. and Riskin, B.J. (1991) The Clinical Use of Barbiturates in Neurological Disorders. Drugs, 42, 365-378. http://dx.doi.org/10.2165/00003495-199142030-00003

[357] Yachkov, D., Ivin, A.I., Smorygo, B.A. and Sochilin, N.A.E.G. (1976) Zhurnal Organicheskoi Khimii, $12,1115$.

[358] Villemin, D. and Labiad, B. (1990) Clay Catalysis: Dry Condensation of Barbituric Acid with Aldehydes under Microwave Irradiation. Synthetic Communications, 20, 3333-3337. http://dx.doi.org/10.1080/00397919008051567

[359] Dewan, S.K. and Singh, R. (2003) One Pot Synthesis of Barbiturates on Reaction of Barbituric Acid with Aldehydes Under Microwave Irradiation Using a Variety of Catalysts. Synthetic Communications, 33, 3081-3084. http://dx.doi.org/10.1081/SCC-120022485

[360] Li, J.C., Li, G.S., Wang, C., Zhang, Y.Q., Li, X.L. and Yang, L.H. (2002) Synthesis of 3-Aryl-3-(5,5-dimethyl-3-hydroxyl-cyclohex-2-ene-1-one-2-yl)-propionamide Derivatives Catalyzed by $\mathrm{KF} / \mathrm{Al}_{2} \mathrm{O}_{3}$. Chinese Journal of Organic Chemistry, 22, 905-908.

[361] Alcerreca, G., Sanabria, R., Miranda, R., Arroyo, G., Tamariz, J. and Delgado, F. (2000) Preparation of Benzylidene Barbituric Acids Promoted by Infrared Irradiation in Absence of Solvent. Synthetic Communications, 30, 1295-1301. http://dx.doi.org/10.1080/00397910008087151

[362] Ali, K.-N. and Aboulghasem, H. (2001) Microwave Enhanced Knoevenagel Condensation of Barbituric Acid with Aromatic Aldehydes on Basic Alumina. Iranian Journal of Chemistry and Chemical Engineering, 20, 9-11.

[363] Prajapati, D. and Sandhu, J.S. (1992) Chemistry Letters, 10, 1945. http://dx.doi.org/10.1246/cl.1992.1945 
[364] Reddy, Ch.S., Nagaraj, A. and Jalapathi, P. (2007) A New and Efficient Method for the synthesis of 5-ArylmethylenePyrimidine-2,4,6-Trione under Solvent and Catalyst Free Conditions. Indian Journal of Chemistry, 46B, 660-663.

[365] Khan, K.M., Ali, M., Farooqui, T.A., Khan, M., Taha, M. and Perveen, S. (2009) An Improved Method for the Synthesis of 5-Arylidenebarbiturates Using $\mathrm{BiCl}_{3}$. Journal of the Chemical Society of Pakistan, 31, 823-828.

[366] Bamanie, F.H.A., Shehata, A.S., Moustafa, M.A. and Mashaly, M.M. (2012) Green Chemistry 1: Simple and Efficient Synthesis-In Water-and Antibacterial Activity of 5-Arylidene Derivatives of Thiobarbituric and Barbituric Acids. The Journal of American Science, 8, 481-485.

[367] Thirupathi, G., Venkatanarayana, M., Dubey, P.K. and Bharathi Kumari, Y. (2013) Facile and Green Syntheses of 5-Arylidene-pyrimidine-2,4,6-triones and 5-Arylidene-2-thioxo-dihydro-pyrimidine-4,6-diones Using L-Tyrosine as an Efficient and Eco-Friendly Catalyst in Aqueous Medium. Chemical Science Transactions, 2, 441-446. http://dx.doi.org/10.7598/cst2013.385

[368] Palasz, A. (2012) Synthesis of Fused Uracils: Pyrano[2,3-d]pyrimidines and 1,4-Bis(pyrano[2,3-d]pyrimidinyl)benzenes by Domino Knoevenagel/Diels-Alder Reactions. Monatshefte für Chemie, 143, 1175-1185. http://dx.doi.org/10.1007/s00706-012-0781-x

[369] Chen, B.-C. (1991) Meldrum’s Acid in Orgnaic Synthesis. Heterocycles, 32, 529-597. http://dx.doi.org/10.3987/REV-90-422

[370] Pita, B., Sotelo, E., Suarez, M., Ravina, E., Ochoa, E., Verdecia, Y., Novoa, H., Blaton, N., de Ranter, C. and Peeters, O.M. (2000) Pyridazine Derivatives. Part 21: Synthesis and Structural Study of Novel 4-Aryl-2,5-dioxo-8-phenylpyrido[2,3-d]pyridazines. Tetrahedron, 56, 2473-2479. http://dx.doi.org/10.1016/S0040-4020(00)00082-X

[371] Corey, E.J. (1952) The Mechanism of the Decarboxylation of $\alpha, \beta$ - and $\beta, \gamma$-Unsaturated Malonic Acid Derivatives and the Course of Decarboxylative Condensation Reactions in Pyridine. Journal of the American Chemical Society, 74, 5897-5905. http://dx.doi.org/10.1021/ja01143a021

[372] Kraus, G.A. and Krolski, M.E. (1986) Synthesis of a Precursor to Quassimarin. The Journal of Organic Chemistry, 51, 3347-3350. http://dx.doi.org/10.1021/jo00367a017

[373] Hedge, J.A., Kruse, C.W. and Snyder, H.R. (1961) Some Condensation Reactions of Isopropylidene Malonate. The Journal of Organic Chemistry, 26, 3166-3170. http://dx.doi.org/10.1021/j001067a032

[374] Rao, P.S. and Venkataratnam, R.V. (1993) Indian Journal of Chemistry, 32B, 484-486.

[375] Bigi, F., Carloni, S., Ferrari, L., Maggi, R., Mazzacani, A. and Sartori, G. (2001) Clean Synthesis in Water. Part 2: Uncatalysed Condensation Reaction of Meldrum's Acid and Aldehydes. Tetrahedron Letters, 42, 5203-5205. http://dx.doi.org/10.1016/S0040-4039(01)00978-9

[376] Tahmassebi, D., Wilson, L.J.A. and Kieser, J.M. (2009) Knoevenagel Condensation of Aldehydes with Meldrum's Acid in Ionic Liquids. Synthetic Communications, 39, 2605-2613. http://dx.doi.org/10.1080/00397910802663345

[377] Zemtsov, A.A., Levin, V.V., Dilman, A.D., Struchkova, M.I., Belyakov, P.A. and Tartakovsky, V.A. (2009) Nucleophilic Trifluoromethylation of Arylidene Meldrum's Acids. Tetrahedron Letters, 50, 2998-3000. http://dx.doi.org/10.1016/j.tetlet.2009.03.188

[378] Tsuno, T. and Sugiyama, K. (2001) Trends in Heterocyclic Chemistry, 7, 91.

[379] Istyastono, E.P., Yuniarti, N. and Jumina, D. (2009) Majalah Farmasi Indonesia, $20,1$.

[380] Allen, J.C., Kociok-Kohn, G. and Frost, C.G. (2012) Rhodium-Catalysed Enantioselective Synthesis of 4-Arylchroman-2-ones. Organic \& Biomolecular Chemistry, 10, 325. http://dx.doi.org/10.1039/c1ob06586f

[381] Lipson, V.V., Orlov, V.D., Desenko, S.M., Karnozhitskaya, T.M. and Shirobokova, M.G. (1999) Reaction of Arylidene Derivatives of Meldrum's Acid with 3-Amino-1,2,4-triazole. Chemistry of Heterocyclic Compounds, 35, 595-599. http://dx.doi.org/10.1007/BF02324645

[382] Meher, S.S., Naik, S., Behera, R.K. and Nayak, A. (1981) Journal of the Indian Chemical Society, 58, 274.

[383] Dabholkar, V.V. and Ansari, F.Y. (2009) Synthesis and Characterization of Selected Fused Isoxazole and Pyrazole Derivatives and Their Antimicrobial Activity. Journal of the Serbian Chemical Society, 74, 1219-1228. http://dx.doi.org/10.2298/JSC0911219D

[384] Mulongo, G., Mbabazi, J., Nnamuyomba1, P. and Mpango, G.B. (2011) Further Biologically Active Derivatives of 1,3-Diketones. Research Journal of Chemical Sciences, 1, 80-84.

[385] Horning, E.C. and Horning, M.G. (1946) Methone Derivatives of Aldehydes. The Journal of Organic Chemistry, 11, 95-99. http://dx.doi.org/10.1021/jo01171a014

[386] Khan, K.M., Maharvi, G.M., Khan, M.T.H., Shaikh, A.J., Perveen, Sh., Begum, S. and Choudhary, M.I. (2006) Tetraketones: A New Class of Tyrosinase Inhibitors. Bioorganic \& Medicinal Chemistry, 14, 344-351. http://dx.doi.org/10.1016/j.bmc.2005.08.029 
[387] Kidwai, M., Bansal, V., Mothsra, P., Saxena, Sh., Somvanshi, R.K., Dey, S. and Singh, T.P. (2007) Molecular Iodine: A Versatile Catalyst for the Synthesis of Bis(4-hydroxycoumarin)methanes in Water. Journal of Molecular Catalysis A: Chemical, 268, 76-81. http://dx.doi.org/10.1016/j.molcata.2006.11.054

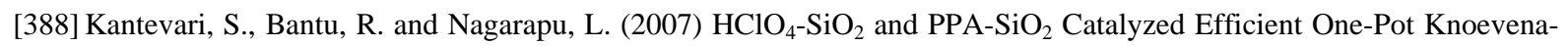
gel Condensation, Michael Addition and Cyclodehydration of Dimedone and Aldehydes in Acetonitrile, Aqueous and Solvent-Free Conditions: Scope and Limitations. Journal of Molecular Catalysis A: Chemical, 269, 53-57. http://dx.doi.org/10.1016/j.molcata.2006.12.039

[389] Al-Orffi, N.M. and Gheath, A.H. (2008) New Method of 2-Amino-4H-Chromene Synthesis. Journal of Applied Sciences, 2, 60-68.

[390] Bayat, M., Imanieh, H. and Hossieni, S.H. (2009) Synthesis of 2,2'-Arylmethylene Bis(3-hydroxy-5,5-dimethyl-2cyclohexen-1-one) in Aqueous Medium at Room Temperature. Chinese Chemical Letters, 20, 656-659. http://dx.doi.org/10.1016/j.cclet.2008.12.050

[391] Maghsoodlou, M.T., Habibi-Khorassani, S.M., Shahkarami, Z., Maleki, N. and Rostamizadeh, M. (2010) An Efficient Synthesis of 2,2'-Arylmethylene Bis(3-hydroxy-5,5-dimethyl-2-cyclohexen-1-one) and 1,8-Dioxooctahydroxanthenes Using $\mathrm{ZnO}$ and ZnO-Acetyl Chloride. Chinese Chemical Letters, 21, 686-689. http://dx.doi.org/10.1016/j.cclet.2010.02.005

[392] Karimian, R., Piri, F., Karimi, B. and Moghimi, A. (2011) Silica Chloride Nano Particle Catalyzed Synthesis of 2,2'(Arylmethylene)bis(5,5-dimethylcyclohexane-1,3-dione) Derivatives. Croatica Chemica Acta, 84, 111-115. http://dx.doi.org/10.5562/cca1721

[393] Rao, V.K., Kumar, M.M. and Kumar, A. (2011) An Efficient and Simple Synthesis of Tetraketone Catalyzed by $\mathrm{Yb}(\mathrm{OTf})_{3}-\mathrm{SiO}_{2}$ under Solvent-Free Conditions. Indian Journal of Chemistry, 50B, 1128-1135.

[394] Khurana, J.M. and Vij, K. (2012) Nickel Nanoparticles: A Highly Efficient Catalyst for One Pot Synthesis of Tetraketones and Biscoumarins. Journal of Chemical Sciences, 124, 907-912. http://dx.doi.org/10.1007/s12039-012-0275-8

[395] Josephrajan, T., Ramakrishnan, V.T., Kathiravan, G. and Muthumary, J. (2005) Synthesis and Antimicrobial Studies of Some Acridinediones and Their Thiourea Derivatives. ARKIVOC, xi, 124-136. 